Würzburger Vorträge zur Rechtsphilosophie, Rechtstheorie und Rechtssoziologie

Herausgegeben von Horst Dreier und Dietmar Willoweit

Begründet von Hasso Hofmann, Ulrich Weber und Edgar Michael Wenz ${ }^{\dagger}$

Heft 45 
Tatjana Hörnle

\section{Kriminalstrafe \\ ohne Schuldvorwurf}

Ein Plädoyer für Änderungen in der strafrechtlichen Verbrechenslehre 
Vortrag gehalten am 27. Juni 2012

Die Deutsche Nationalbibliothek verzeichnet diese Publikation in der Deutschen Nationalbibliografie; detaillierte bibliografische Daten sind im Internet über http://dnb.d-nb.de abrufbar.

ISBN 978-3-8487-0641-9

1. Auflage 2013

(c) Nomos Verlagsgesellschaft, Baden-Baden 2013. Printed in Germany. Alle Rechte, auch die des Nachdrucks von Auszügen, der fotomechanischen Wiedergabe und der Übersetzung, vorbehalten. Gedruckt auf alterungsbeständigem Papier. 


\section{Inhaltsübersicht}

I. Lohnt es sich noch, über Schuld und Willensfreiheit zu diskutieren?

II. Probleme mit dem klassischen Schuldvorwurf

III. Die naturwissenschaftliche Seite: Modellierung menschlichen Entscheidens

IV. Wertungen: Freiheit, Verantwortung und Schuld

V. Umgang der Strafrechtswissenschaft mit dem Dilemma

VI. Fokussierung auf einen Unrechtsvorwurf bei Verzicht auf einen Schuldvorwurf

VII. Konsequenzen für die Verbrechenslehre und das Strafgesetz 


\section{Lohnt es sich noch, über Schuld und Willensfreiheit zu diskutieren?}

Als ich dem Gastgeber Horst Dreier im Jahr 2012 vorschlug, in der Reihe „Würzburger Vorträge zur Rechtsphilosophie, Rechtstheorie und Rechtssoziologie“ zum Themenkomplex „strafrechtliche Schuld, Willensfreiheit, Konsequenzen aus Erkenntnissen der Neurowissenschaften“" zu referieren, war bei ihm zunächst leichte Skepsis zu spüren. Nicht wenige Beobachter der Debatten zu diesen Fragen neigen zu der Einschätzung, dass angesichts der überbordenden Fülle an Literatur mittlerweile alle Argumente ausgetauscht sein müssten. Und vor allem: hatte nicht bei den Würzburger Vorträgen Reinhard Merkel das Thema schon abgehandelt? In der daraus hervorgegangenen Monographie ${ }^{1}$ hat Merkel ausführlich und überzeugend vor allem die in der Philosophie vertretenen Positionen kritisch besprochen, die ein von hirnphysiologischen Grundlagen unabhängiges oder sogar dezidiert abgekoppeltes Bild menschlicher Entscheidungsfindung zeichnen wollen. Gibt es noch Neues zu sagen, zumal dann, wenn man Merkels kritische Herangehensweise an vollmundige Bekenntnisse zum Anders-EntscheidenKönnen für überzeugend hält? Ich hoffe, es gelingt, Sie, verehrte Leser, davon zu überzeugen, dass dieser zweite Beitrag zu den Würzburger Vorträgen trotz des ähnlichen Themas einen anderen Zuschnitt hat.

Erstens setzt er einen anderen Akzent, was die Auseinandersetzung mit naturwissenschaftlichen und philosophischen Vorarbeiten betrifft. Nicht wenige Arbeiten zur Frage der Willensfreiheit beschäftigen sich in abstrakter Form mit den allgemeinen Thesen, die mit „Determinismus“ und „Indeterminismus“ bezeichnet werden, um daraus Konsequenzen für eine konkrete Frage abzuleiten. Wenn allerdings versucht werden soll, die Welt als Ganzes zu erklären, wird die Last der erkenntnistheoretischen Probleme besonders groß. Ob und inwieweit die Idee eines universalen Determinismus eine erwiesene oder wenigstens plausible Welterklärung liefert, ist hochumstritten. ${ }^{2}$ Für unsere Zwecke ist

1 R. Merkel, Willensfreiheit und rechtliche Schuld, 2008.

2 S. dazu R. Merkel (Fn. 1), S. 24 ff.; Keil, Willensfreiheit, 2. Aufl. 2013, S. 33 ff.; Wittwer, Jahrbuch für Recht und Ethik 19 (2011), 397, $411 \mathrm{f}$. 
aber eine andere Herangehensweise ausreichend, die nicht nach der Determiniertheit aller Ereignisse im Universum fragt und auch nicht nach einem Bereichsdeterminismus ${ }^{3}$ (etwa neurophysiologischer Art), sondern mit einem bescheideneren Anspruch die Befunde der Neurowissenschaften rezipiert. Maßgeblich für den Umgang mit strafrechtlichen Folgeproblemen ist, welches Modell auf der Basis der heute vorhandenen wissenschaftlichen Erkenntnisse am plausibelsten typische Vorgänge menschlicher Entscheidungsfindung abbildet (dazu unten III.). Mit dem Verweis auf angemessene Modellierungen typischer Vorgänge kann offen bleiben, inwieweit es ausnahmslos geltende Naturgesetze in dem für uns relevanten Bereich gibt - bei der Entwicklung einer strafrechtlichen Verbrechenslehre sollten wir uns an dem orientieren, was am wahrscheinlichsten ist.

Zweitens war ein Beweggrund für meine Wahl des Themas, auf eine sachgerechte Abschichtung unterschiedlicher Fragestellungen zu drängen. Unklarheiten und Missverständnisse schleichen sich in die Debatte, weil sowohl Naturwissenschaftlern als auch Strafrechtswissenschaftlern zuweilen das Verständnis dafür fehlt, dass zwischen Beschreibungen und der empirisch wie wissenschaftstheoretisch fundierten Entwicklung von Modellen zur menschlichen Entscheidungsfindung einerseits und wertenden Grenzziehungen andererseits differenziert werden muss. Zentrale Begriffe wie „Freiheit“", „Verantwortung“, „Schuld“ sind nicht dem Beweis zugänglich, sondern verweisen auf wertende Entscheidungen, eingeleitet durch Fragen wie ,frei genug, um verantwortlich gemacht zu werden?". Die Vorstellung, dass man „Willensfreiheit“ empirisch beweisen könne, ${ }^{4}$ ist unzutreffend. Ein angemessener Umgang mit Konzepten wie Freiheit, Verantwortung und Schuld setzt vielmehr ein zweistufiges Analyseverfahren voraus (dazu IV.). Zunächst ist mit den empirisch arbeitenden Wissenschaften der Stand des Wissens darüber zu erschließen, wie Menschen entscheiden und handeln. Danach ist in einem zweiten Schritt zu untersuchen, ob und unter welchen Bedingun-

3 S. zu der Unterscheidung Keil (Fn. 2), S. 45 ff.

4 Im strafrechtlichen Schrifttum ist die Aussage, dass Willensfreiheit „,nicht bewiesen“ sei, häufig zu lesen, z.B. Dreher, Die Willensfreiheit, 1987, S. 379; Roxin, Strafrecht AT, 4. Aufl. 2006, § 19 Rn. 41; Hillenkamp, JZ 2005, 313, 319. Zu Recht kritisch Pawlik, Das Unrecht des Bürgers, 2012, S. 284 Fn. 172. 
gen Prädikate wie „frei“ und „,verantwortlich“ verwendet werden sollten. Genauso, wie davor zu warnen ist, aus empirischen Befunden unmittelbar und unreflektiert normative Forderungen abzuleiten (der typische Fehler von Naturwissenschaftlern), ist es inadäquat, auf den ersten Schritt, d.h. die Kenntnisnahme der empirischen Basis, zu verzichten (ein typischer Fehler von Vertretern der normativen Wissenschaften).

Drittens lohnt es wegen der großen Zahl an strafrechtswissenschaftlichen Aufsätzen, die in den letzten Jahren nach teilweise hitzigen, mittlerweile schon wieder etwas abgeflauten Debatten unter Überschriften wie „Hirnforschung und Strafrecht“ erschienen sind, einen ordnenden Überblick zu geben. Dieser zeigt, dass Strafrechtswissenschaftler in der Auseinandersetzung nicht nur mit dem klassischen Schuldvorwurf (für den sich der Bundesgerichtshof und das Bundesverfassungsgericht stark machen, dazu Kapitel II.), sondern auch mit Thesen, die Neurowissenschaftler entwickelt haben, sehr unterschiedliche Strategien entwickelt haben. Diese Ansätze werden in Kapitel V. skizziert - und auch kritisiert. Es ist weder angemessen, eine abwehrende Haltung einzunehmen, noch ist es notwendig, in einem radikalen Umschwung zu fordern, dass Reaktionen auf die Straftat nur noch als präventive Maßnahme zur Besserung des Täters oder zur Sicherung der Gesellschaft erfolgen dürften. Ein weiterer Ansatz verweist auf die Notwendigkeit der Normerhaltung oder die Beseitigung von sog. Normgeltungsschäden (Stichwort: positive Generalprävention). In diese Richtung ging auch der Beitrag Merkels, der aus generalpräventiven Erwägungen am Schuldbegriff letztlich festhalten will und ohne intensivere Begründung meint, dass ein Schuldvorwurf auch gegenüber demjenigen fair sei, der in der konkreten Tatsituation gar nicht anders habe handeln können. ${ }^{5}$ Hier liegt aber ein offensichtliches Problem. ${ }^{6}$

Viertens halte ich es für erforderlich, vor allem an der Stelle weiter zu denken, an der Merkels Analyse in einige knappe Bemerkungen zu einer funktionalen Begründung des Strafrechts ausläuft. Auch wenn man nicht die Schlussfolgerung zieht, dass der Übergang zu einem rein präventiv orientierten Maßnahmenrecht geboten oder sinnvoll ist, sondern

5 R. Merkel (Fn. 1), S. $127 \mathrm{f}$.

6 S. dazu T. Walter, Die Zeit v. 4.8.2008, Nr. 37; Pawlik (Fn. 4), S. 286 Fn. 173 a.E. 
am Paradigma der vergangenheits- und tatbezogenen Kriminalstrafe festhält, kann nicht einfach alles bleiben, wie es ist. Vielmehr sind Anpassungen in der strafrechtlichen Verbrechenslehre (und Änderungen im Strafgesetz) erforderlich. Aufzugeben ist insbesondere die Vorstellung, dass ein Schuldvorwurf zwingende Voraussetzung für Kriminalstrafe sei. Vielmehr kann und sollte auf die Erhebung eines Schuldvorwurfs verzichtet werden. Das mag revolutionär klingen, ist es aber nicht. Erforderlich ist eine Bereinigung von strafrechtswissenschaftlichen Konzepten und Begriffen, entscheidend ist dabei aber, dass man an moralischen wie auch strafrechtlichen Reaktionen festhalten kann, und zwar an Reaktionen, die vergangenheits- und tatbezogen ein Unwerturteil erheben. ${ }^{7}$ Die noch ausführlich zu begründende (unten VI.) These ist, dass ein mit Kriminalstrafe verbundener, auf vergangenes Verhalten bezogener Unrechtsvorwurf seine Berechtigung behält, genauso wie moralische Praktiken von Lob und Tadel - ein zusätzlicher persönlicher Schuldvorwurf ist aber ebenso problematisch wie verzichtbar. Dem sollte durch eine konsequente Eliminierung des Begriffes „Schuld“ in Gesetz und Strafrechtslehre Rechnung getragen werden (unten VII.).

7 Eine Anmerkung zu den in diesem Beitrag häufig auftauchenden Begriffen „Unwerturteil“ und „Unrechtsurteil“: Ich verwende den Begriff „Unwerturteil“ in einem weiteren Sinn als Bezeichnung für negative Werturteile, die in moralischen oder rechtlichen Kontexten abgegeben werden. „Unrechtsurteil“ bezieht sich dagegen auf eine Untergruppe, nämlich die nach einem Strafverfahren abgegebene Feststellung strafrechtlichen Unrechts. 


\section{Probleme mit dem klassischen Schuldvorwurf}

Leitend für die folgende Untersuchung ist die Frage: Ist es angemessen, gegenüber einem Straftäter einen Schuldvorwurf zu erheben, der darauf beruht, dass ihm persönliches Versagen bei der Wahl zwischen Entscheidungsalternativen vorgeworfen wird? Das Verständnis von Schuld, das die deutsche Strafrechtswissenschaft nach 1945 stark geprägt hat, läuft auf einen Vorwurf diesen Inhalts hinaus, den ich im Folgenden als „klassischen Schuldvorwurf“ bezeichnen werde. Prägnant ausgedrückt hat dies der Bundesgerichtshof im Jahr 1952:

„Mit dem Unwerturteil der Schuld wird dem Täter vorgeworfen, daß er sich nicht rechtmäßig verhalten, daß er sich für das Unrecht entschieden hat, obwohl er sich rechtmäßig verhalten, sich für das Recht hätte entscheiden können. “8

In diesem Satz steckt nicht nur ein Bekenntnis zum Anders-HandelnKönnen, sondern vorrangig zum Anders-Entscheiden-Können als Grundlage des „Unwerturteils der Schuld“.9 Für die Richter am Bundesgerichtshof galt Anders-Entscheiden-Können offensichtlich als Postulat, das keinerlei Erläuterung oder Begründung bedurfte. Die Entscheidung beinhaltet zum einen ein Bekenntnis zum Indeterminismus, zum anderen lag es den Richtern fern, die Beschreibung der menschlichen Entscheidungsfindung als Problem zu erkennen, für das Naturwissenschaften zu Rate zu ziehen wären. Auch heute noch geht die höchstrichterliche Rechtsprechung von der Legitimität eines klassischen Schuldvorwurfs auf der Basis eines dezidiert anti-empirischen Vorverständnisses aus. So formulierte das Bundesverfassungsgericht etwa im Lissabon-Urteil 2009 in enger inhaltlicher Anlehnung an das ältere Urteil des Bundesgerichtshofs:

„Das Strafrecht beruht auf dem Schuldgrundsatz. Dieser setzt die Eigenverantwortung des Menschen voraus, der sein Handeln selbst bestimmt und sich kraft seiner Willensfreiheit zwischen Recht und Unrecht entscheiden kann. Dem Schutz der Menschenwürde liegt die

8 BGHSt. 2, 194, 200.

9 Das ist verschiedentlich bezweifelt worden, s. etwa Burkhardt, in: Senn/Puskás (Hrsg.), Gehirnforschung und rechtliche Verantwortung, 2006, S. 86. Der Wortlaut lässt jedoch wenig Interpretationsspielraum. 
Vorstellung vom Menschen als einem geistig-sittlichen Wesen zugrunde, das darauf angelegt ist, in Freiheit sich selbst zu bestimmen und sich zu entfalten (vgl. BVerfGE 45, 187 [227]). “10

Erklärungsbedürftig ist die große Selbstverständlichkeit, mit der die Richter an den obersten Gerichten davon ausgehen, dass es nicht im Entferntesten erforderlich sei, Entscheidungssituationen in einem physiologischen und psychologischen Kontext zu sehen. Die konsequente Ausblendung des Gedankens, dass Anders-Entscheiden-Können ein empirisch zu verankerndes Urteil sein könnte, dürfte auf geistesgeschichtliche sowie zeitgeschichtlich-sozialpsychologische Wurzeln zurückzuführen sein. Zu den geistesgeschichtlichen Wurzeln gehören zum einen christliche Vorstellungen, zum anderen Immanuel Kants Vision des Menschen als „homo noumenon“. Für ein religiöses Konzept, das wesentlich auf dem Glauben an eine nicht materiell gebundene Seele beruht, versteht es sich von selbst, dass es nicht auf hirnphysiologische Gegebenheiten ankommen kann. Aber auch bei Kant ist eine in mancher Hinsicht vergleichbare Differenzierung ein Fundament seines philosophischen Gebäudes, nämlich die Abtrennung des „homo noumenon“ als reinem Vernunftwesen vom „homo phaenomenon“. ${ }^{11}$ Im Hinblick auf die zeitgeschichtlichen Hintergründe des Urteils aus dem Jahr 1952 wird das darin zum Ausdruck kommende „Freiheitspathos“ als Absage an die „Menschenverachtung der soeben untergegangenen unsäglichen Zeit“ interpretiert. ${ }^{12}$ Aus heutiger Sicht liegt ein solcher wertender Verweis auf das „Unsägliche“ der vorangegangenen Epoche nahe. Alternativ ist aber auch folgende These vorstellbar, die statt einer ethischen Bewertung des NS-Unrechts vor allem psychologische Umstände akzentuiert: Es könnte sich um eine Reaktion auf die als chaotisch erlebten und unberechenbar sich verändernden Lebensverhältnisse in den Kriegsjahren und auch der Zeit danach handeln. Vor solchen Hintergründen mag Trost darin zu finden sein, die in den äußeren Verhältnissen nicht mehr zu

10 BVerfGE 123, 267, 413. Ebenso die Ausführungen zum Schuldgrundsatz in der Entscheidung zu den informellen Absprachen im Strafverfahren v. 19.3.2013, Rn. 53 f.

11 S. Kant, Die Metaphysik der Sitten, Werkausgabe Bd. VIII (Hrsg. Weischedel), S. 550 .

12 Hillenkamp, in: ders. (Hrsg.), Neue Hirnforschung - neues Strafrecht?, 2006, S. 85, 106. 
findende Beherrschbarkeit von Ereignissen in das Innere des Menschen zu verlegen. Das Pochen auf eine Steuerung durch bewusste Wahlentscheidungen, auf der Beherrschbarkeit menschlicher Entscheidungsfindung, könnte als Indiz für ein Bedürfnis nach Sicherheit und Kontrolle gelesen werden.

Mehr als rekonstruierend-erklärende Thesen sind mit solchen Überlegungen allerdings nicht zu gewinnen. Die hier zu verfolgende Aufgabe liegt darin, zu überprüfen, ob ein klassischer Schuldvorwurf gerechtfertigt werden kann, und insoweit ist es nicht vertretbar, sich auf Behauptungen ohne Begründung und ohne kritisches Überprüfen zu beschränken.

Eine Prämisse meiner Untersuchung ist, dass die Erhebung eines Schuldvorwurfs durch Strafgerichte, also durch eine staatliche Instanz, in hohem Maße rechtfertigungsbedürftig ist. Die Verhängung von Kriminalstrafen bedarf nicht nur wegen der in der Vollstreckung einer Geldoder Freiheitsstrafe liegenden Freiheitseingriffe der Legitimation, sondern auch mit Blick auf die damit verbundenen Werturteile. Das, was das Bundesverfassungsgericht in ständiger Rechtsprechung als ,sozialethisches Unwerturteil" bezeichnet, ${ }^{13}$ ist vor allem deshalb sorgfältig zu rechtfertigen, weil es eben nicht nur ein ethisches Urteil im Allgemeinen ist, sondern ein solches, das seitens des Staates über einen Bürger abgegeben wird und das als Werturteil bereits einen Grundrechtseingriff (und zwar in das allgemeine Persönlichkeitsrecht) bedeutet.

Ein klassischer Schuldvorwurf, der dem Täter vorhält „Du hättest Dich anders entscheiden können, hast dies aber nicht getan", wäre dann legitim, wenn er auf einer zutreffenden Beschreibung der Situation zum Tatzeitpunkt beruht. Die Frage, ob diese Beschreibung zutrifft, sollte deshalb am Anfang der Analyse stehen. Für einen rationalen Umgang mit der Rechtfertigungsfrage muss eruiert werden, was der Stand des Wissens zu Prozessen der menschlichen Entscheidungsfindung ist. Eine Fülle an Literatur setzte sich in den letzten Jahrzehnten aus der Sicht von Medizinern, Biologen, Psychologen und Philosophen mit hirnphysiologischen Zuständen, Begriffsklärungen und dem Zusammenhang von Physischem und Mentalem auseinander. Ein interdisziplinärer Zugang 
ist unabdingbar. Zum einen sind Fortschritte der Neurowissenschaften zur Kenntnis zu nehmen, die den Bestand an Thesen (auch) zum Vorgang des Entscheidens erweitert haben. Zwar mag der Weg zu einem wirklich vertieften Verständnis der Funktionsweise des Gehirns immer noch weit sein - trotzdem sind Berichte über die Funktionen von Hirnarealen und die darauf aufbauende Modellierung menschlicher Entscheidungsfindung zu rezipieren. Zum anderen haben manche Annahmen über mentale Zustände, die Naturwissenschaftler etwa bei der Vorbereitung von Experimenten gemacht haben, nicht nur Widerspruch verursacht, sondern auch Klarstellungen und Präzisierungen durch Spezialisten für mentale Phänome, also Psychologen und Vertreter der Philosophie des Geistes. Zur Lösung der Aufgabe, menschliche Entscheidungsfindung adäquat zu beschreiben, wäre es ein Irrweg, vom Primat einer einzigen Wissenschaftsdisziplin auszugehen. So kommt etwa der Philosophie des Geistes eine wichtige Rolle zu, da wissenschaftstheoretische Grundannahmen zu erörtern sind. ${ }^{14}$ Allerdings bleibt letztlich die Plausibilität von Modellen auch von empirischen Befunden abhängig, die nur Naturwissenschaftler liefern können.

14 Walde, Willensfreiheit und Hirnforschung. Das Freiheitsmodell des epistemischen Libertarismus, 2006, S. 147. 


\section{Die naturwissenschaftliche Seite: Modellierung menschlichen Entscheidens}

Der folgende kurze Abriss dessen, was gegenwärtig das wohl plausibelste Modell menschlicher Entscheidungsfindung ist, basiert auf drei Thesenkomplexen zur Funktionsweise des Gehirns und zum Zusammenhang von hirnphysiologischen Grundlagen und Entscheidungsverhalten.

1. Thesenkomplex:

Jede Entscheidungsfindung ist auf die physiologischen Grundlagen innerhalb des Nervensystems (vereinfacht-verkürzt: innerhalb des Gehirns) angewiesen. Die Annahme eines die physiologischen Strukturen transzendierenden Geistes, der in einer nicht physiologischen Weise irgendwie auf Nervenzellen einwirken müsste, um so Körperbewegungen zu verursachen, ist spekulativ. ${ }^{15}$

Derartige Formulierungen sind nicht unangefochten, sondern führen zu Diskussionen etwa im Dialog zwischen Hirnforschern einerseits, Psychologen und Vertretern des Fachs „Philosophie des Geistes“ andererseits. So fällt etwa die Bezeichnung „,angewiesen“ (bewusst) weich aus. Was daraus im Einzelnen folgt, ist stark umstritten. Ausführlich debattiert wird z.B. darüber, ob der Zusammenhang zwischen physiologischen Grundlagen und mentalen Phänomenen, die „Wahrnehmung“ und „Bewusstsein“ genannt werden, besser mit Identitäts- oder mit Supervenienztheorien zu erfassen sind. ${ }^{16}$ Philosophen insistieren darauf, dass

15 S. dazu Singer, in: Duncker (Hrsg.), Beiträge zu einer aktuellen Anthropologie, 2006, S. 129, 133 ff.; ders., in: Krüger (Hrsg.), Hirn als Subjekt?, 2007, S. 39, 40 ff.; Roth, Festschrift für Lampe, 2003, S. 43, 44 ff.; ders., in: Könneker (Hrsg.), Wer erklärt den Menschen?, 2007, S. 23 ff.; Vogeley/Neven, in: Könneker (Hrsg.), Wer erklärt den Menschen?, 2007, S. 59 ff.; Elger u.a., Das Manifest, in: Könneker (Hrsg.), Wer erklärt den Menschen?, 2007, S. 80, 83; R. Merkel (Fn. 1), S. 46 ff.; Markowitsch/ Merkel, in: Bonhoeffer/Gruss (Hrsg.), Zukunft Gehirn, 2011, S. $224 \mathrm{ff}$.

16 S. Vogeley/Neven (Fn. 15), S. 63 ff.; Walde (Fn. 14), S. 123 ff., 138 ff.; Pauen, in: Könneker (Hrsg.), Wer erklärt den Menschen?, 2007, S. 143 ff.; R. Merkel (Fn. 1), S. $83 \mathrm{ff}$. 
unpräzise Beschreibungen zu vermeiden sind, etwa indem dem Gehirn psychologische Eigenschaften zugeschrieben werden (psychologisches Vokabular sollte sich auf Personen, nicht auf einzelne Organe beziehen). ${ }^{17} \mathrm{Zu}$ erwähnen ist ferner die Diskussion um die sog. Qualia, d.h. den Umstand, dass die subjektive Wahrnehmung etwa einer Farbe etwas anderes ist als die exakte und vollständige Beschreibung der dabei stattfindenden Prozesse im Gehirn. ${ }^{18}$ Wie genau das Zusammenspiel von mentalen Zuständen und ihrer biologisch-materiellen Grundlage am besten zu beschreiben ist, kann aber offen bleiben. Für die uns interessierenden strafrechtlichen und moralischen Bewertungen kommt es nicht primär auf die korrekte Erfassung von gleichzeitig verlaufenden hirnphysiologischen und mentalen Zuständen an, sondern auf die retrospektive Bewertung einer Handlung und des ihr vorausgegangenen Entscheidungsprozesses. Wichtig sind hierfür zwei Punkte. Erstens: psychische Vorgänge setzen bestimmte Prozesse im biologischen Substrat, d.h. den Strukturen des Gehirns, voraus; zweitens: die Kette hirnphysiologischer Einzelereignisse, die zusammen einen komplexeren Handlungsauslösungsprozess bilden, ist in ihrer physiologischen Grundlage lückenlos. Es gibt keine davon unabhängige Instanz in Form eines "Geistes“ oder "transzendentalen Subjekts“, die irgendwo einhaken und eine neue Kausalkette in Gang setzen könnte.

2. Thesenkomplex:

Die These der Indeterminiertheit auf der Ebene von atomaren und subatomaren Ereignissen wäre nur dann von Bedeutung, wenn hieraus abzuleiten wäre, dass menschliche Entscheidungen unberechenbar verliefen und nicht mit verallgemeinerbaren Aussagen erfassbar seien. Entscheidend ist aber, dass für Phänomene jenseits der Mikroebene typische Abläufe festgestellt werden können, und dass Modelle zur Erklärung und Prognose taugen.

17 S. dazu Bennett/Hacker, in: Bennett/Dennett/Hacker/Searle, Neurowissenschaft und Philosophie, 2010, S. 15 ff. Krit. Dennett und Searle, in: Bennett/Dennett/Hacker/ Searle, a.a.O., S. 105 u. S. $139 \mathrm{ff}$.

18 Bennett/Hacker (Fn. 17), S. 59 ff.; R. Merkel (Fn. 1), S. 87 ff. 
Verschiedentlich wird behauptet, dass Erkenntnisse aus dem Bereich der Quantenmechanik für unser Thema von Relevanz seien, weil damit zu belegen sei, dass es die Naturwissenschaften beschäftigende, gleichzeitig aber dem Kausalgesetz entzogene Phänomene gebe. ${ }^{19}$ Es liegt schon jenseits meines Verständnishorizonts, Details des Diskussionsstandes in diesem Wissenschaftszweig adäquat wiederzugeben, und erst recht ist es mir unmöglich, zuverlässig zu beurteilen, inwieweit experimentell gewonnene Befunde tatsächlich auf die Indeterminiertheit von Ereignissen schließen lassen oder aber, wofür einiges zu sprechen scheint, auf Probleme bei deren Beobachtbarkeit und Prognose. ${ }^{20}$ Eine nähere Beschäftigung mit dieser Materie ist aber auch verzichtbar. Einschlägig sind vielmehr die naturwissenschaftlichen Disziplinen, die sich bemühen, eine realitätsgerechte Beschreibung der physiologischen und psychologischen Prozesse zu geben, die wir „Entscheiden“ nennen, also die Neurowissenschaften. Aus dem Blickwinkel der normativen Wissenschaften ist dabei nicht entscheidend, ob die Aussagen, die Neurowissenschaftler machen können, tatsächlich auf einen strengen kausalen Determinismus hinauslaufen. Auch ohne den Nachweis eines universalen Kausaldeterminismus bleibt es sinnvoll, sich auf feststellbare Wiederholungen und Regelhaftigkeiten in den Abläufen menschlicher Entscheidungen zu konzentrieren. Die Vorstellung, dass Modelle solcher Prozesse wegen der Sprunghaftigkeit atomarer und subatomarer Teilchen sinnlos seien, wäre schon angesichts der Existenz von etablierten deskriptiv arbeitenden Wissenschaftszweigen wie Psychologie und Hirnforschung schwerlich plausibel. Mit dem, was diese fachnäheren Wissenschaften zu sagen haben, müssen sich die Disziplinen auseinandersetzen, deren Aufgabe in der Bewertung menschlicher Handlungen liegt.

19 Eccles, How the Self Controls its Brain, 1994; Kane, The Significance of Free Will, 1996; Hodgson, in: Kane (Hrsg.), The Oxford Handbook of Free Will, 2002, S. 85 ff.; Kasper, in: Krüger (Hrsg.), Hirn als Subjekt?, 2007, S. 151 ff. Krit. Honderich, in: Kane (Hrsg.), The Oxford Handbook of Free Will, 2002, S. 459, 462 ff.; Flohr, in: Krüger (Hrsg.), Hirn als Subjekt?, 2007, S. 165, 170; Herzberg, Willensunfreiheit und Schuldvorwurf, 2010, S. $36 \mathrm{ff}$.

20 S. zu dieser notwendigen Differenzierung Samson, in: Krüger (Hrsg.), Hirn als Subjekt?, 2007, S. 215, 217 ff.; Heun, JZ 2005, 853, 858. 
3. Thesenkomplex:

Die Annahme, dass Handlungsentscheidungen ausschließlich bewusste Entscheidungen nach einer ebenfalls vollständig bewussten Abwägung von Gründen sind, trifft mit großer Wahrscheinlichkeit nicht zu. Vielmehr sind Modelle plausibler, denen zufolge die Abläufe wesentlich komplizierter sind. In Koppelungen und Rückkoppelungen spielen Vorgänge eine wesentliche Rolle, die dem Bewusstsein entzogen sind und die die bewusste Abwägung von Gründen dominieren (Vorauswahl bewusst werdender Abwägungsinhalte, Bewertung und Selektierung der bewussten Entscheidungen). ${ }^{21}$

An dieser Stelle bietet sich reichlich Stoff zum Streit, wenn auch im 21. Jahrhundert, nach einer längeren Wirkgeschichte populär gewordener Annahmen aus der Psychoanalyse, vermutlich niemand mehr grundsätzlich in Frage stellen würde, dass es so etwas wie „Unbewusstes“ gibt. Allerdings sind Modelle der menschlichen Entscheidungsfindung vorläufige Modelle, deren Verfeinerung und Überprüfung im Fluss ist. Annahmen über die Funktionen unterschiedlicher Hirnareale, die teilweise jenseits des Bewusstseins arbeiten, und Annahmen über die Art und Weise ihres Zusammenspiels stützen sich auf unterschiedliche Indizien: bildgebende Verfahren, die über Aktivierungen bestimmter Areale Auskunft geben können; pathologische Zustände, d.h. Ausfälle einzelner Gehirnbereiche und dadurch bewirkte Verhaltensstörungen; sowie im Labor durchgeführte Experimente wie das bekannte Libet-Experiment. ${ }^{22}$ Nochmals sei betont, dass von einem befriedigenden Wissensstand oder gar einem Nachweis der Regeln, die das Zusammenspiel der Milliarden von Nervenzellen bestimmen, nicht die Rede sein kann, ${ }^{23}$

21 Singer, in: Bonhoeffer/Gruss (Hrsg.), Zukunft Gehirn, 2011, S. 257, 264 f.; ders., in: Duncker (Fn. 15), S. 146 ff.; ders., in: Krüger (Fn. 15), S. 48 ff.; Walter, in: Kane (Hrsg.), The Oxford Handbook of Free Will, 2002, S. 565, 570 ff.; Roth, Festschrift für Lampe, 2003, S. 43, 50 ff.; ders., in: Krüger (Hrsg.), Hirn als Subjekt?, 2007, S. 27, 32 f. u. S. 171, 180; Pauen/Roth, Freiheit, Schuld und Verantwortung, 2008, S. $95 \mathrm{ff}$

22 Libet, in: Kane (Hrsg.), The Oxford Handbook of Free Will, 2002, S. $551 \mathrm{ff}$.

23 S. dazu Grothe, in: Hillenkamp (Hrsg.), Neue Hirnforschung - neues Strafrecht?, 2006, S. 35, 39 ff.; Olivier, in: Krüger (Hrsg.), Hirn als Subjekt?, 2007, S. 375, 376; Elger u.a. (Fn. 15), S. 77 ff. 
wobei aber die Vorläufigkeit von Erkenntnissen für (nicht nur) junge Wissenschaften keine Besonderheit ist. In unserem Zusammenhang wurde das Libet-Experiment vielfach kritisiert, das als Indiz für die erhebliche Bedeutung der dem Bewusstsein entzogenen Entscheidungsprozesse gewertet werden kann. ${ }^{24}$ Die Versuchspersonen waren zur Vornahme einer sehr simplen Handlung zu einem von ihnen selbst zu wählenden Zeitpunkt aufgefordert worden und mussten den Zeitpunkt mitteilen, zu dem sie sich konkret zur Handlung entschlossen hatten. Das Ergebnis war, dass ein sog. Bereitschaftspotential im Gehirn der Probanden zeitlich schon vor dem bewussten Fassen des Handlungsentschlusses messbar ist. Hier kann man mit Einwänden einhaken, etwa weil aufgrund der Experimentanordnung von vorneherein ein auf eine vorweggenommene Körperbewegung gerichteter Handlungsentschluss bestand. Aber: auch wenn sich im Forschungsdesign ein Problem verbirgt, sind mit der Kritik an einem bestimmten Experiment nicht die Annahmen von Neurowissenschaftlern insgesamt zu widerlegen.

Ich bin auf keine fundierte Stellungnahme eines einschlägig tätigen Wissenschaftlers im Sinne einer systematischen Modellbildung gestoßen, die ernsthaft die These aufstellen würde, dass menschliche Entscheidungsprozesse ausschließlich oder auch nur maßgeblich, etwa in letzter Instanz, im Abwägen von Gründen liegen. Natürlich gibt es innerhalb der Disziplin Neurowissenschaften Stellungnahmen, die die mediale Aufmerksamkeit für manche Kollegen skeptisch betrachten und die für Zurückhaltung bei weitreichenden Schlussfolgerungen aus begrenzten Forschungsergebnissen plädieren. ${ }^{25}$ Wer sich kritisch äußert, kann z.B. auf die unser Vorstellungsvermögen übersteigende Komplexität der neuronalen Verschaltungen verweisen, und auf die außeror-

24 S. zur Kritik z.B. Burkhardt, Festschrift für Eser, 2005, S. 77, 88; Hillenkamp, JZ 2005, 313, 318 f.; ders. (Fn. 12), S. 108 f.; Grothe (Fn. 23), S. 41 f.; Heun, JZ 2005, 853, 856; T. Walter, Festschrift für Schroeder, 2006, S. 131, 140; Kröber, in: Hillenkamp (Hrsg.), Neue Hirnforschung - Neues Strafrecht?, 2006, S. 63, 68 f.; Koch, ARSP 2006, 223 ff.; Habermas, in: Krüger (Hrsg.), Hirn als Subjekt?, 2007, S. 101, 103 f.; Rösler, in: Lampe/Pauen/Roth (Hrsg.), Willensfreiheit und rechtliche Ordnung, 2008, S. 140 ff.; Duttge, in: ders. (Hrsg.), Das Ich und sein Gehirn, 2009, S. 13, 28 f.; Jäger, GA 2013, 3, 8 ff.

25 Grothe (Fn. 23), S. 45; Kröber (Fn. 24), S. 64; Urbaniok u.a., in: Senn/Puskás (Hrsg.), Gehirnforschung und rechtliche Verantwortung, 2006, S. $119 \mathrm{ff}$. 
dentlich große Dynamik und Selbstorganisationsfähigkeiten des Systems, die es praktisch unmöglich machen, zukünftige Gehirnzustände und menschliches Verhalten vorherzusagen. ${ }^{26}$ So einleuchtend solche Hinweise sind: Sie sind von begrenzter Relevanz für unser Thema. Sie wirken zwar der Erwartung entgegen, dass es mittels Hirnforschung gelingen könne, mentale Zustände zuverlässig zu prognostizieren und so z.B. Straftaten vorherzusagen. Aber auch die zu vorsichtigen öffentlichen Aussagen mahnenden Neurowissenschaftler behaupten nicht, dass die menschliche Selbstwahrnehmung einer bewussten und deliberativen Entscheidungsfindung als zentrale oder gar einzige Grundlage eines wissenschaftlichen Modells tauge.

Auszugehen ist vielmehr von einem Zusammenspiel bewusster Vorgänge (bewusstes Sich-Vergewissern über Gründe, die in Form von moralischen Wertungen oder auch Klugheitsregeln als Gedächtnisinhalte abgerufen werden können, und Abwägen dieser Gründe) und unbewusster Vorgänge. Selbstverständlich können bewusste Abwägungen eine Rolle spielen. Hirnforscher, die wie Gerhard Roth oder Wolf Singer weitreichende Schlussfolgerungen für die normativen Wissenschaften ableiten wollen, gehen nicht etwa davon aus, dass Entscheidungselemente nicht existierten, die man als rational oder moralisch oder als Gewissensentscheidungen bezeichnen kann. Im Gegenteil, Bestandteil von Modellen der Entscheidungsfindung ist stets auch der Verweis auf Hirnareale, die bei der Integration langfristiger Handlungsfolgen im Wege des bewussten Abwägens aktiv werden. ${ }^{27}$ Entscheidend ist aber erstens, dass die Frage, was überhaupt auf die Ebene der bewussten Deliberation vordringen kann, durch nicht bewusste Vorgänge bestimmt wird, ${ }^{28}$ und dass in den durch vergangene emotionale Erfahrungen geprägten Strukturen (dem limbischen System) eine „Endkontrolle“ zu

26 Grothe (Fn. 23), S. 47 f.; Elger u.a. (Fn. 15), S. 83; Rösler, in: Könneker (Hrsg.), Wer erklärt den Menschen?, 2007, S. 85 f.; Nedopil, in: Stompe/Schanda (Hrsg.), Der freie Wille und die Schuldfähigkeit in Recht, Psychiatrie und Neurowissenschaften, 2010, S. 209, 220.

27 Pauen/Roth (Fn. 21), S. 122 ff.; vgl. auch Grothe, der bei aller Skepsis bzgl. vorschneller Behauptungen über feststehende Erkenntnisse in seinem Fach Neurobiologie (Fn. 23, S. 37 ff.) zum Bestand des gesicherten Wissens zählt, dass frontale Areale des Großhirns mit planerischem Handeln verbunden sind (S. 46).

28 Singer in: Bonhoeffer/Gruss (Fn. 21), S. 264. 
vermuten ist. Diese „Endkontrolle“ ist dem Bewusstsein nicht mehr zugänglich und sie scheint, so die Formulierung von Gerhard Roth, „, das letzte Wort" ${ }^{\star 29}$ zu haben. Zweitens sind auch die bewussten Teile von Entscheidungsvorgängen, die im Abwägen von Gründen für und gegen eine Handlung bestehen, davon abhängig, dass zum Zeitpunkt $X$ abrufbare, in Hirnarealen gespeicherte Gehalte zur Verfügung stehen. Ob und vor allem in welchem Ausmaß sich ein Individuum einen Bestand an folgenevaluierendem praktischem Verstand und an moralischem Rüstzeug zugelegt hat, der nun reaktiviert und auf eine konkrete Situation übertragen werden kann, hängt von der (hirnphysiologisch gespeicherten) Vergangenheit dieser Person ab. Wie differenziert die Fähigkeit zur Verarbeitung moralisch und rechtlich relevanter Gründe ausfällt, wird durch eine Mischung aus genetischen Bedingungen und frühkindlichen, aber auch späteren Einflüssen und Erfahrungen bestimmt. Im Längsschnitt gesehen, gelingt es in der Regel, die Rolle der normativ kompetenten Person auszufüllen (die meisten Menschen verhalten sich in den meisten Situationen schließlich rechtstreu), weil sich in der Interaktion von äußeren Einflüssen und Verarbeitung dieser Einflüsse die Strukturen ausgebildet haben, die bei einer konkreten Entscheidung zu einem richtigen Ergebnis führen. Im Querschnitt betrachtet, ist jedoch ein spontanes Hinauswachsen über das bei diesem Individuum konkret Vorhandene nicht möglich. Dies schließt nicht die Möglichkeit aus, dass subjektiv eine Entscheidung als ein „Über-Sich-Selbst-Hinauswachsen“ empfunden wird - das Erlebnis einer großen persönlichen Anstrengung nach einem bewussten Abwägen von Gründen kann aber nur haben, wer zum relevanten Zeitpunkt die entsprechenden Voraussetzungen für Reflexion oder für eine Reaktion auf Appelle von außen mitgebracht hat.

Es bleibt eine berechtigte Frage, inwieweit Modelle menschlicher Entscheidungsfindung tatsächlich auf jede Einzelperson anzuwenden sind, inwieweit sie also generalisierbar sind. Ein Faktor, der immer wieder von Vertretern der Neurowissenschaften betont wird, ist die Plastizität, die ständige Veränderbarkeit individueller Hirnstrukturen. ${ }^{30}$ Könnte es einzelne Individuen geben, bei denen allgemeine Aussagen

29 Roth, Festschrift für Lampe, 2003, S. 43, 52; Pauen/Roth (Fn. 21), S. 97.

30 Grothe (Fn. 23), S. 47. 
etwa zur Dominanz des limbischen Systems vielleicht nicht zutreffen? Das scheint eine nicht unplausible Annahme zu sein, wenn man davon ausgeht, dass das System große Individualität und Komplexität aufweist. ${ }^{31}$ Aber auch, wenn es atypische Konfigurationen geben sollte, in denen bewusster Entscheidungsfindung ein größerer Raum zukommt, ist damit nicht begründet, dass dies das Grundmodell sei, von dem das Strafrecht als Beschreibung des Typischen ausgehen sollte.

31 Grothe a.a.O. 


\section{Wertungen: Freiheit, Verantwortung und Schuld}

Was ist aus den vorstehenden Skizzen für die normativen Wissenschaften wie Moralphilosophie und Rechtswissenschaft abzuleiten? Liegt darin ein Generalangriff auf fundamentale Wertungskategorien? Wird die Verwendung von Begriffen wie „Freiheit“, „Verantwortung“ und „Schuld“ sinnlos? Wichtig ist zunächst die Feststellung, dass an diesem Punkt der Kompetenzbereich der Neurowissenschaften verlassen wird. Berechtigt ist Kritik, die moniert, dass Naturwissenschaftler unreflektiert mit normativen Begriffen hantieren. Man liest gelegentlich Aussagen wie das folgende Zitat von Gerhard Roth „Menschen können im Sinne eines persönlichen Verschuldens nichts für das, was sie wollen und wie sie sich entscheiden..."32. Dieses Zitat schließt normative Begriffe wie „persönliches Verschulden“ und „Dafürkönnen“ ein, und wie diese zu definieren sind, ist keine empirische Frage. ${ }^{33}$ Vielmehr ist es eine Wertungsfrage, ob Willensbildung als frei genug gelten kann, um von Verschulden und Dafürkönnen sprechen zu können. ${ }^{34}$

Natürlich ist ein Konzept wie Willensfreiheit auch für andere empirisch orientierte Wissenschaften jenseits der Neurowissenschaften von Interesse, nämlich für solche Wissenschaften, die sich mit der Beschreibung gesellschaftlicher Praktiken und ihrer sozialen Funktionen befassen: Evolutionstheorie, Soziologie, Politikwissenschaft, Kulturgeschichte und Sprachforschung. Ein Argument aus diesem Kontext verweist etwa auf die Abbildung von Freiheitsannahmen in elementaren Sprachstrukturen. ${ }^{35}$ Auch zur sozialen Nützlichkeit gäbe es Einiges zu

32 Roth, Fühlen, Denken, Handeln, 2003, S. 541. Hervorhebung im Original.

33 Hassemer, ZStW 121 (2009), 829, 847 f.; Mohr, in: Lampe/Pauen/Roth (Hrsg.), Willensfreiheit und rechtliche Ordnung, 2008, S. 72, 92.

34 Burkhardt, in: Lüderssen/Sack (Hrsg.), Vom Nutzen und Nachteil der Sozialwissenschaften für das Strafrecht, 1. Teilbd., 1980, S. 87, 113; Pawlik (Fn. 4), S. 282.

35 So Schünemann, Festschrift für Lampe, 2003, S. 537, 547; ders., in: Hirsch/Weigend (Hrsg.), Strafrecht und Kriminalpolitik in Japan und Deutschland, 1989, S. 147, $151 \mathrm{ff}$. Schünemann trifft dort eine noch weitergehende Aussage, nämlich dass dies eine ,unausweichlich vorgeprägte Wirklichkeitsebene ist, die weder der Einzelne verlassen kann noch irgendeine gesellschaftliche Institution, in der es um die durch 
sagen: Die Entwicklung von Vorstellungen wie Freiheit und Verantwortung ermöglichten es, Handlungen und die daraus resultierenden Folgen Personen zuzurechnen, was ein entscheidender Schritt für die Ausdifferenzierung von Gesellschaften und die Entwicklung moderner, nicht autoritär organisierter politischer Systeme war. ${ }^{36}$ Auf diese deskriptiven Perspektiven soll es für meine Analyse allerdings nicht primär ankommen, sondern auf die normative, also wertende Frage, ob es gelingen kann, Vorstellungen von Freiheit, Verantwortung und Schuld jenseits der Beschreibungen ihrer evolutionären oder sozialen Nützlichkeit zu rechtfertigen.

Unter welchen Bedingungen ist es legitim, Handlungen oder Willensbildung als „frei“ zu bezeichnen, und wann ist eine Bewertung wie „verantwortlich für ..." angebracht? Die Antworten hängen von wertenden Definitionen ab. „Freiheit“ und „Verantwortung" haben weder ein ontologisches Substrat noch eine feststehende Bedeutung, sondern verweisen auf Zuschreibungen, die von bestimmten Bedingungen abhängig gemacht werden. Diese Definitions- und die dahinter stehenden Bewertungsfragen sind Angelegenheit der normativen Wissenschaften, zu denen die Philosophie wie auch die Rechtswissenschaft gehört. Innerhalb der normativen Wissenschaften spielt eine Rolle, was der Erkenntnishintergrund ist, vor allem, welche Konsequenzen an Prädikate wie „frei“ und „verantwortlich“ geknüpft werden. Es ist nicht weiterführend, auf unspezifische Weise zu fragen: „Sind Menschen willensfrei?". Die Überlegung muss vielmehr sein: ,frei genug, damit den zu Beurteilenden die Folge X zugemutet werden kann?"“. Dies wird in den

Sprache konstituierte gesellschaftliche Realität geht.“ Gegen eine solche „Unentrinnbarkeitsthese" wird angeführt, dass Sprache zweideutiger sei und dass es möglich sei, plausibel das volle Wissen um die eigene Determiniertheit zu schildern (dazu Herzberg (Fn. 19), S. 19 f.; ders., FS für Achenbach, 2011, S. 157, 163 f.). Mir erscheint zweifelhaft, wie weit Folgerungen reichen, die man aus sprachlichen Grundstrukturen ziehen kann, insbesondere, ob der Schluss vom ,aktiv handelndem Subjekt" als zentralem Element moderner Sprachen auf die Notwendigkeit eines klassischen Schuldvorwurfs zwingend ist. Handlungen Subjekten zuzurechnen statt diese als passiv Getriebene zu bezeichnen, setzt keine starken Annahmen über AndersEntscheiden-Können voraus.

36 Prinz, in: Hillenkamp (Hrsg.), Neue Hirnforschung - Neues Strafrecht?, 2006, S. 51, $60 \mathrm{f}$. 
Diskussionen um Willensfreiheit meist nicht berücksichtigt. Es ist aber meines Erachtens nicht sinnvoll, in unspezifischer, dekontextualisierter Weise über die Willensfreiheit zu sprechen. Manche Antworten auf die Frage nach Willensfreiheit können zwar für einen spezifischen Kontext überzeugend sein, für den ein geringerer Grad an Freiheit genügen mag, nicht aber, wenn das Prädikat ,frei“ mit anderen Konsequenzen verbunden ist. Wichtig sind vor allem zwei Dimensionen: die Differenzierung anhand der Kategorien prospektiv-allgemein versus retrospektivkonkret, und zwischen begünstigender Freiheitsunterstellung und Tadel oder anderen negativen Reaktionen als Folge einer Freiheitsunterstellung. Auf den zentralen Unterschied zwischen einer retrospektiven Handlungserklärung und einer generellen, in die Zukunft dimensionierten Ordnungsgestaltung wurde vereinzelt in der Literatur eingegangen. ${ }^{37}$ Die Bedingungen, unter denen die Bezeichnung „frei“ als noch angemessen angesehen wird, können großzügiger ausfallen, wenn es allgemein um die angemessene Art und Weise des Umgangs von Menschen miteinander geht (prospektiv-allgemein) und wenn sich aufzeigen lässt, dass großzügige Freiheitszuschreibungen dem Interesse aller Betroffenen dienen. Schwieriger wird es, wenn einem Individuum für eine in der Vergangenheit liegende konkrete Handlung vorgeworfen wird, sich nicht anders entschieden und deshalb nicht anders gehandelt zu haben. Aus der Perspektive der Strafrechtswissenschaft ist deshalb festzustellen, dass manche in der Philosophie zu findenden positiven Einschätzungen der Frage „frei genug?“ in ihrem Zusammenhang wohl überzeugen, sich aber nicht auf die Aufgabe übertragen lassen, einen gegenüber dem Täter zu erhebenden klassischen Schuldvorwurf zu rechtfertigen.

Fragt man allgemein, und nicht auf eine konkrete, vergangene Handlung bezogen, „entscheiden wir Menschen frei?“, ist es vertretbar, den Fokus der Aufmerksamkeit auf folgende Umstände zu richten: die auch beim erwachsenen Menschen noch bestehende Lernfähigkeit; ${ }^{38}$ die

37 Vanberg, in: Riesenhuber (Hrsg.), Das Prinzip Selbstverantwortung, 2011, S. 45, 54 ff. Ähnlich Seelmann, in: Senn/Puskás (Hrsg.), Gehirnforschung und rechtliche Verantwortung, 2006, S. 91, $100 \mathrm{f}$.

38 Grothe (Fn. 23), S. 48; Elger u.a. (Fn. 15), S. 79 f. 
Möglichkeit der kritischen Bewertung eigener Wünsche; ${ }^{39}$ und das Abwägen von Gründen. So argumentieren einige zeitgenössische Philosophen, die Freiheitsannahmen bejahen: Es komme etwa auf die Fähigkeit zum Abwägen von Gründen, auf die Fähigkeit zum Weiterüberlegen oder auf die Fähigkeit an, sich wegen der epistemischen Offenheit der eigenen Zukunft unterschiedliche Konsequenzen vorzustellen. ${ }^{40}$ Man solle, so explizit Geert Keil, dabei nicht vergangenheitsbezogen fragen: „Hätte ich anders handeln können?“; sondern im Präsens „Kann ich so oder anders handeln?" ${ }^{\prime 4}$. Eine derartige Freiheitsunterstellung ist nicht mit negativen Konsequenzen, nicht mit einer Abwertung eines konkret betroffenen Individuums verbunden. Im Gegenteil, es dürfte nicht schwer fallen, zu begründen, dass der Nutzen einer gesellschaftlichen Praxis, die für die Vergabe des Prädikats ,frei“ die menschliche Fähigkeit zu Deliberation ausreichen lässt, auch den davon betroffenen Individuen zu Gute kommt. An dieser Stelle ist aus verschiedenen Perspektiven zu begründen, dass Freiheitsannahmen sinnvoll sind. Zum einen gilt dies aus einer auf das Kollektiv gerichteten Makroperspektive (Vorstellungen von Freiheit und Verantwortung sind essentielle Funktionsbedingungen in modernen Gesellschaften), zum anderen profitiert der Einzelne von den ihm zugeordneten Freiräumen für die Verwaltung seiner eigenen Angelegenheiten, die seine Handlungsfreiheit absichern und erweitern. ${ }^{42}$

Vergleichbare Überlegungen gelten, wenn man sich dem „Menschenbild des Grundgesetzes"43 zuwendet. Auch diesem liegt eine generalisierende, für das Kollektiv wie für Individuen wohlwollende Per-

39 Kröber (Fn. 24), S. 72 f.

40 Nida-Rümelin, in: Bonhoeffer/Gruss (Hrsg.), Zukunft Gehirn, 2011, S. 255 ff.; Habermas (Fn. 24), S. 104 ff. S. für ein komplexes Modell der Willensfreiheit, das mehrere Bedingungen einschließt, Walde (Fn. 14), S. 137 ff., $190 \mathrm{ff}$.

41 Keil (Fn. 2), S. 132.

42 Vanberg (Fn. 37), S. 57 ff. Generell zum Zusammenhang von Freiheit und Verantwortung von Hayek, Die Verfassung der Freiheit, in: ders., Gesammelte Schriften, Bd. 3, 4. Aufl. 2005, S. 93 ff.

43 S. zur verfassungsrechtlichen Dimension des Themas ,Willensfreiheit“ Heun, JZ 2005, 853 ff.; ders., in: Lampe/Pauen/Roth (Hrsg.), Willensfreiheit und rechtliche Ordnung, 2008, S. 276 ff.; H. A. Wolff, JZ 2006, 925 ff.; Möllers, in: Lampe/Pauen/ Roth (Hrsg.), Willensfreiheit und rechtliche Ordnung, 2008, S. 250 ff. 
spektive zugrunde. Es handelt sich um ein normatives Menschenbild, dem das wechselseitige Versprechen zugrunde liegt, sich als vernünftige und freie Wesen zu behandeln und sich rechtlich geschützte Handlungsfreiheiten einzuräumen. Auch insoweit genügt der Verweis auf die bei Menschen bestehende Disposition, Außeneinflüsse im Allgemeinen und normative Anforderungen im Speziellen zu verarbeiten, und auf die menschliche Fähigkeit, Gründe zu verstehen und abzuwägen. ${ }^{44}$ Es ist angemessen, dass wir Menschen als Rechtspersonen, etwa auch für die Zwecke des Zivilrechts, als hinreichend frei einordnen. ${ }^{45}$

Aber: das ist eine andere Frage als die, ob im Strafrecht ein klassischer Schuldvorwurf gerechtfertigt werden kann. ${ }^{46}$ Die Antwort auf Letzteres kann nicht schlicht aus dem „Menschenbild des Grundgesetzes“ oder dem zivilrechtlichen Verständnis von Rechtspersonen abgeleitet werden, sondern bedarf einer gesonderten Analyse. Zwar ist das Argument überzeugend, dass die Aufgabe unseres politisch wie rechtlich fundamental wichtigen Konnexes von Verantwortungs- und Freiheitszuschreibungen zu höchst unerwünschten, ja uns absurd erscheinenden Ergebnissen führen würde. ${ }^{47}$ Aber es bedarf der Begründung, was genau sich aus dieser Prämisse für das Strafrecht ergibt. Nicht überzeugend wäre es, daraus ohne weiteres zu folgern, dass an einem Schuldvorwurf klassischen Zuschnitts festgehalten werden müsse. Unerträgliche Widersprüche zwischen zentralen Prämissen unserer Rechtsordnung und strafrechtlichen Regeln wären nur dann zu erwarten und wären nur dann ein zwingendes Argument für die Beibehaltung des Status quo in der strafrechtlichen Verbrechenslehre, wenn die Alternative darin bestünde, die Praxis des Verantwortlichmachens, die hinter der Verhängung von Kriminalstrafe steht, insgesamt aufzugeben. Würde in staatlichen Verfahren ausgesagt: Täter sind für nichts verantwortlich, würden Basisannahmen zu Freiheit und Verantwortung konterkariert. Aber der klassische Schuldvorwurf ist nur eine von mehreren möglichen Ausgestal-

44 Heun, in: Lampe/Pauen/Roth (Fn. 43), S. 296 f.; Möllers (Fn. 43), S. 258 ff.

45 Die Einschätzung, dass der „Neurodeterminismus“ die „Architektur eines freiheitlichen Verfassungsstaates" bedrohe (so Duttge, Fn. 24, S. 17), ist zu pessimistisch.

46 Streng, ZStW 101 (1989), 273, 281.

47 Darauf verweisen z.B. Hillenkamp (Fn. 12), S. 95; Mohr (Fn. 33), S. 89 f.; Möllers (Fn. 43), S. $253 \mathrm{ff}$. 
tungen des Verantwortlichmachens (s. dazu unten VI.). Deshalb wäre es kurzschlüssig, aus einem verfassungsrechtlich begründeten Bekenntnis zur Willensfreiheit umstandslos die Notwendigkeit eines strafrechtlichen Schuldvorwurfs abzuleiten.

Genauso wenig entfällt die Aufgabe von Strafnormen, als Verhaltensnormen Verhalten beeinflussen zu wollen, weil eine Drohung gegenüber einem determiniert handelnden Täter ,einfach sinnlos"48 sei. Ein differenziertes Modell menschlicher Entscheidungsfindung muss natürlich die Wirkung von Außeneinflüssen anerkennen, seien diese abstrakt-normativer Art wie Strafgesetze oder konkret-situationsbezogen wie ein verbaler Appell durch eine Bezugsperson. Wolf Singer bezeichnet es als ,eine der wichtigsten Funktionen von Nervensystemen, Informationen aus der Umwelt aufzunehmen“" und betont, dass Gehirne nicht linearen Gesetzen folgen und sich nicht ,auf unveränderlichen, vollständig determinierten Bahnen“" bewegen..$^{49}$ Die Feststellung, dass „die Kultur der Freiheit eine sich selbst erzeugende Praxis“ sei, ${ }^{50}$ steht deshalb nicht im Widerspruch zu neurowissenschaftlichen Beschreibungen.

Wenn es darum geht, in einem Strafverfahren festzustellen, dass Frau Müller sich hätte anders entscheiden können, als sie am 1.2.2013 um 20.13 Uhr eine strafbare Handlung vornahm, muss die Bewertung differenzierter ausfallen als bei allgemein gehaltenen Überlegungen zur Freiheit des Menschen oder des Menschen als Rechtsperson. Der vom Bundesgerichtshof für angemessen gehaltene Vorwurf im Falle der falschen Entscheidung $(, \ldots$ obwohl er sich rechtmäßig verhalten, sich für das Recht hätte entscheiden können“) ${ }^{51}$ koppelt den Begriff ,Schuld“ an das Bestehen einer Entscheidungsalternative. Das Vergleichsverfahren als solches ist methodisch nicht ungewöhnlich, sondern entspricht gängigen Herangehensweisen an moralische Bewertungen. ${ }^{52}$ Der Verweis auf eine nicht gewählte, moralisch oder rechtlich vorzugswürdige Alternative ist aber nur dann als Grundlage eines Vorwurfs geeignet, wenn

48 So Schünemann, Festschrift für Lampe, 2003, S. 537, 545.

49 Singer (Fn. 21, in: Bonhoeffer/Gruss), S. 262 f.; ebenso Elger u.a. (Fn. 15), S. 79.

50 Mohr (Fn. 33), S. 90.

51 S. oben Fn. 8.

52 S. Nagel, The View from Nowhere, 1986, S. 121. 
dem Handelnden diese Alternative tatsächlich offen stand. Das Problem des klassischen Schuldvorwurfs liegt darin, dass er suggeriert, es werde eine Situation beschrieben, die so tatsächlich bestanden habe, nämlich eine echte Entscheidungsalternative zu einem spezifizierten Zeitpunkt. Ein Vorwurf wäre dann berechtigt, wenn davon auszugehen wäre, dass sich normativ relevante Gründe ,,als letztes Wort" gegen andere Faktoren hätten durchsetzen können. Diese Bedingungen sind aber nicht als Standardannahme gesichert. Vielleicht hat ein Abwägen stattgefunden, aber nur rudimentär, weil zu diesem Zeitpunkt das relevante Abwägungsmaterial nur rudimentär vorhanden war. Oder es gab als Zwischenstadium die auf Gründe bezogene Erkenntnis, dass man dies besser nicht tun solle, die sich aber letztlich nicht gegen die Aktivitäten des limbischen Systems durchsetzen konnte. Ein Schuldvorwurf klassischen Zuschnitts würde nicht nur im Modell menschlicher Entscheidungsfindung Dominanz und Endkontrolle der Hirnprozesse voraussetzen, die für das bewusste Abwägen von Gründen zuständig sind, sondern darüber hinaus beim individuellen Täter den Nachweis, dass die relevanten Hirnstrukturen adäquat ausgeprägt waren. Ohne diese Voraussetzungen fehlt die Basis für einen persönlichen Vorwurf, der den Inhalt hat, eine falsche Entscheidung getroffen zu haben, obwohl man als dasselbe Individuum zum selben Zeitpunkt die richtige hätte treffen können.

Dies bedeutet nicht, dass die Erhebung jeglicher Vorwürfe ausscheidet und die Konsequenz entweder Fatalismus und Teilnahmslosigkeit wären oder aber die Behandlung von Menschen als gefährliche Objekte, vor denen die Gesellschaft gesichert werden müsse (dazu sogleich V. 1.). Das in Kapitel VI. zu entwickelnde Argument wird sein, dass ein Vorwurf für die Tat berechtigt bleibt, auch wenn der klassische Schuldvorwurf „Du hättest anders entscheiden können“ nicht mehr erhoben wird. 


\section{Umgang der Strafrechtswissenschaft mit dem Dilemma}

Eine Absage an den klassischen Schuldbegriff bedeutet eine Herausforderung. Nach wie vor gehen viele Strafrechtswissenschaftler davon aus, dass erstens nur Anders-Handeln-Können und Anders-EntscheidenKönnen einen Schuldvorwurf tragen könnten und dass zweitens ein Schuldvorwurf notwendiges Element für die Legitimität von Kriminalstrafe sei..$^{53}$ Wie aber ist das durch neurowissenschaftliche Thesen entstehende Dilemma zu bewältigen? Eine Möglichkeit liegt darin, zu kapitulieren und auf einen klassischen Schuldvorwurf sowie Kriminalstrafe zu verzichten (unten 1.). Der deutlich größere Block der Autoren präferiert allerdings Strategien, die den Angriffen trutzen und sowohl an einem Schuldvorwurf als auch an Kriminalstrafe festhalten wollen. Innerhalb dieses Blocks lassen sich wiederum zwei größere Strömungen unterscheiden: zum einen eine defensive Strategie, die sich darauf beschränkt, naturwissenschaftliche Thesen und naturwissenschaftliches Denken abzuwehren (2.), zum anderen konstruktivere Ansätze, die an einem Schuldvorwurf festhalten, der aber anders als mit Verweis auf Anders-Entscheiden-Können begründet wird (3.-6.).

\section{Verzicht auf Verantwortungszuschreibung und Übergang zu einem Maßnahmenrecht}

Jedenfalls in der deutschen Literatur ${ }^{54}$ lassen sich nur wenige Autoren in einem Maße auf die Rezeption neurowissenschaftlichen Schrifttums ein, dass ihre Schlussfolgerungen mit dem Stichwort „Kapitulation“ beschrieben werden können. Diese folgern, dass man sich von der Krimi-

53 S. z.B. Schünemann, Festschrift für Lampe, 2003, S. 537, 543; Hillenkamp, JZ 2005, 313, 316; ders. (Fn. 12), S. 97 ff.; T. Walter, Festschrift für Schroeder, 2006, S. 131; H.-L. Schreiber, in: Duttge (Hrsg.), Das Ich und sein Gehirn, 2009, S. 135, 136; Koriath, GA 2011, 612, 629; Schönke/Schröder/Lenckner/Eisele, 28. Aufl. 2010, Vorbem. $\S \S 13$ ff. Rn. 110. A.A. Krauss, Festschrift für Jung, 2007, S. 411, 427 ff.; Streng, Festschrift für Jakobs, 2007, S. 675, 685; T.M. Spranger, JZ 2009, 1033, 1035.

54 S. auch Greene/Cohen, Phil Trans. Royal Society London (2004), 1775, 1783 f. 
nalstrafe im klassischen Sinne verabschieden müsse. ${ }^{55}$ Die Alternative liege in einem Maßnahmenrecht, das Rechtsfolgen nicht mit Blick auf die Vergangenheit, nicht mit Blick auf die begangene Tat bestimmt, sondern mit Blick in die Zukunft. Dies vertritt etwa Grischa Merkel: „Die Erkenntnisse der Neurowissenschaften weisen den Weg in einen therapeutischen Maßnahmevollzug". ${ }^{56}$ Ein konsequent dem Gedanken der Prävention zukünftigen Fehlverhaltens durch denselben Täter verschriebenes Rechtsfolgensystem ist keine neue Erfindung, sondern wurde u.a. von Franz von Liszt skizziert und in der zweiten Hälfte des 20. Jahrhunderts unter der Flagge „Abschaffung der Strafe“ propagiert. $^{57}$ Die Vertreter dieser Strömung würden sich vermutlich gegen die Bezeichnung als „Kapitulation“ wenden, da es sich aus ihrer Sicht nicht lediglich um einen Legitimierungsnöten geschuldeten, aber bedauerlichen Verzicht handeln würde, sondern um eine positiv zu bewertende Neujustierung des Rechtsfolgensystems. Verbunden wird damit die Hoffnung, dass ein Maßnahmenrecht einen humaneren Umgang mit Straftätern bedeute. ${ }^{58} \mathrm{Ob}$ diese Hoffnung berechtigt ist, ist allerdings fraglich: ${ }^{59}$ Es gibt gute Gründe dafür, dass im Vergleich mit manipulativen Praktiken der offene Einsatz von Vorwürfen und Zwang letztlich humaner ist. ${ }^{60}$

Ein großes Problem liegt darin, dass ein konsequenter Verzicht auf Verantwortungszuschreibung und auf Reaktionen, die retrospektiv statt

55 G. Detlefsen (nunmehr G. Merkel), Grenzen der Freiheit-Bedingungen des Handelns - Perspektive des Schuldprinzips, 2006, S. 335 ff.; dies., Festschrift für Herzberg, 2008, S. 3, $25 \mathrm{ff}$.

56 G. Merkel (Fn. 55), S. 346; dies., Festschrift für Herzberg, 2008, S. 3, 30 ff. Ebenso Roth, Festschrift für Lampe, 2003, S. 43, 57; Singer, Ein neues Menschenbild, 2003, S. 65.

57 S. von Liszt, Der Zweckgedanke im Strafrecht, in: ders., Strafrechtliche Aufsätze und Vorträge, 1905, S. 126 ff.; Plack, Plädoyer für eine Abschaffung des Strafrechts, 1989.

58 So etwa Hochhuth, JZ 2005, 745, 752; ders., in: Gander/Fludernik/Albrecht (Hrsg.), Bausteine zu einer Ethik des Strafrechts, 2008, S. 117, 130; G. Merkel, Festschrift für Herzberg, 2008, S. 3 , 33 ff. Krit. Hassemer, ZStW 121 (2009), 829, 840 f.

59 Skeptisch K. Günther, KJ 2006, 116, 130; Hillenkamp, JZ 2005, 313, 317 f.; ders. (Fn. 12), S. 101; Duttge (Fn. 24), S. 53 ff.; Frisch, Festschrift für Maiwald, 2010, S. 239, 246.

60 Burkhardt (Fn. 34), S. 122 f. 
präventiv begründet werden, sowohl mit Grundstrukturen unserer moralischen Alltagspraktiken als auch mit Basisannahmen moderner Rechtsordnungen nicht vereinbar ist. In seinem vielzitierten Essay „Freedom and Resentment“ wies Peter Strawson darauf hin, dass reaktive Einstellungen und reaktive Praktiken des Lobes und des Tadels auch dann beibehalten würden, wenn sich intellektuell die Überzeugung von der Determiniertheit menschlichen Verhaltens durchsetzen würde. ${ }^{61}$ Strawsons Aufsatz ist Zeugnis einer angelsächsisch-pragmatischen Herangehensweise. Ihn interessiert vorwiegend das Faktum der reaktiven Einstellungen und reaktiven Praktiken, weniger die tiefer bohrende Frage nach ihrer Legitimität. An dieser Stelle genügt jedoch tatsächlich der Verweis auf die Existenz moralischer Praktiken (s. auch unten VI. 1.). Eine strafrechtliche Lösung, die nicht auf vergangenes Unrecht mit einem Werturteil reagieren würde, wäre schon deshalb angreifbar, weil damit ein scharfer Kontrast zu den Basisstrukturen unserer moralischen Praxis entstehen würde. Es ist nicht erforderlich, ausführlicher zu erörtern, inwieweit rechtliche Wertungen alltagsmoralisch vorgegebenen Bewertungsmustern folgen sollten oder müssen. ${ }^{62}$ Denn auch, wenn man davon ausgeht, dass ein gewisser Spielraum für strafrechtliche Wertungen besteht (der vor allem dann erforderlich werden kann, wenn das Rechtssystem andere Aufgaben zu erfüllen hat als moralische Bewertungssysteme), wäre es jedenfalls problematisch, bei Basisstrukturen scharfe Abweichungen vorzusehen. Insoweit ist es erforderlich, dass strafrechtliche Wertungen mit fundamentalen moralischen Prinzipien ebenso wie mit dem Konzept der Rechtsperson als Verantwortung tragende Person kompatibel sind. ${ }^{63}$ Das Umschwenken auf eine rein präventiv begründete Rechtsfolge statt der erwarteten reaktiven Einstellung und reaktiven Kommunikation wäre ein zu radikaler Schnitt - und ein unnötiger Schritt.

61 P. Strawson, in: Watson (Hrsg.), Free Will, 1982, S. 59, 67 ff.

62 S. zum grundsätzlich bestehenden Zusammenhang von strafrechtlicher und alltagsmoralischer Zurechnung Neumann, Zurechnung und „Vorverschulden“. Vorstudien zu einem dialogischen Modell strafrechtlicher Zurechnung, 1985, S. 274 f.

63 S. zu letzterem Frisch, Festschrift für Maiwald, 2010, S. 239, 245 f. 


\section{Verweigerung der Beschäftigung mit neurowissenschaftlichen Modellen}

Eine unter Strafrechtswissenschaftlern verbreitete Reaktion ist, dass die (als solche empfundenen) Zumutungen von Neurowissenschaftlern eine Abwehrhaltung hervorrufen. Allerdings führt es nicht weiter, darauf zu verweisen, dass auch im Kreis der Hirnforscher keine Einigkeit bestehe und eindeutige Aussagen noch nicht möglich seien. ${ }^{64}$ Der Verweis auf „noch keine eindeutigen Ergebnisse“ und „nicht verifiziert“ weckt den Verdacht erkenntnistheoretischer Naivität. Gesellschaftliche und damit auch rechtswissenschaftliche Implikationen müssen bereits dann diskutiert werden, wenn es sich „lediglich“ um Modelle handelt, die einen zwar vorläufigen, aber bis zur Ersetzung durch bessere Modelle ernst zu nehmenden Stand der Wissenschaft bilden. Problematisch sind ferner düster eingefärbte Fehlinterpretationen dessen, was sich aus neurowissenschaftlichen Stellungnahmen entnehmen lässt, etwa Formulierungen wie „dass die moderne Hirnforschung ... von einer möglichen vollständigen neuronalen Fremdsteuerung menschlichen Verhaltens durch das Gehirn ausgehe“65 (hier ist der Ausdruck ,Fremdsteuerung“ deplatziert) oder dass psychisch vermittelte Kausalität nicht mehr möglich sei, wenn man an eine ,vollständige naturgesetzliche Erklärung der menschlichen Willensentschließung" glaube ${ }^{66}$ (es wäre in der Tat eine absurde Vorstellung, dass Menschen nicht auf Außeneinflüsse reagieren könnten, was so aber auch nicht vertreten wird - Hirnforscher beschreiben menschliches Verhalten nicht analog zu simplen Systemen, die, einmal programmiert, roboterartig vorgegebenen Abläufen folgen ${ }^{67}$ ).

Eine andere Abwehrstrategie findet sich etwa im Vortrag von Winfried Hassemer, den er 2009 auf der Strafrechtslehrertagung in Hamburg gehalten hat. Hassemer führt aus, dass man einen „Kategorienfehler“ begehe, wenn man die Begründungen eines Wissenschaftszweigs in die eines anderen übertrage. Jede Wissenschaft habe ihre eigenen Frage-

64 So Hillenkamp, JZ 2005, 313, 318; Kröber (Fn. 24), S. 64; Koch, ARSP 2006, 223, 233 ff.; Frisch, Festschrift für Maiwald, 2010, S. 239, 244 f.

65 Jäger, GA 2013, 3, 4.

66 Jäger, GA 2013, 3, 4, 13; ähnlich Spilgies, HRRS 2005, 43, 46.

67 Singer, in: Krüger (Hrsg.), Hirn als Subjekt?, 2007, S. 39, 53. 
stellungen und eigenen Methoden. ${ }^{68}$ In ähnlicher Weise argumentiert Michael Pawlik, dass die ,naturwissenschaftlich-kausalistische Beschreibungssprache" zwar im naturwissenschaftlichen Kontext fruchtbar sei, aber eben „nur eine Beschreibungssprache“ unter mehreren sei ${ }^{69}$ Für das Strafrecht trete ,das Sprachspiel der Gründe dem Sprachspiel der Ursachen ontologisch und epistemologisch gleichberechtigt zur Seite " ${ }^{70}$ Gegen eine strikte Segmentierung in nebeneinanderstehende Wissenschaften sind allerdings Einwände zu erheben. Insbesondere sind die empirischen Wissenschaften nicht eine gleichgeordnete Wissenschaft neben den normativen Disziplinen, sondern sie haben auch die Funktion einer ,Zuliefererwissenschaft" - nicht nur für die angewandten Wissenschaften (etwa Ingenieurswissenschaften), sondern auch für die normativen Disziplinen. Dies gilt für Erkenntnistheorie und Moralphilosophie, und insbesondere auch für das Strafrecht. Strafrechtliche Urteile treffen Aussagen über Menschen und knüpfen daran belastende Rechtsfolgen. Der Verweis auf „Sprachspiele“ (ein Begriff, der auch von Habermas verwendet wird) ${ }^{71}$ ist in einem solchen Kontext missverständlich. Er könnte Beliebigkeit, ja Frivolität implizieren: Spielregeln sind nach Gutdünken und Konsens der Spielenden änderbar. Strafrechtsurteile treffen dagegen aus der Position staatlicher Macht Entscheidungen zu Lasten von Menschen, für die dies alles andere als ein Spiel ist und die in diesen Kommunikationen keineswegs zu einer Konsensgemeinschaft gehören. Zwar ist Habermas ' Einschätzung zutreffend, dass Teilnehmer- und Beobachterperspektive (die freiheitserlebende Perspektive der 1. Person und die beschreibende Perspektive der 3. Person, dazu sogleich unten 3.) sich nicht vollkommen entkoppeln lassen. ${ }^{72}$ Und Hassemer ist insoweit zuzustimmen, dass normative Konsequenzen, die an empirisches Wissen geknüpft werden, nicht mehr in die Zuständigkeit der empirischen Wissenschaften fallen. ${ }^{73}$ Aber dies

68 Hassemer, ZStW 121 (2009), 829, $846 \mathrm{f}$.

69 (Fn. 4), S. 283; s. auch K. Günther, KJ 2006, 116, 120 f.; Stübinger, Bonner Rechtsjournal 2/2010, 211, 214.

70 Pawlik (Fn. 4), S. 283 f.

71 S. Habermas (Fn. 24), S. $101 \mathrm{ff}$. Hervorhebung im obigen Text durch die Verf.

72 Habermas (Fn. 24), S. $112 \mathrm{f}$.

73 Hassemer, ZStW 121 (2009), 829, 848 ff. 
ändert nichts daran, dass die Strafrechtswissenschaft nicht ignorieren darf, was ihr als Thesen über die Prozesse menschlicher Entscheidungsfindung präsentiert wird. ${ }^{74}$ Für jedes einzelne Element, das in einem an den Täter adressierten Vorwurf steckt, muss überprüft werden: Bezieht sich an dieser Stelle eine Behauptung auf physikalische, physiologische oder psychologische Gegebenheiten, und wenn ja, ist diese Behauptung kompatibel mit dem, was in den jeweiligen Bezugswissenschaften als angemessene Beschreibung anerkannt ist? Dieser Pflicht ist nicht mit dem Verweis auf ,andere Sprachspiele“ zu entgehen.

\section{Abstellen auf Entscheidungsalternativen aus der Perspektive der 1. Person}

Ist eine Rechtfertigung des klassischen Schuldvorwurfs nicht wenigstens deshalb möglich, weil aus der Perspektive der 1. Person Menschen nicht anders können, als sich frei zu fühlen? Dass unter der Überschrift „Willensfreiheit“ anhaltende und besonders hartnäckige Debatten geführt werden, hat auch mit dem Graben zu tun, der zwischen der Perspektive der 1. Person und der Perspektive der 3. Person klafft. ${ }^{75}$ Thomas Nagel hat die vielfältigen Probleme, die sich aus der Divergenz von interner und externer Perspektive ergeben und die Aussichten für eine Annäherung des Subjekts an eine objektive Perspektive in seinem Buch „The View from Nowhere“ analysiert. ${ }^{76}$ Offensichtlich stellt sich das Problem besonders dringlich, wenn individuelles Erleben in Entscheidungssituationen mit den Beschreibungen kontrastiert wird, die die Neurowissenschaften ermöglichen. ${ }^{77}$ Erstens sind unbewusste Entschei-

74 So auch Schiemann, NJW 2004, 2056, 2059; T. Walter, Festschrift für Schroeder, 2006, S. 131, 142 f.; Duttge (Fn. 24), S. 13, 34 f.; Hirsch, ZIS 2010, 62, 65; Crespo, GA 2013, 15, 24.

75 S. dazu Max Planck: „Von außen betrachtet, ist der Wille kausal determiniert, von innen betrachtet, ist der Wille frei“, in: Scheinprobleme der Wissenschaft, abgedr. in: Roos/Herrmann (Hrsg.), Max Planck. Vorträge, Reden, Erinnerungen, 2001, S. 193, 203.

76 Nagel (Fn. 52), zu Freiheitsproblemen: S. $110 \mathrm{ff}$.

77 Dazu Singer, in: Krüger (Hrsg.), Hirn als Subjekt?, 2007, S. 39, 40 ff. 
dungsvorgänge ebenso wie die Rahmenbedingungen für das eigene Abwägen von Gründen dem Bewusstsein nicht zugänglich, weshalb Menschen die Bedeutung und den Stellenwert der bewussten und begründeten Entscheidungen systematisch überschätzen müssen. Zweitens kann im Zustand des bewussten Abwägens von Gründen die eigene Zukunft nur als offene Zukunft erlebt werden. ${ }^{78}$ In der subjektiv-persönlichen Erfahrung muss sich selbst derjenige in der Rolle des Gründe-Abwägenden und (teilweise mühsam) Entscheidenden erleben, der fest davon überzeugt ist, dass die Welt deterministisch verfasst ist. ${ }^{79}$

Was folgt hieraus für die Berechtigung eines Schuldvorwurfs? Kann man statt auf Anders-Entscheiden-Können auf die individuelle Überzeugung vom Anders-Entscheiden-Können abstellen? Würde es nicht ausreichen, wenn der Straftäter selbst auf die Frage, ob er sich auch hätte anders entscheiden können, mit ,ja “ antworten würde? ${ }^{80}$ Das subjektive Erleben von Kontrolle und Freiheit wird gelegentlich in der Literatur als vermeintlicher Beleg dafür angeführt, dass dies die tatsächliche Verfasstheit der Welt sei. ${ }^{81}$ Dagegen ist aber zweierlei vorzubringen. Erstens wäre nachzufragen, ob sich ein Gefühl von Freiheit (manchmal auch: ein Gefühl der Qual) in der Zeitspanne, die als gegenwärtiger, unabgeschlossener Prozess einer Entscheidungsfindung erlebt wird, ohne weiteres auf eine Selbsteinschätzung übertragen lässt, die dieselbe Person nachträglich, im Hinblick auf eine in der Vergangenheit getrof-

78 Burkhardt, Festschrift für Eser, 2005, S. 77, 91 ff.

79 Burkhardt a.a.O.

80 So Burkhardt, Festschrift für Eser, 2005, S. 77, 100; ders., Festschrift für Maiwald, 2010, S. 79, 88 ff. (s. aber auch Burkhardt, Fn. 34, S. 88 mit der Aussage: „Ein unbedingter Wille, Willensfreiheit im Sinne eines ,Unter-denselben-physiologischenBedingungen-willentlich-andershandeln-Könnens" “ entspreche nicht unserem Freiheitserleben). Krit. Engisch, Die Lehre von der Willensfreiheit in der strafrechtsphilosophischen Doktrin der Gegenwart, 2. Aufl. 1965, S. 4 ff.; Schiemann, NJW 2004, 2056, 2058 f.; Hillenkamp, JZ 2005, 313, 320; ders. (Fn. 12), S. 102; Seelmann (Fn. 37), S. 98 f.; R. Merkel (Fn. 1), S. 120 f.; G. Merkel, Festschrift für Herzberg, 2008, S. 3, 13; Schroth, Festschrift für Roxin z. 80. Geburtstag, 2011, S. 705, 712; Herzberg (Fn. 19), S. 37 ff.; ders., ZStW 124 (2012), 12, 49 ff.; Crespo, GA 2013, $15,18$.

81 Griffel, GA 1989, 193, 200 ff.; ders., GA 1996, 457, 459 ff.; Guss, Willensfreiheit, 2002. 
fene Entscheidung, abgeben würde. ${ }^{82}$ Es mag plausibel sein, die typische Selbstbeschreibung von Entscheidenden bei noch nicht getroffener Entscheidung, beim Erwägen und Abwägen, mit dem Stichwort „Freiheitsgefühl“" zu charakterisieren. ${ }^{83}$ Aber es handelt sich hier um ein epistemisches Phänomen: Natürlich kann man in der Entscheidungssituation nicht wissen, wie sie ausgehen wird. Hieraus folgt nicht, dass die eigene retrospektive Bewertung zwangsläufig genauso ausfallen muss. Je größer der zeitliche Abstand zu einer Handlung wird, umso eher ist vorstellbar, dass der Handelnde im Rückblick sagen würde: „ich konnte damals nicht anders". 84

Zweitens: Selbst wenn ein Individuum zu einer anderen Beschreibung seiner damaligen Handlungssituation käme, ist die Relevanz dieser Selbstbeschreibung fraglich. Es wäre nicht überzeugend, die relevanten Phänomene nur aus der Perspektive der 1. Person zu erfassen. Wolfgang Prinz formuliert ebenso prägnant wie unabweisbar: „Was immer wir aus der Introspektion über psychische Prozesse zu wissen glauben - es ist nichts anderes als das Ergebnis selektiver Repräsentation und kategorialer Überformung. Deshalb sagt, dass wir uns frei fühlen, nichts - aber auch gar nichts - darüber aus, wie frei oder unfrei die zu Grunde liegenden Prozesse in Wirklichkeit sind" ${ }^{85}$ Ein im unmittelbaren Erleben der eigenen Situation entstehendes Empfinden des Anders-EntscheidenKönnens steht der Möglichkeit nicht entgegen, bei der Beurteilung der Entscheidung anderer Personen einen externen 3. Person-Standpunkt einzunehmen. Strafrechtliche Werturteile werden aus dieser Außenperspektive formuliert, und sobald der Verdacht aufkeimt, dass eine Divergenz zwischen Binnen- und Außenperspektive besteht, sollte die

82 Dazu Wittwer, Jahrbuch für Recht und Ethik 19 (2011), 397, $420 \mathrm{f}$.

83 S. aber auch Herzberg (Fn. 19), S. 49 f. dazu, dass dies keine zwingende Annahme ist. Die intellektuelle Überzeugung, dass eine zu treffende Entscheidung determiniert ist, ist jedenfalls für reflektierte und analytisch ausgebildete Menschen (nicht zufällig wählt Herzberg als Beispiel einen Professor für Philosophie) durchaus mit der Erkenntnis vereinbar, dass die eigene Zukunft zwangsläufig offen erscheint.

84 S. Kriele, ZRP 2005, 185, 187: „Den Vorwurf ,du hättest anders handeln können“ kann er, der ja seine damalige Motivationslage kennt, kaum ernst nehmen, er treibt ihn in Trotz und Wut“; Seelmann (Fn. 37), S. 100 f.; Herzberg (Fn. 19), S. 39.

85 Prinz, in: Hillenkamp (Hrsg.), Neue Hirnforschung - neues Strafrecht?, 2006, S. 51, 54. 
Wahl auf die Außenperspektive fallen. Man muss nicht einem einseitig auf naturwissenschaftliche Errungenschaften fixierten Szientismus huldigen, um zu vertreten, dass das menschliche Streben nach Überwindung der 1. Person-Perspektive einen unhintergehbaren Fortschritt bedeutet. ${ }^{86}$ Es wäre zudem inkonsequent, wenn man sich im Normalfall damit begnügen würde, zur Legitimation eines Schuldvorwurfs auf das subjektive Gefühl des Anders-Entscheiden-Können abzustellen, aber in anderen Fällen auf eine externe Perspektive umzuschwenken - verwiesen sei z.B. auf das Verfahren gegen Anders Breivik in Oslo im Jahr 2012, der nicht etwa deshalb als schuldfähig eingestuft wurde, weil dies seiner eigenen festen Überzeugung entsprach, sondern weil sich das Gericht auf schwieriger gutachterlicher Basis schließlich diese Meinung gebildet hatte. Würde ungefiltert auf das subjektive Empfinden eines Täters abgestellt, müsste eine solche „einfache“ Begründung eines Schuldvorwurfs als zynisch erscheinen.

Zu erwägen ist allerdings, ob man, ohne in den Verdacht einer zynischen Ausnutzung der Fehleranfälligkeit der 1. Person-Perspektive des Täters zu geraten, ein rechtssoziologisches Argument einführen könnte. Dieses Argument wäre, dass die Rechtsordnung keinen höheren Grad an Rationalität beanspruchen kann, als es der intersubjektiv geteilten Einschätzung aller Rechtsgenossen entspricht. Entscheidend wäre dann nicht, dass der einzelne Täter individuell glaubt, frei und bewusst zwischen Alternativen entschieden zu haben, sondern vielmehr, dass wir alle gemeinsam unseren Ausgangspunkt in der 1. Person-Perspektive haben. ${ }^{87}$ Es ist zu vermuten, dass es einen Unterschied gibt zwischen Fällen wie dem von Anders Breivik, die offensichtlich den Verdacht der Pathologie wecken und deshalb die Einnahme der distanzierteren externen Perspektive nahe legen, und „Normalfällen“. Wenn sich eine Entscheidung nach einem Alltagsverständnis als „,noch irgendwie normal" darstellen lässt, sind Beurteiler vermutlich eher geneigt, eigene subjektiv geprägte Einschätzungen von Anders-Entscheiden-Können auch in die externe Perspektive einzubringen. ${ }^{88}$ Aus der Sicht eines

86 Dazu Nagel (Fn. 52), S. 9.

87 S. dazu Habermas (Fn. 24), S. 263, 287; Ruske, Ohne Schuld und Sühne, 2011, S. 338. Ähnlich Hirsch, ZIS 2010, 62, 65 ff.

88 Streng, ZStW 101 (1989), 273, $298 \mathrm{ff}$. 
Rechtssoziologen dürfte hier die Erklärung dafür liegen, warum etwa in öffentlichen Debatten der Verweis auf subjektive Freiheitsgefühle nach wie vor einen großen Raum einnimmt. Daneben gibt es erkenntnistheoretische Überlegungen, die darauf verweisen, dass der Überwindung einer 1. Person-Perspektive gewisse Grenzen gesetzt sind. So betont etwa Habermas die Verschränkungen zwischen den Perspektiven und die Abhängigkeiten von Beobachtung einerseits, Teilnahme an einem intersubjektiven Austausch andererseits. ${ }^{89}$ In der Tat wäre es vermessen, zu erwarten, dass Menschen eine genuine 3. Person-Perspektive einnehmen können: Naturwissenschaftler bleiben Teilnehmer an interpersonalen Verständigungsprozessen und können keinen der Welt externen Standpunkt einnehmen, keinen echten „Blick von Nirgendwo“. Trotz des berechtigten Verweises darauf, dass die Perspektiven Idealtypen sind, die in der realen Lebenswelt und in der Forschungspraxis so nicht vorkommen, wäre aber die Folgerung zu pessimistisch, dass es vollkommen unmöglich sei, die 1. Person-Perspektive zu transzendieren und deshalb die Rechtsordnung unentrinnbar auf die Welt der internen Erfahrungen angewiesen sei. Gefordert ist das Bemühen darum, die 1. Person-Perspektive so weit wie möglich hinter sich zu lassen. Ein für Perspektiven aufgeschlossener Blick erklärt aber die Zähigkeit des Glaubens an Anders-Entscheiden-Können bei manchen Diskussionsteilnehmern: weil diese nicht analytisch zwischen den unterschiedlichen Perspektiven zu differenzieren vermögen.

\section{Fiktion des Anders-Entscheiden-Könnens aus funktionalistischen Gründen}

$\mathrm{Zu}$ erwägen ist, ob es überzeugende Gründe dafür geben könnte, am klassischen Schuldvorwurf festzuhalten, indem man die Möglichkeit des Anders-Entscheiden-Könnens bewusst fingiert. Die Vorstellung, dass Schuld normativ konstruiert werde, dass Schuld Personen zugeschrieben werde, hat in der zeitgenössischen deutschen Strafrechtswis- 
senschaft nicht wenige Anhänger. ${ }^{90}$ Sieht man die Dinge so, ist der Verweis auf Schuld kein Verweis auf reale Möglichkeiten, die einer empirischen Untersuchung zugänglich sind. Die entscheidende Frage gilt der Legitimation eines solchen Vorgehens. Natürlich kann man Schuld zuschreiben (das Rechtssystem kann alles Mögliche zuschreiben und fingieren), aber kann man Gründe angeben, die dies rechtfertigen? Über dieses Problem geht etwa Claus Roxin zu schnell hinweg. Er zieht eine Parallele zwischen Gleichheitsfiktion und Freiheitsfiktion: So, wie man Menschen, die faktisch nicht gleich sind, als gleich behandeln müsse, so müsse man sie auch als frei behandeln.${ }^{91}$ Hier wird nicht gewürdigt, dass die Fiktion von Gleichheit sich in der Regel zugunsten derjenigen auswirkt, die sich darauf berufen. Die Fiktion von Freiheit zur Zuschreibung von strafrechtlicher Schuld wirkt sich dagegen (mit sehr erheblichen Folgen) zu Lasten der Betroffenen aus. ${ }^{92}$ Das Legitimationsproblem ist deshalb unbedingt ernst zu nehmen.

Man muss in diesem Zusammenhang nicht zu einer Grundsatzkritik daran ausholen, dass im Rechtssystem teilweise mit kontrafaktischen Fiktionen gearbeitet wird. Eine kontrafaktische Fiktion liegt z.B. dann vor, wenn wir in Bezug auf junge Menschen an festen Altersgrenzen auch im möglichen Widerspruch zu Einzelfällen festhalten. Normative Systeme sind nicht zwingend an empirische Befunde in der Weise gebunden, dass sie diese 1:1 umsetzen müssen. Mein Plädoyer bezieht sich darauf, dass die Rechtswissenschaft solche Befunde zur Kenntnis nehmen muss und Abweichungen in hohem Maße begründungsbedürftig sind. Je gravierender die Rechtsfolgen für Betroffene ausfallen, umso größer wird der auf Fiktionen lastende Rechtfertigungsdruck.

Wer den Zuschreibungscharakter von Schuld betont, verweist meist auf die Notwendigkeit, die durch die Straftat missachteten Normen zu

90 Jakobs, ZStW 107 (1995), 247, 257 ff.; ders., System der strafrechtlichen Zurechnung, 2012, S. 59 ff.; Streng, ZStW 101 (1989), 273, 288 ff.; MK/Freund, 2. Aufl. 2011, Vorbem. zu den $\S \S 13$ ff. Rn. 242; Weißer, GA 2013, 26, 37 f. Krit. Schünemann, Festschrift für Lampe, 2003, S. 537, 539 ff.

91 Roxin (Fn. 4), § 19 Rn. 37.

92 Kindhäuser, Festschrift für Hassemer, 2010, S. 761, 773. 
bestätigen.$^{93}$ Es soll hier nicht prinzipiell in Frage gestellt werden, dass Normbestätigung durch Kriminalstrafe, auch ,positive Generalprävention" genannt, ein sinnvolles und legitimes Anliegen ist. Es bleibt allerdings die Frage: Könnte dies genügen, um eine kontrafaktische Unterstellung von Anders-Entscheiden-Können zu legitimieren? Man könnte an dieser Stelle die Fragen aufwerfen, wieweit im Umgang von Menschen miteinander moralische Gebote der Wahrhaftigkeit und Transparenz gelten, und vor allem, näher an unserem Thema, inwieweit dies für Staatsorgane im Umgang mit Bürgern gelten muss. In aller Breite muss dieses Problem hier nicht erörtert werden. In unserem Kontext geht es nicht um unvollständige Informationen oder manipulatives Vorgehen im Allgemeinen, sondern um die engere Frage, ob explizite Vorwürfe zulässig sind, wenn begründete Zweifel daran bestehen, dass der Vorwurf eine so nicht gegebene Sachlage unterstellt (in unserem Fall: der Vorwurf, dass der Täter sich zum Tatzeitpunkt hätte anders entscheiden können). Die Antwort hängt offensichtlich davon ab, ob man es für zulässig erachtet, Bedenken durch besonders wichtige Interessen zu überspielen, die das Kollektiv aller Bürger teilt (etwa das Interesse an der Bestätigung von Normgeltung). Ein konsequent funktionalistisch-kollektivistischer Zugang zu moralischen und rechtlichen Fragen kann zu solchen Folgerungen kommen. Ein anderes Ergebnis ist aber dann erforderlich, wenn man davon ausgeht, dass Eingriffe auch gegenüber den unmittelbar davon Betroffenen, also gegenüber den verurteilten Tätern, zu rechtfertigen sind. Liegt der Eingriff in einem expliziten und persönlichen Vorwurf, dann ist unverzichtbare Minimalbedingung, dass dieser Vorwurf als solcher berechtigt sein muss (nach meiner Auffassung gilt dies sowohl im moralischen als auch im strafrechtlichen Kontext). Es liegt in der Logik des Machens von Vorwürfen, dass diese intrinsisch legitimiert, d.h. sachlich gerechtfertigt sein müssen, um zulässig zu sein.

Reinhard Merkel erörtert das Fairness- und Gerechtigkeitsproblem, das durch einen zur Normbestätigung erhobenen Schuldvorwurf entsteht. Er meint allerdings, wofür er als Beispiel die Kündigung eines unehrlichen Geschäftsführers anführt, dass belastende Reaktionen trotz-

93 Jakobs (Fn. 90, System der strafrechtlichen Zurechnung), S. 59 ff.; Streng, ZStW 101 (1989), 273, 288 ff.; R. Merkel (Fn. 1), S. 124 ff. 
dem zulässig seien. ${ }^{94}$ Allerdings handelt es sich in Merkels Beispiel um eine Schutzmaßnahme mit präventiver Ausrichtung: Es soll durch Kündigung verhindert werden, dass dieser Geschäftsführer in Zukunft weitere Unterschlagungen vornimmt. Das Legitimationsproblem ist gewichtiger, wenn die Reaktion eine solche ist, die auf einen persönlichen, tatbezogenen Vorwurf hinausläuft. In Bezug auf unsere strafrechtliche Praxis kommt Merkel zu der Folgerung, dass wegen der Wichtigkeit einer Sicherung von Normgeltung keine Alternative zur Bestrafung des Täters bestehe. ${ }^{95}$ Seine Argumentation läuft darauf hinaus, eine Notstandssituation anzunehmen: Es seien zwar utilitaristisch begründete Eingriffe in die Rechte von Personen grundsätzlich nicht akzeptabel, aber es stehe „der Bestand der Normenordnung als ganzer auf dem Spiel“ ${ }^{96}$ Das Fairnessproblem ist damit aber nicht gelöst.

Folgende Argumente könnten angeführt werden, um den Einwand der fehlenden Fairness eines Schuldvorwurfs zu mildern: Da in demokratischen Systemen Normadressaten auch Normschöpfer sind, trage jeder, auch der Täter, Verantwortung für die Sicherung der Geltung von Normen. ${ }^{97}$ Oder man könnte darauf verweisen, dass derjenige, der als Straftäter für die Sicherung der Normgeltung in Anspruch genommen werde, in seiner Rolle als Bürger selbst auch von einer stabilen Normenordnung profitiert hat und weiterhin profitieren wird. Aber auch dann, wenn man entlang dieser Linien denkt, kommt man nicht ohne weiteres zu der Folgerung, dass deshalb gerade ein auf Anders-Entscheiden-Können gegründeter Vorwurf fingiert werden müsste. Man kann mit der Kombination von Notwendigkeits- und Fairnessargumenten zwar in allgemeiner Weise begründen, dass Täter Einbußen in Kauf nehmen müssen. Aber diese Argumente helfen nicht über das speziellere Problem hinweg, dass, soweit es um explizite Vorwürfe geht, die Eigenlogik von Vorwürfen (diese müssen sachlich berechtigt sein) beachtet werden sollte. Und es ist auch aus einer funktionalistischen Sicht keineswegs selbstverständlich, dass ausgerechnet ein klassischer

94 R. Merkel (Fn. 1), S. $127 \mathrm{ff}$.

95 R. Merkel, Festschrift für Roxin z. 80. Geburtstag, 2011, S. 737, 760 f.

96 R. Merkel (Fn. 1), S. 136.

97 S. zu demokratietheoretischen Argumenten Günther, in: Maasen/Prinz/Roth (Hrsg.), Voluntary Action. Brains, Minds, and Sociality, 2003, S. 263, 275 f. 
Schuldvorwurf des Inhalts „Sie hätten anders entscheiden können“ für die Bestätigung von Normgeltung erforderlich wäre. Mein Anliegen ist es, im folgenden Kapitel VI. zu begründen, dass eine retrospektiv begründete Rechtsfolge (eine Übelszufügung zur Verdeutlichung des Vorwurfs, Unrecht begangen zu haben) als Reaktion auf eine Straftat legitim ist - ohne, dass damit ein zusätzlicher Vorwurf verbunden sein muss, der dem Täter persönliches Versagen bei der Entscheidung vorhält. Wer bei der Rechtfertigung von Kriminalstrafe ausschließlich auf positive Generalprävention abstellt, müsste mit einer solchen Lösung ebenfalls zufrieden sein. ${ }^{98}$

\section{Fiktion des Anders-Entscheiden-Könnens aus nicht- funktionalistischen Gründen}

Es gibt in der Literatur weitere Ansätze, die das Erheben eines klassischen Schuldvorwurfs damit begründen, dass dies entweder erlaubt oder sogar geboten sei. Johann Braun meint, dass die Neurowissenschaften "die bedeutendsten Errungenschaften der westlichen Welt" in Frage stellten und die Gefahr einer „Expertokratie“ drohe, in der der Einzelne „zur Verfügungsmasse einer herrschenden Clique degradiert" werde. ${ }^{99}$ Seine (leicht paranoid anmutende) Zukunftsprognose wird mit einer normativen These dazu untermauert, warum am Anders-EntscheidenKönnen festzuhalten sei. Diese These verknüpft die Beschreibung des subjektiven Selbstverständnisses mit wertenden Geboten, die sich auf wechselseitige Anerkennung und Gleichheit beziehen. Da der einzelne Mensch sich selbst nur als frei zu anderen Entscheidungen begreifen könne, müsse er dies auch allen anderen zugestehen. Die notwendige

98 Jakobs verwendet zwar nach wie vor den Schuldbegriff und es findet sich bei ihm auch an einer Stelle die Umschreibung „Versagen des Täters“ (System der strafrechtlichen Zurechnung, Fn. 90, S. 60). Allerdings bleibt sein Schuldbegriff blass, ja letztlich gehaltlos, da Schuld in erster Linie negativ definiert wird, d.h. als Unmöglichkeit, das Geschehen als Teil von „Natur“ zu erklären (a.a.O., S. 60 ff.). Jakobs verzichtet damit auf einen zum Unrechtsvorwurf hinzukommenden Vorwurf. Nach seinem Konzept ist Zuständigkeit die wesentliche Kategorie, S. 66 und passim.

99 J. Braun, JZ 2004, 610, $612 \mathrm{f}$. 
Behandlung anderer als „,meinesgleichen“ $z$ winge dazu, diesen anderen entsprechend dem eigenen Selbstbild Schuldfähigkeit zuzuschreiben. ${ }^{100}$ Mit diesem Argument ist aber allenfalls zu begründen, warum wir uns wechselseitig prospektiv als frei behandeln sollten, also nur eine Antwort auf die Frage möglich, warum wir am „Menschenbild des Grundgesetzes" und an einem auf Selbstbestimmung des Einzelnen zugeschnittenen Zivilrecht festhalten sollten. Die Erhebung eines retrospektiv ausgerichteten klassischen strafrechtlichen Schuldvorwurfs lässt sich jedoch schwerlich ernsthaft unter „Akt der Anerkennung“ subsumieren. In diesem Kontext, wenn es um die Belastung von Personen durch einen konkreten Vorwurf geht, ist die Forderung, dass man aus normativen Gründen das eigene Erlebnis einer offenen Zukunft (das zwangsläufig mit Fehlwahrnehmungen verbunden ist) auf andere Personen übertragen müsse, noch problematischer als die Folgerung (vorstehend 3.), dass man auf die Selbstwahrnehmung des Täters zurückgreifen dürfe.

Anders, nämlich nüchterner und unter Rückgriff auf demokratietheoretische Überlegungen, argumentiert Urs Kindhäuser. Ausgangspunkt seiner Überlegungen ist, dass strafrechtliche Schuld nur in einer demokratisch verfassten Gesellschaft begründbar sei, die dem Einzelnen die Möglichkeit des Widerspruchs gegen solche Verhaltensnormen ermögliche, die er inhaltlich nicht billige. In einer solchen Gesellschaft werde die Kompetenz einer Person als Normautor unterstellt und nicht näher untersucht, weshalb im Gegenzug auch die Fähigkeit unterstellt werden dürfe, dass man in der Lage sei, sich ggf. kritisch zu missliebigen Verhaltensnormen zu äußern, was gleichzeitig zum Unterlassen von Normverstößen verpflichte. ${ }^{101}$ Dieses Argument erscheint mir überzeugend, aber in seiner Reichweite begrenzt. Man kann auf die Rollen für Bürger im demokratischen Staat abstellen, um zu begründen, warum man verpflichtet ist, auch solche Verhaltensnormen zu beachten, die man inhaltlich als nicht überzeugend gerechtfertigt einstuft. Aber daraus ergibt sich meines Erachtens nur, dass bei Normverstößen ein Vorwurf erlaubt

100 J. Braun, JZ 2004, 610, $611 \mathrm{ff}$.

101 Kindhäuser, Festschrift für Hassemer, 2010, S. 761, 772 f. 
sei, nicht aber, dass dieser unbedingt die Form eines klassischen Schuldvorwurfs annehmen solle oder müsse.

\section{Ein anders begründeter Schuldvorwurf: die Wiederauferstehung der Charakterschuld}

Eine andere Möglichkeit, einen Schuldvorwurf zu retten, liegt darin, den Inhalt des Vorwurfs zu ändern, indem der Bezugspunkt verschoben wird, auf den sich die Bewertung bezieht. Der Grund für die Berechtigung eines Vorwurfs könnte darin liegen, dass dieser dem Charakter des Täters gilt. Es handelt sich dann nicht mehr um einen klassischen, den Entscheidungszeitpunkt betonenden Schuldvorwurf. In jüngerer Zeit hat Rolf Herzberg einen solchen Ansatz wiederbelebt, ${ }^{102}$ wobei Herzberg von einem konsequent deterministischen Weltbild ausgeht, aus dem er ableitet, dass niemand zu einem bestimmten Zeitpunkt anders hätte handeln können, als er oder sie dies tatsächlich getan hat. ${ }^{103}$ Trotzdem sei nicht zu folgern, dass ein Schuldvorwurf unzulässig sei. Vielmehr gelte der Schuldvorwurf nur der Tat als Durchgangsstadium, aber eigentlich der Person des Täters. Für seinen Charakter müsse man einstehen, unabhängig von Freiheit bei der Formung des Charakters. ${ }^{104}$ Charakterbezogene Ansätze sind im deutschen zeitgenössischen strafrechtswissenschaftlichen Schrifttum im Übrigen kaum mehr zu finden (anders bei jüngeren englischsprachigen Strafrechtstheoretikern, die sich dem Strafrecht von der Moralphilosophie kommend annähern ${ }^{105}$ ). Außerdem bestehen punktuelle Gemeinsamkeiten zwischen Charakterschuldlehre und einigen prominent vertretenen Ansätzen in der Philosophie, die unter der Überschrift „Kompatibilismus“ ebenfalls den Fokus von der Tat zur Person verschieben. Sie stellen den Punkt „Urheberschaft“ als Be-

102 Herzberg (Fn. 19); ders., Festschrift für Achenbach, 2011, S. 157 ff.; ders., ZStW 124 (2012), S. 12 ff. S. für einen in diese Richtung weisenden Ansatz ferner Burkhardt (Fn. 34); zu den älteren Ausarbeitungen von Charakterschuldlehren Engisch (Fn. 80), S. $44 \mathrm{ff}$.

103 Herzberg (Fn. 19), S. 1 ff.; ders., Festschrift für Achenbach, 2011, S. 157, 162 ff.

104 Herzberg (Fn. 19), S. 90 ff. Krit. Weißer, GA 2013, 26, 34.

105 Tadros, Criminal Responsibility, 2005, S. 44 ff. 
gründung dafür in den Vordergrund, warum Personen auch dann verantwortlich gemacht werden dürften, wenn von der Determiniertheit ihrer Einzelhandlungen auszugehen sei. Maßgeblich sei, dass die Handlung auf eine Person als Urheber zurückgeführt werden könne. ${ }^{106}$

Formuliert man allerdings einen strafrechtlichen Schuldvorwurf auf dieser Grundlage, bedeutet das, gegenüber dem Täter genaugenommen zwei Vorwürfe zu formulieren: zum einen den tatbezogenen Unrechtsvorwurf, der sich z.B. auf die vorsätzliche Zufügung einer schweren Verletzung des Opfers bezieht; zum anderen ein zweites Werturteil, nämlich einen Schuldvorwurf. Inhalt des Schuldvorwurfes ist, dass sich der Täter durch die Tat etwa als bösartiger, mitleidloser Mensch entpuppt habe. Herzberg formuliert das explizit so: „Vorgeworfen wird dem Übeltäter, nach Maßgabe seiner einzelnen Tat, ein Wesenszug, ein charakterliches Defizit, sei es sein Leichtsinn, oder welchen Grades auch immer, seine Bosheit". ${ }^{107}$ Der Vorwurf bezöge sich auf den Ursprung der Tat, den Charakter und „nur durchgangsweise auch [auf] die Tat selbst". ${ }^{108}$ Ein solcher Vorschlag wirft allerdings mehrere Fragen auf. Konzepte der Charakterschuld gehen davon aus, dass „Charakter" als hinreichend stabiles Phänomen existiert und jenseits einer konkreten Einzelhandlung beschrieben werden kann, insbesondere auch über längere Zeiträume hinweg. Es müsste analysiert werden, inwieweit solche Annahmen auf Zuschreibungen und inwieweit sie auf empirische Grundlagen zurückzuführen sind, insbesondere auch, wie schnell und nachhaltig sich die vielfältigen Einflüsse, denen Menschen ausgesetzt sind, auf die verschiedenen Reaktions- und Verhaltensdispositionen auswirken, die mit dem Schlagwort „Charakter“ zusammengefasst werden. Und was ist mit ,charakterfremden“ Taten, wenn eine Einzelhandlung nicht zu Verhaltensdispositionen passt, die sich zuvor und danach in anderen Handlungen zeigten? Wenn man in solchen Situationen der Inkonsistenz darauf abstellt, dass dann eben die fragliche Einzelhandlung, d.h. die Straftat, den „wahren“ Charakter jedenfalls in seiner Beschaffenheit zum Tatzeitpunkt zeige, so verliert ein Charakterschuld-

106 S. unten Fn. 159.

107 Herzberg, Festschrift für Achenbach, 2011, S. 157, 184 (Hervorhebungen im Original).

108 Herzberg (Fn. 19), S. 99 (Hervorhebung im Original). 
vorwurf seinen eigenständigen Bezugspunkt und ein entsprechendes Konzept mündet in eine zirkuläre Argumentation. ${ }^{109}$

Vor allem aber ist kritisch zu fragen, ob Tadel für den Charakter eines Menschen tatsächlich Aufgabe des Strafrechts ist. Was sind die Funktionen eines staatlichen Unwerturteils, in wessen Interesse und aus wessen Perspektive wird es abgegeben? Auf diese Punkte ist im folgenden Kapitel noch ausführlich zurückzukommen. Es sei an dieser Stelle nur kurz vorweggenommen, dass nach der von mir vertretenen Auffassung der Vorwurf, der mit dem Strafurteil verbunden ist, stellvertretend für den Verletzten abgegeben wird und sich deshalb auf die konkrete Interaktion, die konkrete Tat (einschließlich der in diesem Moment bestehenden subjektiven Einstellungen des Täters) beschränken sollte. Weiterreichende Urteile über die Person und ihren Charakter sind nicht Angelegenheit des Staates. Soweit Herzberg auf moralische Vorwürfe im sozialen Alltag verweist, die anlässlich einer Missetat die Person mit Formulierungen wie „Schwindler, Spitzbube, mieser Typ, bösartiger Rassist“, „du bist gemein“, „du bist böse“ usw. charakterisieren, ${ }^{110}$ ist daraus nicht umstandslos auf eine ähnliche Lage für rechtliche Unwerturteile zu schließen. Vielmehr gibt es einen entscheidenden Unterschied. Strafrechtsurteile sollten zwar einen Vorwurf machen, dessen Reichweite aber enger ausfallen sollte als dies im Alltagsleben der Fall sein mag.

109 A.A. Tadros (Fn. 105), S. 50 ff.

110 Herzberg (Fn. 19), S. 99; ders., Festschrift für Achenbach, 2011, S. 157, 184 (Hervorhebungen im Original). 


\section{Fokussierung auf einen Unrechtsvorwurf bei Verzicht auf einen Schuldvorwurf}

\section{Die zentrale Bedeutung des Unrechtsvorwurfs}

Die im Folgenden zu begründende These ist: Wir sollten uns konzeptuell wie begrifflich von der Vorstellung eines Schuldvorwurfs verabschieden. Dabei ist hervorzuheben, dass dies weder auf eine abolitionistische Position noch auf das Einfordern eines präventiv begründeten Maßnahmenrechts ${ }^{111}$ hinausläuft. Entgegen der verbreiteten Annahme, dass, wenn man den Schuldbegriff abschaffen will, dann folgerichtig auch ein staatlicher Vorwurf und Kriminalstrafe ausscheiden müsse, ${ }^{112}$ ist daran festzuhalten, dass der Konnex zwischen „Kriminalstrafe“ und „Schuldvorwurf" nicht aus konzeptuellen Gründen zwingend ist. Verantwortung und Verantwortlichmachen sind weder auf den klassischen Schuldvorwurf angewiesen, wie ihn der Bundesgerichtshof im Jahr 1952 beschrieb, noch auf eine Erweiterung des Schuldverständnisses durch die Lehre von der Charakterschuld. Das entscheidende Kriterium für die Feststellung, dass dieser Täter für diese Tat verantwortlich ist, ist, dass ihm das Tatunrecht (die schädlichen Effekte oder eine Gefährdung) objektiv und subjektiv zuzurechnen sind. Ist eine solche Zurechnung möglich, steht damit der Inhalt des Vorwurfes fest. ${ }^{113}$ Das Werturteil lautet, dass der Täter für die Rechtsverletzung verantwortlich ist und dass er in der Interaktion mit einem anderen (oder den vielen anderen, die die „Allgemeinheit“" ausmachen) Unrecht begangen hat. Aus der konzeptuell angemessenen Struktur eines Strafverfahrens, das den Täter als Kommunikationspartner versteht, ${ }^{114}$ ergibt sich zwangsläufig, dass das Unwerturteil (jedenfalls auch) an den Täter adressiert wird, und deshalb

111 So Baurmann, Zweckrationalität und Strafrecht, 1997.

112 S. die Nwe. in Fn. 53, ferner G. Merkel, Festschrift für Herzberg, 2008, S. 3, 35; K. Günther, KJ 2006, 116, 129.

113 Insoweit stimme ich mit der von Günther Jakobs in seiner Monographie „System der strafrechtlichen Zurechnung“" vertretenen These überein, dass die wesentliche Feststellung eine Zuständigkeitsfeststellung ist (Fn. 90, S. 25 ff. und passim).

114 S. dazu grundlegend Duff/Farmer/Marshall, The Trial on Trial, Bd. 3: Towards a Normative Theory of the Criminal Trial, 2007. 
zwangsläufig aus einer sachlichen Unrechtsfeststellung ein personalisierter Unrechtsvorwurf werden muss. Dieser Vorwurf ist nicht schon deshalb legitim, weil er nützlich und funktional ist, nicht deshalb, weil wir davon persönlichkeitsbildende Wirkung erwarten. ${ }^{115}$ Er ist vielmehr nur deshalb zu erheben, weil und insoweit er als Unwerturteil intrinsisch berechtigt ist. ${ }^{116}$

Eine wesentliche Hürde, die eine solche Argumentation nehmen muss, liegt darin, zu begründen, dass man Menschen überhaupt für irgendetwas verantwortlich machen darf. Die hier vertretene Verschiebung von einem Schuldvorwurf zu einem Unrechtsvorwurf könnte daran scheitern, dass das oben skizzierte Modell menschlichen Entscheidens uns generell daran hindert, Menschen für eine konkrete Handlung retrospektiv einen Vorwurf zu machen. Verlangte man auch für den Vorwurf, Unrecht begangen zu haben, eine Letztverantwortung im Sinne einer bewussten Beherrschung der Entscheidungssituation, also Letztverantwortung im Sinne eines anspruchsvollen Verständnisses von Kontrolle des Handelnden über seine Handlung, würde auch ein solcher Vorwurf scheitern.

Als möglicher Gegeneinwand ist zunächst zu erwägen, ob es ausreichen kann, interkulturell feststellbare Reaktionen auf normativ abweichendes Verhalten zu beschreiben. An diesem Punkt ist nochmals auf Peter Strawsons Beschreibung der reaktiven Einstellungen zu verweisen, die Menschen im Umgang miteinander einnehmen und zu denen Reaktionen wie Übelnehmen gehören. Er kontrastiert damit objektivierende Einstellungen, die nur unter ungewöhnlichen Umständen als angemessen gelten, etwa im Umgang mit Kindern oder geistig erkrankten Personen. ${ }^{117}$ Strawson geht davon aus, dass die den Normalfall bilden-

115 So Engisch (Fn. 80), S. 65.

116 Ähnlich in der Sache: Schroth, Festschrift für Roxin z. 80. Geburtstag, 2011, S. 705, 717. S. auch Herzberg, FS für Achenbach, 2011, S. 157, 160 f. mit dem Beispiel des Mordes, auf den mit Strafe reagiert werden müsse - diesen Gedanken teile ich. Aber man kann dies ohne Begriffe wie „Schuldvorwurf“ und „Schuldvergeltung“ begründen, wobei der Verzicht auf diese Begriffe (jedenfalls konzeptuell, zum geltenden Recht s. unten VII.) ohne weiteres möglich ist und transparenter macht, worum es bei dem gegenüber dem Mörder unverzichtbaren Vorwurf geht: um den Vorwurf, Unrecht begangen zu haben.

117 P. Strawson (Fn. 61), S. $63 \mathrm{ff}$. 
den reaktiven Einstellungen und die darauf beruhende Praxis von Lob und Tadel auch dann Bestand hätten, wenn Menschen von einer deterministischen Weltsicht ausgingen. ${ }^{118}$ Auch deutsche Autoren verweisen auf vorrechtliche Grundmuster des Verantwortlichmachens, etwa Björn Burkhardt mit der Einschätzung, dass eine moralische Regel des Inhalts, dass man niemals einem Menschen seine Taten vorwerfen könne, abwegig sei. ${ }^{119}$ Klaus Günther meint, dass wir uns nicht dauerhaft wechselseitig objektifizieren könnten. ${ }^{120}$ Mit einem Verweis auf die sehr feste Verwurzelung einer sozialen Praxis wie der Praxis des Übelnehmens wird sich allerdings derjenige, der nach Legitimität fragt, nicht zufrieden geben. Das Faktum, dass es so gut wie unmöglich wäre, sich von tief eingeschliffenen gesellschaftlichen Verhaltensmustern zu befreien, belegt nicht zwangsläufig die Angemessenheit dieser Praktiken aus wertender Sicht.

Aber es ist zu begründen, dass Wert- wie Unwerturteile legitim bleiben, obwohl ein anspruchsvolles Verständnis von Kontrolle (das den Nachweis voraussetzt, dass sich der Handelnde anders hätte entscheiden können) als nicht realitätsgerecht eingestuft werden muss. Eine solche Begründung muss weder auf die soziale Nützlichkeit von Praktiken des Lobs und Tadels abstellen (das wäre nur eine mögliche Argumentationsschiene) noch ist sie in umgekehrter Weise dem Vorwurf ausgesetzt, dass die von Strawson beschriebenen negativen reaktiven Einstellungen Ausdruck einer problematischen menschlichen Neigung zur Abwertung anderer oder zur Grausamkeit seien. Vielmehr sind Unwerturteile der Sache nach angemessen. ${ }^{121}$ Dazu folgende These: Für Unwerturteile wie den strafrechtlichen Vorwurf, eine unrechtmäßige Handlung begangen zu haben, genügen zwei Voraussetzungen: erstens, begründete Verhaltensnormen, und zweitens, dass die Person, der ein Vorwurf gemacht werden soll, in begründeter Weise als diejenige zu identifizieren ist, die

118 P. Strawson (Fn. 61), S. 67 ff.

119 Günther (Fn. 34), S. 113, auf S. 118 f. zu Strawson; s. auch R. Merkel (Fn. 1), S. 131.

120 Günther, KJ 2006, 116, 127 f., Hervorhebung durch die Verf. S. ferner Streng, ZStW 101 (1989), 272, 288, der auf die ,Selbststabilisierungsbedürfnisse der mit der Tat konfrontierten Mitbürger des Täters“ abstellt; ebenso ders., Festschrift für Jakobs, 2007, S. $675,682$.

121 Das ist die These in R. Jay Wallace, Responsibility and the Moral Sentiments, 1994. 
unter Missachtung von Rücksichtnahmepflichten gegenüber anderen eine Normverletzung begangen hat. ${ }^{122}$

Theoretischer Hintergrund sind Überlegungen zur richtigen Perspektive bei Wert- bzw. Unwerturteilen. Der amerikanische Philosoph Stephen Darwall hat vor einigen Jahren ein vielzitiertes Buch unter dem Titel „The Second Person Standpoint“ veröffentlicht. Mit dem Standpunkt der 2. Person meint er ,die Perspektive, die Du und Ich einnehmen, wenn wir bezüglich des Verhaltens und der Absichten des anderen Ansprüche erheben und anerkennen ". ${ }^{123}$ Ohne auf die Einzelheiten dieser weitgespannten Abhandlung zur Moralphilosophie einzugehen, ist hervorzuheben, dass es eine entscheidende Festlegung bedeutet, aus welcher Perspektive beurteilt wird. In moralischen wie in rechtlichen Kontexten beziehen sich Werturteile auf eine Verletzung von Verhaltenspflichten, die als Verhaltenspflicht gegenüber einem oder mehreren anderen bestanden haben müssen ${ }^{124}$ und in diesem interpersonalen Verhältnis missachtet wurden. Ein Strafurteil reagiert auf die Verletzung von Verhaltenspflichten, und zwar nicht nur auf die Verletzung abstraktgeneralisierter Verhaltenspflichten, sondern wesentlich auf die Verletzung konkreter, d.h. interpersonal konkretisierter Verhaltenspflichten. Deshalb sollte die 2. Person-Perspektive für die Bewertungsmaßstäbe eine wesentliche Rolle spielen.

Ein denkbarer Einwand gegen diese These ist, dass Strafurteile ,im Namen des Volkes" ergehen. Dies könnte so interpretiert werden, dass sie sich ausschließlich auf die Perspektive des Normgebers (in demokratischen Staaten: das Volk) bezögen und ausschließlich der Verstoß gegen eine generelle und abstrakte Normenordnung interessiere, ${ }^{125}$ nicht aber die Verletzung konkretisierter Verhaltenspflichten im Verhältnis zweier Individuen (oder mehrerer Individuen). Damit würde jedoch die Bedeutung der „im Namen des Volkes“-Formel überdehnt. Diese ist zwar Ausdruck eines wichtigen zivilisatorischen Fortschritts, der in der

122 Ähnlich Pauen, in: Lampe/Pauen/Roth (Hrsg.), Willensfreiheit und rechtliche Ordnung, 2008, S. 41, $56 \mathrm{f}$.

123 Darwall, The Second-Person Standpoint: Morality, Respect, and Accountability, 2006, S. 3 (Übersetzung durch die Verf.).

124 Wallace (Fn. 121), S. 64 ff.

125 So etwa Jakobs (Fn. 90, System der strafrechtlichen Zurechnung), S. 13 ff. 
Entstehung staatlicher Strafverfolgung und der Verdrängung von Opfern aus der praktischen Durchsetzung von Strafansprüchen liegt. Die Entwicklung eines formalisierten, von staatlichen Verfolgungsbehörden betriebenen Verfahrens und das Pochen auf einen staatlichen Strafanspruch sind bedeutsam, weil nur auf diese Weise die Reaktionen auf deliktische Verhaltensweisen zu kontrollieren und zu mäßigen sind. Ziel ist es, eskalierende Gewalttätigkeiten und Willkürlichkeiten zu verhindern und durch das Bemühen um unparteiliche Beschreibungen der Fakten (weshalb insoweit eine 3. Person-Perspektive anzustreben ist, s. oben V. 3.) sowie die Verhängung von standardisierten, staatlicherseits vollzogenen Sanktionen möglichst breite Akzeptanz verfahrensbeendigender Urteile zu sichern. Aber hinter der Durchführung von Strafverfahren durch den Staat steht trotzdem noch dasselbe ursprüngliche (nun regulierte und gezähmte) Phänomen: die Enttäuschung des Geschädigten über die vom Täter im Verhältnis zu ihm missachtete Verhaltenspflicht. ${ }^{126}$ Das Unwerturteil, das der Staat am Ende des Erkenntnisverfahrens abgibt, sollte diesen Aspekt aufnehmen, indem die Beschreibung sich darauf fokussiert, was einer anderen Person angetan wurde. ${ }^{127}$ Damit ist nicht die Forderung verbunden, die Bewertung zu versubjektivieren und zu individualisieren, etwa indem den persönlichen Gefühlen und idiosynkratischen Einschätzungen des Tatopfers Rechnung getragen wird. Der entscheidende Punkt bei der Übernahme der Reaktion durch den Staat liegt genau darin, Bewertungen zu vereinheit-

126 An dieser Stelle weiche ich von Jakobs ‘ Ansatz ab: Strafrecht dient nicht nur dazu, die Geltung abstrakter Normen zu erhalten, sondern wesentlich auch der Aufarbeitung interpersonaler Delikte, soweit es um erhebliche Delikte gegen die Person geht. Die Vorstellung, dass dies Angelegenheit des Zivilrechts sei (s. etwa Lüderssen, Festschrift für Hirsch, 1999, S. 879 ff.), geht fehl. Die Aufgabe des Zivilrechts liegt in der Korrektur von Vermögenseinbußen. Es übersteigt aber bei Weitem die Möglichkeiten eines zivilrechtlichen Verfahrens, in angemessener Weise die Rechtsverletzung aufzuarbeiten, die in einer erheblichen Straftat liegt.

127 Die herrschende Ansicht in der deutschen Strafrechtswissenschaft sieht dies anders. Sie greift zwar nicht explizit die Frage der Perspektive auf, geht aber davon aus, dass das Unrechtsurteil ein Urteil über die Sozialschädlichkeit der Tat sei (s. nur Roxin, Fn. 4, § 7 Rn. 21) oder stellt darauf ab, dass der Täter ,seiner Mitwirkungspflicht gegenüber der Rechtsgemeinschaft zuwider [handle], indem er in seinem Verhalten einen Mangel an Rechtstreue zum Ausdruck" bringe (Pawlik, Fn. 4, S. 280, Hervorhebungen durch die Verf.). 
lichen und zu versachlichen ${ }^{128}$ und das Durchschlagen von Gefühlsaufwallungen zu blockieren. Die hier betonte 2. Person-Perspektive ist deshalb nicht als individualisierende Re-Personalisierung des Konflikts zu verstehen, sondern als eine Perspektive, die der Staat mit standardisierenden Bewertungsmaßstäben treuhänderisch für konkrete Tatopfer einnimmt.

Die Alternative einer nicht nur bei der Beschreibung, sondern auch bei der Bewertung konsequent durchgehaltenen 3. Person-Perspektive läge dagegen dann nahe, wenn erstens die interpersonale Dimension von Missetaten fehlt, d.h., wenn nicht Vorkommnisse im Verhältnis gleichgestellter Rechtspersonen zu bewerten wären, und wenn zweitens der Urteilende ein distanziert-hierarchisches Verhältnis betonen möchte. Vorstellbar ist die Einnahme eines konsequenten „Blickes von außen auf den Täter" bei religiösen Bewertungen, die davon ausgehen, dass sich ein Mensch vor Gott verantworten müsse, oder wenn Gehorsamspflichten im Verhältnis zu einem absoluten Monarchen oder einer anderen Herrscherfigur verletzt wurden. Soweit es um rechtliche Wertungen in modern verfassten Staaten geht, sind jedoch Verhaltenspflichten nicht als derartige Gehorsamspflichten zu beschreiben. Dieser Gedanke ist bereits in Kants Definition der Aufgabe des Rechts angelegt: Recht sei ,der Inbegriff der Bedingungen, unter denen die Willkür des einen mit der Willkür des anderen nach einem allgemeinen Gesetze der Freiheit zusammen vereinigt werden kann" ${ }^{129}$. Werturteile in Gerichtsurteilen müssen sich mit der Abgrenzung von horizontal angeordneten Freiheitssphären befassen, ${ }^{130}$ nicht mit der Missachtung von vertikalen, in einem hierarchischen Über-Unterordnungsverhältnis gründenden Gehorsamspflichten. Dabei sollten sie die Perspektive derjenigen aufnehmen, in deren Freiheitssphäre eingegriffen wurde.

128 Hier stimme ich Pawlik (Fn. 4), S. 90 f., zu.

129 Kant (Fn. 11), S. 337.

130 Insoweit bestehen gewisse Parallelen zur Argumentationslinie von Pawlik (Fn. 4, S. 99 ff.), wobei aber nach meinem Verständnis das Verbrechen nicht „begrifflich ein Unrecht gegenüber der Rechtsgemeinschaft als Ganzer" ist (a.a.O., S. 107; ders., Festschrift für Otto, 2007, S. 133, 143). Das Unrecht bleibt vielmehr das Unrecht gegenüber den Tatverletzten (die nur bei Universalrechtsgütern das Kollektiv aller Bürger sind), während die Rechtsgemeinschaft es aus eigenen Friedenssicherungsinteressen übernehmen muss, den Unrechtsvorwurf zu formulieren. 
Nach dem hier vorgestellten Ansatz gibt es nur einen Unrechtsvorwurf, ${ }^{131}$ dessen Funktion darin liegt, die Freiheitssphären im Verhältnis von Täter und Opfer nachträglich richtig zu markieren. Das Urteil ist an Personen, vor allem den Täter selbst adressiert, etwa: „X ist dafür zu tadeln, unrechtmäßig Y körperlich verletzt zu haben“. Es bedarf deshalb natürlich auch für den Unrechtsvorwurf einer Verantwortungszuschreibung. ${ }^{132}$ Durch diese Verantwortungszuschreibung ist klarzustellen, dass die Verletzung nicht ausschließlich auf natürliche Einflüsse zurückzuführen war oder die Verantwortung für das Geschehen beim Opfer selbst oder Dritten lag. Hieraus ergeben sich Prüfungselemente, auf die hier nicht näher eingegangen werden muss. Erforderlich ist eine Handlung des Täters, die kausal für den Erfolg war, und die Feststellung einer Pflichtverletzung, die man aus der Perspektive der 2. Person beschreiben kann: als Missachtung interpersonaler Pflichten der Rücksichtnahme, des Schutzes usw.

Eine Rückfrage könnte sich ergeben, wenn man die starke Bedeutung analysiert, die dem voluntativen Element zukommt: Nicht nur im deutschen Strafrecht, sondern auch in anderen modernen Rechtsordnungen hängt die Bewertung der Tatschwere wesentlich davon ab, ob der Täter den strafbaren Erfolg gewollt hat. ${ }^{133}$ Genealogisch betrachtet, weist dies vermutlich auch auf eine ursprünglich religiös begründete 3. PersonPerspektive hin: Die absichtliche und die wissentliche Begehung der verbotenen Handlung wird deshalb besonders negativ bewertet, weil darin ein Akt der Verweigerung geschuldeten Gehorsams gesehen wird. Das ist jedoch nicht die einzige mögliche Erklärung. Vielmehr lässt sich

131 Auch hier ergibt sich im Ergebnis (allerdings nicht in der Begründung) insofern eine Gemeinsamkeit mit dem Entwurf von Pawlik (Fn. 4, S. 258, 281 und passim), als dieser ebenfalls für den Verzicht auf eine Unrecht-Schuld-Dichotomie plädiert. Allerdings teile ich nicht seine These, dass ,schuldunabhängiges Unrecht“ deshalb unmöglich sei, weil etwa Personen, die unter die Definition in $\S 20$ StGB fielen, in „verbrechenstheoretisch irrelevanter“ Weise handelten, da ihre Handlungen nicht das Recht verneinten (s. Pawlik, Festschrift für Otto, 2007, S. 133, 147). Eine auf pathologische Zustände zurückzuführende, eindeutig fehlende normative Ansprechbarkeit macht mangels Kommunikationsfähigkeit nur den Versuch einer Kommunikation sinnlos, obwohl zurechenbares Unrecht vorliegt (s. unten S. 70 ff.).

132 Jakobs, ZStW 107 (1995), 247, 263 f.; T.M. Spranger, JZ 2009, 1033, 1035.

133 S. zum Vorsatz statt vieler Roxin (Fn. 4), § 12. 
unabhängig von genealogischen Erklärungen aus einer zeitgenössischen Perspektive begründen, warum z.B. eine absichtliche Schadenszufügung eine andere Bedeutung hat als eine nur fahrlässige Verursachung derselben Verletzung. Dabei kommt es nicht auf den Aspekt „Ausmaß der Kontrolle durch den Täter" an, sondern auf die soziale Bedeutung des Verhaltens aus der 2. Person-Perspektive. Diese Bedeutung liegt bei absichtlichem Verhalten in der gezielten Infragestellung der Freiheitssphäre des anderen, während bei nur fahrlässigem Handeln diese Dimension fehlt. Wertende Urteile über Pflichtverletzungen des Inhalts, der Akteur habe die Rechte anderer nicht respektiert oder in gedankenloser Weise missachtet, schließen zwangsläufig den Zugriff auf die intentionale Dimension ein - Werturteile wie „respektieren“ oder „,missachten" sind komplex angelegt und nehmen die innere Tatseite in sich auf. ${ }^{134}$ Auch die Bewertungen von Vorsatz oder Fahrlässigkeit gehören deshalb in den Bereich des Unrechtsurteils.

Weil das Wollen aus der 2. Person-Perspektive relevant ist, ist es möglich, an dieser Stelle auf ein Nachbohren zu verzichten, das der Freiheit hinter dem voluntativen Element gelten könnte. Dies läge nur dann nahe, wenn man die Wertungsrelevanz von Intentionen damit begründen würde, dass dies „Kontrolle des Handelnden über sein Tun (oder Unterlassen)" signalisiere. Aus diesem Blickwinkel gesehen, würde sich auch bei der Prüfung dessen, was nach heute fest etablierter deutscher Verbrechenslehre als ,subjektiver Tatbestand“ geprüft wird, die Frage stellen: War denn dieses Wollen, das wir dem Täter zum Vorwurf machen, frei? Konnte der Täter sein Wollen kontrollieren? Wer ein klassisches Verständnis von Freiheit als „,anders wäre es auch möglich gewesen" vertritt, dürfte nicht erst beim Nachdenken über den Schuldbegriff in Schwierigkeiten geraten. Vielmehr müssten derartige Fragen schon vorher gestellt werden, ${ }^{135}$ nicht nur im Hinblick auf die Relevanz von Vorsatz, sondern bereits für den Handlungsbegriff, wenn man Handlungen als „gewillkürte Körperbewegungen“ oder „Persönlich-

134 Dazu Wallace (Fn. 121), S. 127 ff. Für die Relevanz der subjektiven Tatseite aus einer Opferperspektive auch schon H.L.A. Hart, in: ders., Punishment and Responsibility: Essays in the Philosophy of Law, 2. Aufl. 2008, S. $182 \mathrm{f}$.

135 S. dazu Lampe, ZStW 118 (2006), 1 ff.; ders., in: Lampe/Pauen/Roth (Hrsg.), Willensfreiheit und rechtliche Ordnung, 2008, S. 304 ff.; Detlefsen (Fn. 55), S. 143 ff. 
keitsäußerungen"136 definiert. Aber dieses verworrene Knäuel an Problemen löst sich auf, wenn man sich vom Kontrollparadigma verabschiedet und akzeptiert, dass Feststellungen auf der Basis einer 2. Person-Perspektive (etwa: „Du hast mich willentlich/absichtlich verletzt und das nehme ich Dir als Zeichen fehlenden Respekts für meine Rechte und meine Freiheitssphäre besonders übel") genügen, ohne dass die Analyse weiter in die Innerlichkeit des Täters verlagert werden muss.

\section{Unverzichtbarkeit eines Schuldvorwurfs?}

Die vorstehend entwickelte These bedarf der Verteidigung gegen die ganz herrschende Ansicht, derzufolge es eines persönlichen Vorwurfs an den Täter bedarf, den man als Schuldvorwurf bezeichnen sollte. ${ }^{137}$ Für Verwirrung sorgt allerdings, dass der Begriff „Schuld“ in heterogener Weise eingesetzt wird. ${ }^{138}$ Die verschiedentlich verwendete Kurzumschreibung, dass Schuld ,Vorwerfbarkeit“ sei, ${ }^{139}$ ist für sich genommen gehaltlos, da offen bleibt, was dem Täter eigentlich vorgeworfen wird. ${ }^{140}$ Man kann sie so verstehen, dass ihm das Unrecht der Tat vor-

136 Dazu Roxin (Fn. 4), § 8.

137 S. aber auch für eine abweichende Ansicht Achenbach, Historische und dogmatische Grundlagen der strafrechtssystematischen Schuldlehre, 1974, S. 220 f., der vorschlägt, den Begriff der Strafbegründungsschuld durch ,individuelle Zurechnung“ zu ersetzen. Eine Ausnahme von der weitgehend unkritischen Hinnahme des Elements „Schuldvorwurfs“ bildet ferner der Aufsatz von Ellscheid und Hassemer, in: Lüderssen/Sack (Hrsg.), Seminar: Abweichendes Verhalten II. Die gesellschaftliche Reaktion auf Kriminalität, Bd. 1, 1975, S. 266 ff. Die dort zu findende Kritik am Schuldvorwurf führt die Autoren einerseits zu Folgerungen, denen ich zustimme, nämlich, dass Strafe der Ahndung von Freiheitsverletzungen diene (S. 280). Andererseits zieht sich durch den ganzen Aufsatz die Einschätzung, dass ein strafrechtlicher Tadel gegenüber dem Täter illegitim sei. Diese Folgerung ist nicht notwendig: Das Unrecht kann dem Täter aus der Perspektive der 2. Person vorgeworfen werden.

138 Achenbach (Fn. 137), S. 218.

139 S. R. Frank, Über den Aufbau des Schuldbegriffs, 1907, Wiederauflage 2009, S. 15; BGHSt. 2, 194, 200; Lackner/Kühl, StGB, 27. Aufl. 2011, Vor § 13 Rn. 23.

140 Zur Kritik an der Vorwerfbarkeitsformel s. Lenckner/Eisele (Fn. 53), Vorbem. $\S \S 13$ ff. Rn. 114 m.w.Nwen. 
geworfen werde. ${ }^{141}$ Bei diesem Ausgangspunkt ansetzend, liefe mein Vorschlag auf eine nur begriffliche Klarstellung hinaus. Die konsequente Bezeichnung des dem Täter zu machenden Vorwurfs als „Unrechtsvorwurf" statt „Schuldvorwurf“ hätte auf den Gehalt keine Auswirkung. In der Regel wird jedoch mit dem Begriff des Schuldvorwurfs ein Vorwurf bezeichnet, der dem Unrechtsvorwurf ein zusätzliches Element hinzufügt. Charakteristisch für Versuche, den eigenständigen Gehalt eines Schuldvorwurfs zu umschreiben, ist eine Verlagerung des Vorwerfbaren in die innere Welt des Täters: Ihm wird ein persönliches Versagen, ein persönliches Dafürkönnen, ein „Verdienen der Strafe "142 vorgehalten. Formulierungen dieses Versagensvorwurfs können eher nüchtern-sachlich ausfallen, mit dem Verweis auf Anders-Handelnund Anders-Entscheiden-Können, aber in älteren Ansätzen auch pathetischer, etwa mit dem Verweis auf eine ,geistige Wertverfehlung“"143 oder das „Verfehlen der existenziellen Aufgabe des Menschen, seiner sittlichen Selbstverwirklichung"144.

Ich habe den Begriff „Schuldvorwurf" in früheren Veröffentlichungen ebenfalls verwendet, ${ }^{145}$ neige aber heute dazu, dass man zwar am Vorwurf festhalten, aber das Wort „Schuld“ konsequent vermeiden sollte. Meine eigene verneinende Antwort ist zu kontrastieren mit der Einschätzung, die die meisten deutschen Strafrechtswissenschaftler abgeben würden. Die Differenzierung zwischen Unrecht und Schuld gilt als ein zentrales Paradigma der deutschen Straftatlehre. ${ }^{146}$ Selbst eher nüchtern gestimmte Strafrechtswissenschaftler, die dezidiert hervorheben,

141 S. z.B. Gropp, Strafrecht Allgemeiner Teil, 3. Aufl. 2005, § 7 Rn. 25: Vorgeworfen werde nicht Schuld, sondern die Tat.

142 Arthur Kaufmann, Das Schuldprinzip, 2.Aufl. 1976, S. 128 f.; Maiwald, Festschrift für Lackner, 1987, S. 149, 164; Roxin (Fn. 4), § 7 Rn. 71.

143 Schmidhäuser, Strafrecht AT, 2. Aufl. 1984, S. 191.

144 Kaufmann (Fn. 142), S. 195.

145 S. vor allem Hörnle, in: Hefendehl (Hrsg.), Empirische und dogmatische Fundamente, kriminalpolitischer Impetus, 2005, S. $105 \mathrm{ff}$.

146 S. nur Jescheck/Weigend, Strafrecht AT, 5. Aufl. 1996, S. 425; Kühl, Strafrecht AT, 7. Aufl. 2012, § 1 Rn. 22; Stratenwerth/Kuhlen, Strafrecht AT, 6. Aufl. 2011, S. 62 ff.; Stratenwerth, in: Lüderssen/Sack (Hrsg.), Seminar: Abweichendes Verhalten II. Die gesellschaftliche Reaktion auf Kriminalität, Bd. 1, 1975, S. 251 ff.; Schünemann, FS für Roxin z. 70. Geburtstag, 2001, S. 1, 10 ff.; jüngst Leite, GA 2012, 688, 692. Krit. Pawlik, Festschrift für Otto, 2007, S. 133 ff. 
dass Strafrecht nicht metaphysisch aufzuladen sei, sondern der Verarbeitung sozialer Konflikte diene, lösen sich nicht konsequent vom althergebrachten Begriff der „Schuld““. ${ }^{147}$ Warum aber dieses Beharren darauf, dass ohne Schuld und ohne einen berechtigten Schuldvorwurf der Täter nicht bestraft werden dürfe? Warum das ausgeprägte Interesse an der inneren Welt des Täters?

Die geistesgeschichtlichen Wurzeln dürften ebenfalls im christlichen Denken liegen. Die Fokussierung auf die innere Welt des Täters, auf sein höchstpersönliches Versagen angesichts von Sollensanforderungen, ist dann nachvollziehbar, wenn dem eine Beziehung zugrunde liegt, deren Essenz nicht in der materiellen Welt der Außenbeziehungen liegt, sondern in der inneren Einstellung des Menschen zu göttlichen Geboten. Es ist nicht überraschend, dass aus rechtshistorischer Sicht der Prozess der Christianisierung als entscheidende Weichenstellung für das neuzeitliche Schuldkonzept eingestuft wird. ${ }^{148}$ In den säkularisierten Varianten wurde aus der falschen Einstellung zu Gott die ,geistige Sollensoder Wertverfehlung". Für rechtliche Bewertungen ist es dagegen nicht per se evident, warum es jenseits des Unrechtsurteils wichtig sein soll, dem Täter ein persönliches Versagen vorhalten zu können. Ich sehe an dieser Stelle einen merkwürdigen blinden Fleck bei vielen Strafrechtswissenschaftlern. Die Frage, wie man Schuld begründen kann, findet viel Aufmerksamkeit - nicht aber die an sich wichtigere vorgelagerte Frage, ob die Kategorie „Schuld“ innerhalb der strafrechtlichen Verbrechenslehre überhaupt angemessen ist. ${ }^{149}$

Hartnäckiges Wiederholen der Fragen „warum bedarf es eines Schuldvorwurfs, warum haben wir eine Kategorie ,Schuld“ in der Verbrechenslehre?" würde vermutlich unter Befragten (mindestens) drei unterschiedliche Typen von Antworten hervorbringen. Erstens wäre mit

147 S. etwa Stratenwerth, Die Zukunft des strafrechtlichen Schuldprinzips, 1977, S. 46; Streng, Festschrift für Jakobs, 2007, S. 675 ff.

148 S. zur historischen Entwicklung Meder, Schuld, Zufall, Risiko, 1993, S. 59 ff.; Pallauf, Festschrift für Michael Fischer, 2010, S. 113, 115.

149 Selbst Autoren, die zu Recht zur Schlussfolgerung kommen, dass der Schuldbegriff „nicht geeignet [sei], zu Lasten des Täters ... sittliche Vorwürfe zu legitimieren“ (Roxin, Fn. 4, § 19 Rn. 46), ziehen daraus nicht die an sich nahe liegende Folgerung, auf die Verwendung des Schuldbegriffs zu verzichten. 
verfassungsrechtlichen Argumenten zu rechnen, zweitens mit moralischen Intuitionen oder moralphilosophischen Begründungen zu den Bedingungen für eine Verantwortlichkeit von Personen, und drittens mit soziologischen Thesen.

a) Zu ersterem: Es scheint nahe zu liegen, auf das verfassungsrechtliche Schuldprinzip ${ }^{150}$ Bezug zu nehmen, auf das das Bundesverfassungsgericht (zuletzt im Lissabon-Urteil) ${ }^{151}$ in ständiger Rechtsprechung verweist. Insoweit ist allerdings Vorsicht erforderlich, weil das Bundesverfassungsgericht im Kontrast zur strafrechtlichen Verbrechenslehre einen anderen, deutlich weiteren Begriff von Schuld verwendet. Vieles von dem, was zu einem solch weiten Verständnis von Schuld gehört, betrifft Aspekte, die bereits Anforderungen an ein legitimes Unrechtsurteil sind. Wichtig ist z.B., dass die Tat objektiv dem angeklagten Individuum als seine eigene Handlung zugerechnet werden kann. Er muss es gewesen sein, der die Freiheitssphäre des anderen oder der anderen verletzt hat (was etwa eine strafrechtliche Vertreter- oder Sippenhaftung ausschließt, bei der Bestrafung nicht von einer eigenen Handlung abhängt). Genauso ist es als Ausfluss des verfassungsrechtlichen Schuldgrundsatzes einzuordnen, dass eine Pflichtverletzung vorliegen muss, was eine „strict liability“-Haftung ausschließt, wie sie das englische und amerikanische Recht ${ }^{152}$ kennen. Aber auch insoweit handelt es sich um Anforderungen an das Unrechtsurteil. Das Bundesverfassungsgericht betont ferner unter der Überschrift „Schuld“ strafzumessungsrelevante Konsequenzen (die Schwere einer Straftat und das Verschulden des Täters müssen zu der Strafe in einem gerechten Verhältnis stehen). ${ }^{153}$ Auch dies führt keineswegs zwingend zu der Schlussfolgerung, dass dem Täter neben dem Unrecht zusätzlich ein persönliches Versagen vorgeworfen werden müsse - der Begriff „Verschulden“ kann als Verweis auf

150 Dazu Hörnle, Festschrift für Tiedemann, 2008, S. 325 ff.

151 BVerfGE 123, 267, 413.

152 S. Smith/Hogan/Ormerod, Criminal Law, 12. Aufl. 2008, S. 150 ff.; Dubber/Kelman, American Criminal Law: Cases, Statutes and Comments, 2. Aufl. 2009, S. $325 \mathrm{ff}$.

153 S. z.B. BVerfGE 90, 145, 173; 110, 1, 13. 
das Ausmaß der Pflichtverletzung und die Intensität des Wollens als Ergänzung des Erfolgsunwertes gedeutet werden.

Aus einer Absage an das Erfordernis eines Schuldvorwurfs ergibt sich deshalb nicht, dass damit eine „strict liability“-Haftung, eine „Sippenverantwortlichkeit“, eine ausschließlich am Erfolgsunwert orientierte Strafe oder ein ausschließlich auf Straftatenprävention zugeschnittenes Strafrechtssystem befürwortet werde! Vielmehr ist daran zu erinnern, dass ein Teil der Probleme, die sich aus dem Begriff „Schuld“ ergeben, in dessen mehrdeutiger Verwendung liegen. ${ }^{154}$ Aus der Tatsache, dass unterschiedliche Themen in gängiger, aber missverständlicher Weise unter einen schillernden Oberbegriff, nämlich „Schuld“ gefasst werden, ergibt sich nicht, dass Aussagen in einem Teilbereich (etwa: ein Schuldvorwurf ist verzichtbar und es bedarf nicht der Kategorie „Strafbegründungsschuld“ in der Verbrechenslehre) Konsequenzen für die anderen Teilbereiche haben müssten. Für unser Thema sind etwa Argumente nicht relevant, die bei der Strafzumessung ansetzen und insoweit die Alternativen „Schuldprinzip versus Verhältnismäßigkeitsgrundsatz“ diskutieren. ${ }^{155}$ Wer von der Tauglichkeit des Verhältnismäßigkeitsgrundsatzes als Strafzumessungsprinzip nicht überzeugt ist, kann dafür gute Gründe vorbringen, ohne dass daraus aber abzuleiten wäre, dass unter der Überschrift „Strafbegründungsschuld“ an einem Schuldvorwurf klassischen Zuschnitts festzuhalten sei. ${ }^{156}$

b) Der Erörterung bedürfen aber moralische Intuitionen, denen zufolge eine Bestrafung des Täters nur legitim sein kann, wenn zusätzlich zur subjektiven Zurechnung der Tat zum Täter auch noch Strafbe-

154 Dazu Baurmann (Fn. 111), S. $259 \mathrm{ff}$.

155 Vgl. Ellscheid/Hassemer (Fn. 137), S. 281 ff.; Baurmann (Fn. 111), S. 269 ff.

156 So aber Dölling, Forensische Psychiatrie, Psychologie, Kriminologie 2007, 59, $61 \mathrm{f}$. Ich teile seine Einschätzung, dass Strafzumessung retrospektiv orientiert erfolgen sollte, d.h., dass das Strafmaß proportional zur Schwere der Tat ausfallen sollte. Das Verhältnismäßigkeitsprinzip erlaubt dagegen, dass z.B. bei einer Betonung von Wiederholungsgefahren die Strafe disproportional hoch ausfällt, s. Dölling a.a.O. Aber: solche Überlegungen sind schlüssig vorzubringen, ohne dass der Begriff „Schuld“ fällt und ohne dass aus Überlegungen zur Strafzumessung zu folgern wäre, dass es eines Schuldvorwurfs bedürfe. 
gründungsschuld im Sinne einer Letztverantwortung, einer tiefen persönlichen Verantwortung des Täters für sein Tun festgestellt werden kann. Entscheidend ist hier das Stichwort „tief“. Ohne persönliche Verantwortung ist bei einem an eine Person adressierten Unwerturteil natürlich nicht auszukommen. Verantwortungszuschreibungen müssen in einem dünneren Sinn das Kriterium „Kontrolle über die Ereignisse" aufgreifen, was strafrechtsdogmatisch in Erfordernissen wie „eigene Handlung“ und „Kausalität dieser Handlung für den tatbestandlichen Erfolg" zum Ausdruck kommt. Fraglich ist allein, ob dies ausreicht, oder ob es darüber hinaus einer tieferen Verwurzelung von Verantwortung bedarf. Als Antwort auf die Frage, was eine solche Letztverantwortung begründen könne, gibt es zwei mögliche Herangehensweisen: entweder wird das Stichwort „Kontrolle“ oder aber „Urheberschaft“ lauten. Wer AndersEntscheiden-Können als unabdingbare Bedingung für Praktiken des Verantwortlichmachens ansieht, betont damit das Kriterium der Kontrolle. Für einen auf Kontrolle fokussierten Ansatz wird angeführt, dass dahinter ein fundamentales menschliches Bedürfnis stehe, nämlich das Bedürfnis, sich nicht selbst als machtloses Objekt des Schicksals erleben zu müssen, und das Bedürfnis, sich selbst in Bezug auf eigene Leistungen und Errungenschaften als ultimativ verantwortlich, d.h. als verdienstvoll Handelnden zu erleben. ${ }^{157}$ Dieser Punkt ist allerdings umstritten. Das Gegenargument lautet, dass Zufriedenheit über den eigenen Werdegang sich auch dann einstellen kann, wenn man offen zugesteht, die Dinge nicht selbst in der Hand gehabt zu haben. Auch derjenige, der seine eigene günstige Persönlichkeitsentwicklung sowie harmonische Familien- und Berufsverhältnisse mit guten Genen, der liebevollen Erziehung durch die eigenen Eltern und einem fördernden sozialen Umfeld erklärt, werde typischerweise durch diese Einsicht nicht verunsichert oder unzufrieden. ${ }^{158}$ Diese These ist durchaus plausibel (wobei allerdings bei

157 S. für diese Erklärung des menschlichen Bedürfnisses nach ,ultimate responsibility“ Kane, The Significance of Free Will, 1996, S. 4 und passim. Für die Unmöglichkeit einer Begründung von Letztverantwortung: Galen Strawson, in: Kane (Hrsg.), The Oxford Handbook of Free Will, 2002, S. 441, $457 \mathrm{f}$.

158 Pereboom, in: Kane (Hrsg.), The Oxford Handbook of Free Will, 2002, S. 477, 482 f. 
negativ bewerteten Handlungen und Zuständen die Neigung, auf Vorwürfe mit dem Einwand ,,ich hatte keine Kontrolle“ zu reagieren, verbreiteter sein dürfte).

In der philosophischen Literatur wird dagegen vielfach nicht mehr auf ein tiefes Verständnis von Kontrolle, sondern auf Urheberschaft abgestellt. Auf dieser Linie argumentieren viele sog. Kompatibilisten, die sich nicht von einer deterministischen Weltsicht kategorisch distanzieren. Die viel rezipierten Ansätze von Peter Bieri und Michael Pauen basieren wesentlich auf dem Argument „Urheberschaft", wobei für dieses Verständnis von Urheberschaft entscheidend ist, dass die Tat mit der Persönlichkeit des Täters verknüpft wird (ausgedrückt etwa mit der Formulierung, dass die Entscheidung auf personale Präferenzen des Entscheidenden zurückführbar sein müsse ${ }^{159}$ ). Auch für das Charakterschuldverständnis von Rolf Herzberg ist der Aspekt der Urheberschaft entscheidend, die Tatsache, dass ,das Bewirkte das Werk seiner Person ist, während ein aus der Zwangsherrschaft des Kausalgesetzes befreites Wollen und Handeln ein Wunder wäre und den Täter zum Spielball des Zufalls machen würde“. 160

Nicht nur das auf Kontrolle (durch Anders-Entscheiden-Können) zugespitzte, sondern auch das auf Urheberschaft konzentrierte Verständnis von Letztverantwortung kontrastiert mit meinem Ansatz. Dieser basiert auf einer relativ oberflächlichen Querschnittsbetrachtung, die sich auf den Handlungszeitpunkt konzentriert und davon ausgeht, dass ein Längsschnitt durch die Täterbiographie auf der Suche nach „Letztverantwortung“ entbehrlich ist. Dem würden vermutlich viele Strafrechtswissenschaftler widersprechen, und zwar ungeachtet der Tatsache, dass die Lehre von der Charakterschuld in der zeitgenössischen deutschen Strafrechtswissenschaft viele Jahre (bis zu Rolf Herzbergs Reformulierung, s. oben) praktisch keine Rolle mehr gespielt hat. Vermutlich würden auch Vertreter von sog. Tatschuldlehren, wenn entsprechend intensiv befragt, letztlich sa-

159 Bieri, Das Handwerk der Freiheit, 2001, S. 239 ff.; Pauen (Fn. 16), S. 150 ff.; Pauen (Fn. 122), 45 ff.; Pauen/Roth (Fn. 21), S. 26 ff.

160 Herzberg, ZStW 124 (2012), 12, 59. 
gen, dass ,eigentlich“ Schuld in tiefer Weise mit der Person des Täters verbunden sein müsse und dass Bewertungen deshalb zwangsläufig weiter in die Vergangenheit (in die Biographie des Täters) zurückgreifen müssten. Bei Arthur Kaufmann findet sich das explizite Eingeständnis, dass auch in der Tatschuld ,ein Stück Persönlichkeitsschuld"stecken müsse. ${ }^{161}$ Reinhard Merkel betont in seinen Arbeiten zu Willensfreiheit und Schuld die Berechtigung des Radbruchschen Verweis auf das ,schlechte Gewissen des Strafrichters“, den er als Verweis auf ,dunkle Reste" im Strafrechtssystem versteht. Merkel führt ausdrücklich aus, dass nach dem „Alltagsverständnis von Schuld" damit doch höchstpersönliche Vorwerfbarkeit, doch „Letztverantwortung" gemeint sei. ${ }^{162}$

Stellt man allerdings auf die Perspektive derjenigen ab, die durch eine Straftat verletzt wurden, leuchtet das Erfordernis einer Letztverantwortung nicht ein. Man stelle sich vor, der Angeklagte habe nach einer heftigen verbalen Auseinandersetzung in einer Gaststätte dem Kontrahenten mit Wucht und absichtlich einen schweren Bierkrug auf den Kopf geschlagen; der Verletzte leidet nach stationärer Behandlung noch monatelang an den Folgen der schweren Schädelverletzung. Legt man die 2. Person-Perspektive zugrunde, reichen diese Bedingungen der Handlungsbeschreibung aus, um einen das Verfahren abschließenden Vorwurf zu tragen. Bringt der Angeklagte z.B. vor, dass er als Jugendlicher infolge von dysfunktionalen Familienverhältnissen eine ungünstige Persönlichkeitsveränderung durchgemacht habe, so entfällt aufgrund dieser Information nicht die Berechtigung des Urteils, dass er gegenüber dem Verletzten Unrecht getan hat, und dieses Urteil genügt für einen strafrechtlichen Vorwurf. Seine Legitimität hängt weder von einer Tiefenanalyse der Täterbiographie noch von der Frage ab, ob er sich zum relevanten Zeitpunkt hätte anders entscheiden können.

Derartige Schlussfolgerungen werden auch als moralphilosophische Überlegungen vertreten: Es bedürfe keiner Letztheitsbedingungen, um die Angemessenheit von reaktiven Einstellungen und von Ver-

161 Kaufmann (Fn. 142), S. 195.

162 R. Merkel, Festschrift für Roxin z. 80. Geburtstag, 2011, S. 737, 745, 760 f. 
antwortungszuschreibungen zu begründen. ${ }^{163}$ Wenn es um rechtliche Verantwortlichkeit geht, um Verhaltensbewertungen durch den Staat, ist es in besonderem Maße empfehlenswert, darauf zu verzichten, Letztverantwortung zu verlangen. Nach meiner Überzeugung ist es ein verfehltes, überzogenes, ja anmaßendes Verständnis der richterlichen Aufgabe, ein Urteil über die Person in ihrer Gesamtheit abzugeben oder Aussagen zu machen, die das Schwergewicht des Vorwurfs ins Innerliche des Täters verlegen. Für einen engen Zuschnitt der Umstände, auf die sich Verantwortungszuschreibungen beziehen, sprechen folgende Gründe: Zwar hat der Verweis auf eine genuine Letztverantwortung des Täters eine psychologische Entlastung für Strafrichter zur Folge - aber dies begründet auch die Gefahr von „moralisierenden Überreaktionen“ und einem durch Selbstgerechtigkeit geprägten Umgang mit Straftätern. ${ }^{164}$ Für einen sachlich-respektvollen Umgang mit Angeklagten und für ein zurückhaltendes Sanktionsniveau ${ }^{165}$ dürfte es eher förderlich sein, wenn Aussagen über deren Letztverantwortung vermieden werden. Es sollte ein Anliegen von Richtern sein, im Selbstverständnis ihrer beruflichen Rolle und in der Kommunikation mit Angeklagten den Eindruck zu vermeiden, eine „Gesamtbilanzierung" des Lebens und der Persönlichkeit von Angeklagten vornehmen zu dürfen oder vornehmen zu wollen. Die Beschränkung der staatlichen Aufgabe darauf, stellvertretend für Tatgeschädigte ein Unrechtsurteil abzugeben, das sich auf eine Querschnittsbewertung statt einer Längsschnittanalyse beschränkt, sollte eindeutig kommuniziert werden. Es ist klarzustellen, dass es um einen sozialen, zwischen Bürgern bestehenden Abgrenzungskonflikt geht. ${ }^{166}$

163 Wallace (Fn. 121), S. 118 ff.; Pereboom (Fn. 158), S. 484 ff.; Lohmar, Moralische Verantwortung ohne Willensfreiheit, 2005, S. 293 ff.; ebenso Heun, JZ 2005, 853, 860; Kindhäuser, Festschrift für Hassemer, 2010, S. 761, 763 ff.; i. Erg. auch Singer, in: Duncker (Fn. 15), S. 149.

164 Streng, ZStW 101 (1989), 273, 293.

165 S. zu diesem Punkt Seelmann (Fn. 37), S. 101 f.

166 Mit Blick auf das geltende Recht ist zuzugestehen, dass sich im Text des StGB das traditionelle Verständnis strafrichterlicher Aufgaben widerspiegelt, das nicht durch 
c) Die dritte Kategorie von Argumenten, die für ein Festhalten an einem strafrechtlichen Schuldvorwurf angeführt werden können, ist soziologischer Natur. Klaus Günther sieht die Funktion strafrechtlicher Zurechnung darin, ein tief verwurzeltes gesellschaftliches Selbstverständnis zu reproduzieren, das sich auf individuelle Freiheit beziehe. ${ }^{167}$ Franz Streng stellt für die Legitimierung des strafrechtlichen Schuldkonzepts darauf ab, dass ansonsten negative Folgewirkungen in Form von „kulturelle[n] Langzeiteffekte[n] eines wahrgenommenen Ausgeliefertseins an das Unbewusste unvermeidlich“ seien. Diese würden sich bei der „Norminternalisierung in Primärund Sekundärsozialisation", d.h. der Vermittlung von Prinzipien personaler Verantwortung in der Erziehung von Kindern und Jugendlichen auswirken. ${ }^{168} \mathrm{Im}$ Prozess der Erziehung ist es üblich und erforderlich, kontinuierlich prospektiv Forderungen des Inhalts „Gib dir Mühe, dich normgemäß zu verhalten“ einzusetzen und korrespondierend retrospektiven Tadel des Inhalts „Du hast dir nicht genug Mühe gegeben“. Gefühle des Verantwortlich-Seins entstehen durch derartige Zuschreibungsprozesse, die von den zu Erziehenden verinnerlicht werden. ${ }^{169}$ Dass in diesem Zusammenhang überschießende Freiheitsvorstellungen vermittelt werden, wenn es um den retrospektiven Tadel für eine konkrete Handlung geht, dürfte anspornende Wirkung haben, und Sozialisationsprozesse wirken sich auf die physiologischen Strukturen aus, die spätere Entscheidungen bestimmen. Es leuchtet deshalb ohne weiteres ein, dass das Bewusst-

Zweifel an der Berechtigung eines Eingehens auf Einstellungen, Persönlichkeit und Täterbiographie geprägt ist. Insbesondere finden sich Spuren der Intuition, dass es auf das Urheberschaftsprinzip als Quelle für Letztverantwortung ankomme, in den Normen des Strafgesetzbuches. So nennt etwa die Strafzumessungsvorschrift in $\S 46$ Abs. 2 StGB als Strafzumessungsfaktoren u.a. das Vorleben des Täters und seine persönlichen Verhältnisse. Mein Anliegen liegt aber in erster Linie darin, auf der strafrechtswissenschaftlichen Ebene für ein Umdenken zu plädieren, wobei gegen derartige konzeptuelle Überlegungen weder der Verweis auf die feste Etablierung des Begriffs „,Schuld“ in der deutschen Strafrechtsdogmatik noch der Verweis auf die Verankerung traditioneller deutscher Auffassungen im Text des StGB ein zwingender Einwand sein sollte.

167 Günther (Fn. 97), S. 271.

168 Streng, Festschrift für Jakobs, 2007, S. 689 ff.

169 Darauf verweisen z.B. Singer (in: Krüger, Fn. 15), S. 50 f.; Prinz (Fn. 36), S. 58 f. 
sein personaler Verantwortung in Erziehungsprozessen gefördert werden sollte (wobei allerdings auch die Gegenthese zu beachten ist, dass übertriebene Verantwortungszuschreibungen dysfunktional sein können ${ }^{170}$ ).

Fraglich ist aber, inwieweit sich hieraus die Folgerung ergibt, dass deshalb im strafrechtlichen Kontext an einem Schuldvorwurf festgehalten werden müsse. Dagegen spricht, dass sich die Modellierung des angemessenen Umgangs jedenfalls mit erwachsenen Straftätern nicht ohne weiteres an dem orientieren sollte, was bei der Primärsozialisation von Kindern sinnvoll ist. Und auch an dieser Stelle liegt wieder ein Problem im diffusen Umgang mit dem Begriff „Schuld“. Auch wenn der gegenüber einem Kind erhobene Vorwurf „Das war deine Schuld“" sprachlich identisch mit dem zu sein scheint, was nach dem klassischen Schuldverständnis im Strafverfahren auszusagen ist, folgt hieraus nicht, dass Letzterer unverzichtbar ist. Man mag alltagssprachlich das Verantwortlichmachen (nicht nur) von Kindern mit Anleihen aus der Begriffsfamilie „Schuld“ verbinden, weil sich damit prägnant und eingängig das Ergebnis „Du bist verantwortlich“ formulieren lässt. Das ist jedoch kein Argument gegen einen bewussteren, durchdachteren Umgang mit dem Begriff „Schuld“ in rechtlichen Zusammenhängen. Dass in der Rechtssprache nach dem hier begründeten Vorschlag „Schuld“ eliminiert werden sollte und im „zurechenbaren unrechtmäßigen Handeln“ eine hinreichende Grundlage für die Bestrafung liegt, ist eine dem Kontext geschuldete Präzisierungsleistung. Ob sich eine sprachliche Präzisierung der strafrechtlichen Verantwortungszuschreibung dahingehend auswirken würde, dass der Alltagseinsatz von Floskeln wie „Du bist schuld“ verschwinden würde, mag dahinstehen (das wäre allenfalls langfristig zu erwarten, und vielleicht nicht einmal dann). Entscheidend ist, dass die hier vorgeschlagenen Korrekturen nicht zur Folge hätten, dass die Praktiken des Verantwortlichmachens in der familiären und gesellschaftlichen Sozialisationsarbeit gefährdet würden. Schließlich ist nach meinem Vorschlag am Grundsatz der personalen Ver-

170 S. zu diesem Punkt von Hayek (Fn. 42), S. 107 ff.; Vanberg (Fn. 37), S. 68; ferner Kriele, ZRP 2005, 185, 187. 
antwortung in Form von individueller strafrechtlicher Zurechnung festzuhalten - allerdings mit „dünnerem Auftrag“, d.h. ohne anspruchsvolle Konzepte der Letztverantwortung zu bemühen. 


\section{Konsequenzen für die Verbrechenslehre und das Strafgesetz}

Was folgt aus den vorstehenden Überlegungen für die Strafrechtslehre und die Kriminalpolitik? Zunächst ist auf einen nahe liegenden Einwand einzugehen: Wenn nur noch ein Unrechtsvorwurf zu legitimieren ist, soll dieser dann auch gegenüber Personen erhoben werden, die in objektiv wie subjektiv zurechenbarer Weise und nicht gerechtfertigt die strafrechtlich geschützten Rechte anderer verletzt haben, aber nach der traditionellen Verbrechenslehre unter einen sog. Schuldausschließungsgrund fallen? Gesetzliche Ausschließungsgründe dieser Art sind junges Alter (unter 14 Jahre, §19 StGB) und geistige Erkrankungen i.w.S. (§ 20 StGB). Wie passt die Existenz solcher Normen zu meiner These, dass es nur auf einen Unrechtsvorwurf ankommen solle? Rechtswidrige Taten, also Unrecht, können auch Kinder und Geisteskranke begehen. Es wäre theoretisch-konzeptuell auch durchaus vorstellbar, in diesen Fällen ein Unrechtsurteil abzugeben, dass die Situation von Tatopfern klarstellt, aber nicht als Vorwurf gegenüber den Handelnden formuliert und auch nicht mit Sanktionen verbunden ist. Tatsächlich verzichten moderne Strafrechtssysteme jedoch gegenüber Personen, die nach üblicher Diktion als „schuldunfähig“ gelten, auf die formelle Erhebung eines Unrechtsvorwurfs. Wie ist dies zu erklären?

In der strafrechtlichen Literatur ist der Begriff ,,normative Ansprechbarkeit“" gebräuchlich. Auf die Grundvorstellung einer „,normalen normativen Ansprechbarkeit" (mit diesem Begriff oder der Sache nach) verweisen viele Publikationen zum Thema Schuld, und zwar als Basis für einen Schuldvorwurf. ${ }^{171}$ Es fehlt allerdings typischerweise ein Begründungselement: warum sollte ,allgemeine normative Ansprechbarkeit" für einen tatbezogenen Schuldvorwurf ausreichen? Hält man dem Angeklagten vor: „Sie sind im Allgemeinen in der Lage, Verbotsnormen zu verstehen und zu befolgen“, so liegt der Gegeneinwand nahe „,vielleicht schon, aber in der konkreten Situation war der Handlungsimpuls

171 S. z.B. Roxin (Fn. 4), § 19 Rn. 36 ff.; LK/Schöch, 12. Aufl. 2007, § 20 Rn. 24; MK/ Paeffgen, 2. Aufl. 2011, Vorbem. zu §§ 32 ff. Rn. 231; Lackner/Kühl (Fn. 138), Vor $\S 13$ Rn. 23; Weißer, GA 2013, 26, 34 ff. 
zu stark“. Hier gibt der gängige Verweis auf ,normative Ansprechbarkeit" ein Rätsel auf: Handelt es sich um ein statistisch begründbares Normalitätsurteil oder um eine normative Unterstellung? 172 Und warum sollte man einen Schuldvorwurf darauf stützen, dass der Täter im Allgemeinen normativ ansprechbar war, wenn sich zum entscheidenden Zeitpunkt, bei einer Querschnittsbetrachtung, dies nicht in einer Entscheidungsalternative niederschlug? ${ }^{173}$

Weiter kommt man, wenn man zwischen dem Inhalt eines Vorwurfs und den Bedingungen für die Erhebung eines Vorwurfs unterscheidet. Das, was mit „,normaler normativer Ansprechbarkeit“ gemeint ist, ist nur eine Bedingung dafür, dass der Staat den Täter für die Begehung der unrechtmäßigen Tat verantwortlich machen darf. Das Vorliegen der Bedingung kann das Gewicht des Vorwurfs nicht beeinflussen. Dieses ergibt sich ausschließlich aus dem Maß des verwirklichten Unrechts. Dass wir die Bedingung der normativen Ansprechbarkeit voraussetzen müssen, ergibt sich aus der Logik des Machens eines Vorwurfs, aus der Logik einer Kommunikation, die in einem demokratischen Rechtsstaat eine Kommunikation unter Gleichgestellten sein sollte. In einem rational zu strukturierenden Verfahren wie einem Strafverfahren genügt es nicht, nur in expressiver Weise den Unrechtsvorwurf irgendwie loszuwerden. In einem dialogisch konstruierten Modell ${ }^{174}$ müssen vielmehr beide Seiten, d.h. auch der Angeklagte, zu einer Kommunikation über das relevante Thema und vor allem auch zum Verständnis und zum Nachvollziehen des Unrechtsvorwurfs in der Lage sein. Bedingung für das Stattfinden eines Dialogs im Strafverfahren ist, dass die Beteiligten zu einer normativen Gemeinschaft gehören, die durch bestimmte Minimalbedingungen normativer Kompetenz gekennzeichnet ist. Diese Bedingung ist in doppelter Hinsicht zu prüfen: zum einen als Kommunikationsfähigkeit zum Zeitpunkt des Strafverfahrens, d.h. unter dem Stichwort „Prozessfähigkeit“ als Verfahrensvoraussetzung, zum anderen

172 K. Günther, KJ 2006, 116, 120.

173 Krit. Streng, ZStW 101 (1989), 273, 279; Hillenkamp (Fn. 12), S. 104; Hoyer, Festschrift für Roxin z. 80. Geburtstag, 2011, S. 727 ff.; R. Merkel (Fn. 1), S. 117 f. (s. aber auch a.a.O. S. 131 f.); Weißer, GA 2013, 26, 33.

174 S. dazu Neumann (Fn. 62), S. 276 ff.; Duff/Farmer/Marshall (Fn. 114). 
aber auch für den vorgelagerten Zeitpunkt der Tat. ${ }^{175}$ Dass Strafurteile oder Strafbefehle de facto Monate oder Jahre nach der Tat ergehen, ändert nichts daran, dass der Vorwurf sich auf den Tatzeitpunkt bezieht. Ein fiktiver Dialog mit dem Täter zu diesem Zeitpunkt wäre als Geltendmachung von Unterlassungsansprüchen (bzw. Handlungsgeboten bei Unterlassungsdelikten) zu verstehen, wobei die Sinnhaftigkeit eines solchen Dialogs von Vorbedingungen in der Person des Täters abhängt. Eine Parallele wäre zu ziehen zu Vorwürfen gegenüber Abwesenden: Eine nicht kommunikativ erreichbare (da nicht anwesende und nicht durch Telekommunikation verbundene) Person zum Adressaten des an sie gerichteten Vorwurfs zu machen, soeben zu einer Pflichtverletzung anzusetzen, wäre als Akt der Kommunikation ein sinnloses „Rufen in den Wind", auch wenn der Vorwurf sachlich vollkommen berechtigt ist. Genauso verhält es sich mit mental nicht erreichbaren Personen.

Anders als bei der Erhebung eines Schuldvorwurfs genügt es für die Feststellung der Dialogfähigkeit des Täters zum Tatzeitpunkt, eine allgemeine Fähigkeit festzustellen, die mit dem Stichwort ,normative Ansprechbarkeit“ oder (was mir treffender erscheint) „,normative Kompetenz" bezeichnet werden kann. Dazu gehört zum einen die Fähigkeit, die Berechtigung von Ansprüchen anderer Personen auf Unterlassen des Eindringens in ihre Freiheitssphäre zu verstehen oder aber jedenfalls die Klugheitsregeln zu erfassen, die wegen der sonst zu erwartenden Sanktionen ein Unterlassen gebieten. Zum anderen bedarf es bestimmter Grundvoraussetzungen in Form von Aufmerksamkeit, Urteilsfähigkeit und grundsätzlich möglicher Impulskontrolle, damit dieses Wissen innerhalb der eigenen Entscheidungsfindung angemessen verarbeitet werden kann. ${ }^{176}$ Wie Reinhard Merkel für den Begriff „,normative Ansprechbarkeit" dargelegt hat, handelt es sich um ein Dispositionsprädikat, das auf bestimmte Minimalfähigkeiten der Rezeptivität und Reaktivität Bezug nimmt. ${ }^{177}$ Der Denkfehler vieler Autoren, die auf normative Ansprechbarkeit abstellen, liegt in der Erwartung, man könne damit

175 Duff, Answering for Crime, 2009, S. $40 \mathrm{f}$.

176 Wallace (Fn. 121), S. 158 ff.

177 R. Merkel, Festschrift Roxin z. 80. Geburtstag, 2011, S. 737, 754 ff. S. ferner Frister, Die Struktur des voluntativen Schuldelements, 1993, S. 125 ff. (hinreichend differenziert strukturierte Willensbildung). 
einen Schuldvorwurf inhaltlich ausfüllen. Das kann man nicht. Es handelt sich lediglich um die Bedingung für die Erhebung eines Unrechtsvorwurfs. Dies sollte sprachlich wie konzeptuell zum Ausdruck gebracht werden, indem der Begriff ,Schuld“ konsequent vermieden wird.

Was würde dies für die Formulierungen im Strafgesetzbuch bedeuten, welche Änderungen wären de lege ferenda erforderlich? Die Antwort ist: es wäre überwiegend mit kleineren sprachlichen Anpassungen getan. Formulierungen wie in $\S 19$ StGB (,Schuldunfähig ist, wer ..."), $\S 20$ StGB („Ohne Schuld handelt, wer ...“), § 17 StGB und $\S 35$ StGB $(, \ldots$ handelt ohne Schuld ...") sind ohne substantielle Änderungen nach dem Vorbild von $\S 33$ StGB (,... wird er nicht bestraft") umzuformulieren. Dass insbesondere bei $\S 20$ StGB eine relativ triviale Gesetzesänderung ausreichen würde, bedarf allerdings der Begründung. In der strafrechtlichen Literatur wird vertreten, dass das Gesetz eine ausdrückliche Festlegung des Inhalts enthalte, dass eine Bestrafung Anders-Handeln-Können zum Tatzeitpunkt voraussetze. ${ }^{178}$ Dem ist entgegenzuhalten, dass dies in $\S 20$ StGB so nicht zum Ausdruck kommt. Die Bedeutung dieser Norm beschränkt sich auf die Aussage, dass eine Strafbarkeit ausscheidet, wenn einer der erwähnten pathologischen Zustände vorliegt, wobei der zweite Teil der Norm ,wegen [dieses Zustands] unfähig ist, das Unrecht der Tat einzusehen und nach dieser Einsicht zu handeln“ sich nur auf Situationen bezieht, in denen eine krankhafte seelische Störung etc. vorliegt, und insoweit ein einschränkendes Kriterium formuliert. Für den Normalfall des nicht von einem pathologischen Zustand erfassten Täters enthält $\S 20$ StGB keine, auch keine implizite Aussage. ${ }^{179}$

Für die Verbrechenslehre ist allerdings im Hinblick auf die $\S \S 19,20$ StGB zu erwägen, die Prüfungsabfolge zu ändern. In diesen Normen sind Grundbedingungen der normativen Ansprechbarkeit festgelegt, die Voraussetzung für die Erhebung eines Unrechtsvorwurfs sind. Es liegt deshalb nahe, die Prüfung und die Feststellung, dass beim Beschuldigten

178 R. Merkel (Fn. 1), S. 112 ff., 115; ders., Festschrift für Roxin z. 80. Geburtstag, 2011, S. 737, 759; G. Merkel, Festschrift für Herzberg, 2008, S. 3, 4; Duttge (Fn. 24), S. $35,44 \mathrm{f}$.

179 Hassemer, ZStW 121 (2009), 829, 852; Herzberg (Fn. 19), S. 105 ff.; ders., ZStW 124 (2012), 12, $24 \mathrm{f}$. 
weder „,unter 14 Jahre“ noch eine krankhafte seelische Störung o. Ä. vorliegt, als Einstiegsvoraussetzung zu behandeln. So legt etwa Anthony Duff die Struktur seines Buches „Answering for Crime“ an: Er beginnt mit der Frage, wer verpflichtet ist, in einen Verantwortungsdialog einzutreten (,to answer for crime") und sieht in der Beantwortung dieser Frage logische Priorität. ${ }^{180}$ Erst nachdem dieser Punkt geklärt ist (hier läuft die Erörterung parallel zu einer Beschreibung von normativer Ansprechbarkeit), erörtert Duff, wem gegenüber man Rechenschaft schulde und für was. Staatsanwälten und Strafrichtern würden solche Überlegungen vermutlich ohne weiteres einleuchten: Wenn feststeht, dass mangels der Voraussetzungen, die die normative Verständigungsmöglichkeit zum Tatzeitpunkt betreffen, eine strafrechtliche Verurteilung ausscheiden muss, wird in der Praxis nicht vorher umständlich das Tatunrecht geprüft.

Auf der Basis dieser Überlegungen ergibt sich folgende Prüfungsabfolge:

I. Normative Ansprechbarkeit zum Zeitpunkt der Handlung/Unterlassung

II. Tatbestandsmäßigkeit in objektiver und subjektiver Hinsicht

III. Rechtfertigungsgründe

IV. Sonstige Strafausschließungsgründe ( $\S 33,35$ StGB, 24 StGB, u.a.)

Günther Jakobs deutet ebenfalls kurz an, dass es vorstellbar wäre, die fehlende strafrechtliche Zurechnung bei Kindern vorab, ohne weitere Zurechnungserwägungen „durch einen Verweis auf das Evidente“ zu erledigen. ${ }^{181}$ Er spricht sich aber im Ergebnis dagegen aus, da man ansonsten in die Situation kommen könne, ,die anderen Elemente des Ganzen implizit bei der Schuldfähigkeit zu erörtern“. ${ }^{182}$ Welche prüfungspragmatischen Gründe sind damit gemeint? Zum einen ist es natürlich möglich, dass die Feststellung der rechtswidrigen Tat etwa eines Kindes für die Strafbarkeit anderer Personen relevant wird, etwa wenn

180 Duff/Farmer/Marshall (Fn. 114), S. 37 ff., zum logischen Vorrang dieses Punktes S. 38 .

181 Jakobs (Fn. 90, System der strafrechtlichen Zurechnung), S. 24.

182 A.a.O., S. 24. 
sich diese gegenüber einem Angriff des Kindes auf Notwehr berufen oder wenn sie Teilnehmer an dieser Tat waren. Es spricht aber nichts dagegen, bei den Beteiligten, die den Filter ,normative Kompetenz“ passiert haben, die ,rechtswidrige Tat eines anderen “ innerhalb der Prüfung der Tatbestandsmäßigkeit ihrer Handlung zu erörtern. Ferner könnte in ungewöhnlichen Fällen schon bei der Frage der Anwendbarkeit der $\S \S 19,20$ StGB, also schon beim Prüfungspunkt I., zu klären sein, was als „die Tat" zählt, was also der relevante Lebensausschnitt ist. Die Festlegung, wann genau normative Kompetenz vorgelegen haben muss, wird zwar in aller Regel unproblematisch sein, aber nicht immer. Trotzdem ist im Ergebnis ein Umbau der Verbrechenslehre vorzugswürdig, da der Nachteil einer selten erforderlichen Implizitprüfung (wenn man darin überhaupt einen gewichtigen Nachteil sieht) durch den Vorteil aufgewogen wird, dass so mit aller Deutlichkeit zum Ausdruck kommt, dass das strafrechtliche Unwerturteil keinen Schuldvorwurf beinhaltet.

Die vorstehenden Überlegungen betreffen die (jedenfalls aus strafrechtswissenschaftlicher Sicht) „Kleinigkeit“ einiger klarstellender Wortänderungen im StGB sowie eine Modifikation des Straftatsystems in Lehrbüchern. Beides hätte auf den Inhalt von Fallentscheidungen in der strafgerichtlichen Praxis keine Auswirkungen. Kein weitergehender kriminalpolitischer Handlungsbedarf entstünde nach meinem Vorschlag im Hinblick auf die sog. Entschuldigungsgründe. Mit dem Stichwort „Entschuldigungsgründe“ werden in der Strafrechtswissenschaft Umstände bezeichnet, die in den $\S \S 33,35$ StGB angeführt werden. Die in diesen Normen angeordnete Straffreiheit lässt sich argumentativ untermauern, ohne dass es dazu des Begriffs, „Schuld“ bedarf und ohne dass auf Anders-Entscheiden-Können oder andere Inhalte eines Schuldvorwurfs Bezug genommen werden muss. ${ }^{183}$ Die hinter dem Verzicht auf Bestrafung stehenden Gründe lassen sich folgendermaßen rekonstruieren: Unter bestimmten situativ geprägten Umständen ist es möglich, in Anbetracht einer sehr außergewöhnlichen Situation für die Lage des Täters Verständnis zu entwickeln und das begangene Unrecht als Faktum zu tolerieren, das trotz des Unrechtscharakters soweit menschlich

183 Frister (Fn. 177), S. 157 ff.; Kindhäuser, Festschrift für Hassemer, 2010, S. 761, 774; Schroth, Festschrift für Roxin z. 80. Geburtstag, 2011, S. 705, 714. 
verständlich ist, dass der Verzicht auf ein staatliches Unwerturteil vertretbar ist. ${ }^{184}$

Es bleibt aber ein für die Praxis bedeutsamer Punkt anzusprechen: Führt die soeben vorgeschlagene Modifikation in der Verbrechenslehre dazu, dass die Abschaffung von $\S 21$ StGB zu empfehlen wäre? Das geltende Recht erlaubt in $\S 21$ StGB eine Strafminderung, wenn die Fähigkeit des Täters, das Unrecht der Tat einzusehen oder nach dieser Einsicht zu handeln, aus einem der in $\S 20$ StGB bezeichneten Gründe bei Begehung der Tat erheblich vermindert war. Eine solche Regelung (und ihre Ausdehnung auf andere schuldmindernde Strafzumessungsumstände) ist dann unmittelbar einsichtig, wenn man davon ausgeht, dass ein Schuldvorwurf zum Unrechtsvorwurf hinzukommt und beides zusammen das Gewicht des Gesamtunwerturteils bestimmt. Vor diesem Hintergrund bedeutet natürlich ,weniger gewichtiger Schuldvorwurf": „geringeres Gesamtunwerturteil“", weshalb eine mildere Strafe angemessen ist. Eine Abstufung setzt aber voraus, dass es ein Substrat gibt, das als ,verringert" angesehen werden kann. Das könnte Charakterschuld sein (es gibt mehr oder weniger schlechte Charaktere), aber Abstufbarkeit ergibt sich auch dann, wenn man von der Hintergrundfolie des Anders-Entscheiden-Könnens ausgeht: dann ist es konsequent, Er-

184 S. Bernsmann, Entschuldigung durch Notstand, 1989, S. 254 ff.; Hörnle, JuS 2009, 873 ff.; T. Walter, Der Kern des Strafrechts, 2006, S. 136 f.; LK/Walter, 12. Aufl. 2007, Vor $\S 13$ Rn. 170 f. Die Berücksichtigung sog. Entschuldigungsgründe, also der Verzicht auf einen Unrechtsvorwurf, ist auf eine andere Gewichtung der Perspektiven zurückzuführen. Jedenfalls bei erheblichen Verletzungen der Person würde man auch mit einer standardisierten und entemotionalisierten Opferperspektive an einem Vorwurf festhalten - der Verzicht auf Strafe ergibt sich hier aus Wertungen der Gemeinschaft (unser Verständnis für die schwierige Situation, in der sich der Täter befand). Es ist zuzugestehen, dass hierin ein „Nebeneinander zweier widerstreitender Bewertungsperspektiven“ liegt (kritisch dazu Pawlik, Fn. 4, S. 271). Es scheint mir jedoch vorzugswürdig, eine Heterogenität von Bewertungsperspektiven in bestimmten Grenzen (Verzicht auf einen Unrechtsvorwurf nur unter sehr außergewöhnlichen Umständen) zu akzeptieren - eine klare Präferenz für Geschlossenheit und Einheitlichkeit von Bewertungsmaßstäben ergibt sich nur dann, wenn man der Geschlossenheit und Stringenz eines Systems einen (ästhetisch bedingten?) Eigenwert beimessen würde. 
schwernisse beim Anders-Entscheiden-Können als schuldmindernd anzurechnen. ${ }^{185}$

Zweifel am Anders-Entscheiden-Können führen jedoch dazu, dass diese Erwägung nicht mehr überzeugt: wenn Anders-Entscheiden-Können zum Tatzeitpunkt für niemanden überzeugend festgestellt werden kann, erledigt sich die Frage, wie man Abstufungen behandeln müsse. Die Vorstellung „Schuldminderung“ passt nicht mehr, wenn man den Punkt ,normative Kompetenz zum Tatzeitpunkt“ nicht als quantifizierbaren Schuldvorwurf versteht. Handelt es sich lediglich um ein Kriterium, mit dem die Zugehörigkeit des Täters zu einer normativen Kommunikationsgemeinschaft festgestellt wird, liegt es nahe, dies als Ja/ Nein-Frage zu sehen. Die Konsequenz ist, dass $\S 21 \mathrm{StGB}$ zu streichen wäre und der Punkt „Schuldminderung“ aus der Theorie der Strafzumessung verschwinden würde. Als Reaktion auf eine solche Überlegung ist massiver Widerspruch zu antizipieren, da dies eine deutliche Abweichung von Grundlagen bedeutet, die für unser Strafrechtssystem charakteristisch sind. Für viele Praktiker wie Strafrechtstheoretiker sind wahrscheinlich der Gedanke einer (jedenfalls nach unten) abstufbaren Schuld und die darauf gestützte Strafmilderungsmöglichkeit unverzichtbare Elemente eines modernen Strafrechts. Aber es ist an dieser Stelle eine Gegenfrage aufzuwerfen: Ist es aus kriminalpolitischer Sicht wirklich eine Frage der gerechten Sanktionierung, dass Auffälligkeiten in der Persönlichkeitsstruktur oder eine Alkoholisierung des Täters (jedenfalls unter bestimmten Umständen) ${ }^{186}$ zu einer Strafmilderung führen? ${ }^{187}$ Was rechtfertigt eigentlich eine solche Besserstellung im Vergleich zu den nicht erheblich berauschten, nicht von einer Sachverständigenbegutachtung profitierenden Tätern? Wenn man sich von dem Gedanken

185 So Hörnle, Tatproportionale Strafzumessung, 1999, S. 306 ff. Nach intensiverer Beschäftigung mit dem Thema "Schuld“ vertrete ich das heute nicht mehr.

186 S. zur neueren Rspr. bzgl. Strafminderungen nach § $21 \mathrm{StGB}$ für alkoholisierte Täter BGHSt. 49, 239, 241 ff.; BGH NStZ 2003, 480; BGH NStZ 2006, 274 f.; BGH 2 StR 419/05 und zur Rspr. betreffend Persönlichkeitsstörungen BGH NStZ 1996, 380; BGH 5 StR 301/01. Zu Recht krit. gegenüber einer zu großzügigen Zubilligung einer Schuldminderung bei Persönlichkeitsstörungen Schöch (Fn. 171), §20 Rn. $174 \mathrm{f}$.

187 Krit. zum Merkmal der anderen schweren seelischen Abartigkeit Herzberg (Fn. 19), S. $116 \mathrm{ff}$. 
verabschiedet, dass es Aufgabe des Strafrechts sei, sich maßgeblich auf die inneren Zustände des Täters zu konzentrieren, ist es nicht mehr evident, dass es eine Norm wie $\S 21$ StGB geben sollte. Versucht man, graduelle Unterschiede in der normativen Kompetenz auszumachen, muss für alle Menschen und für alle Straftäter davon ausgegangen werden, dass die Intensität der Beeinflussbarkeit durch moralische Erkenntnis und durch Klugheitsregeln von Individuum zu Individuum unterschiedlich ausfällt. Es erscheint willkürlich, einerseits Individuen trotz dieser in ihrer jeweiligen Vergangenheit ausgebildeten, hirnphysiologisch abgespeicherten Unterschiede gleich zu behandeln, ${ }^{188}$ andererseits aber etwa bei Vorliegen der Diagnose ,dissoziale Persönlichkeitsstörung" solchen Unterschieden doch strafmindernd Rechnung zu tragen. Warum nur dann?

Mit einer Abschaffung des $\S 21$ StGB wäre zudem dem Problem zuvorzukommen, dass sich der Bereich dessen, was sachverständig als „pathologisch“ diagnostiziert werden kann, ausweitet. Je mehr es möglich ist, spezifische hirnphysiologische Gegebenheiten bei Gewaltverbrechern zu erfassen, die sich von denen bei anderen Personen unterscheiden, ${ }^{189}$ umso deutlicher häufen sich die Anhaltspunkte, dass es jenseits der „klassischen“ von Psychiatern beschriebenen Persönlichkeitsstörungen pathologische taterklärende Umstände gibt. Eine Ausweitung des $\S 21$ StGB auf alle verhaltensrelevanten hirnphysiologischen Pathologien wäre eine Möglichkeit - dies hätte aber zur Konsequenz, dass gerade bei besonders aggressivitätsgeprägten Taten mit besonders schwerem Unrecht regelmäßig Strafminderungen gewährt werden müssten. ${ }^{190}$ Solche Inkonsistenzen und Dilemmata entstehen nicht,

188 So Keil (Fn. 2), S. 187 ff.: keine Differenzierungen im nichtpathologischen Bereich.

189 Dazu Roth u.a., in: Senn/Puskás (Hrsg.), Gehirnforschung und rechtliche Verantwortung, 2006, S. 105, 108 ff.; Roth, in: Roth/Hubig/Bamberger (Hrsg.), Schuld und Strafe. Neue Fragen, 2012, S. 89, 92 ff.

190 Roth (in: Roth/Hubig/Bamberger, Fn. 189), S. 101 f.: ,je schwerer in ihren Folgen und in der öffentlichen Empfindung die Straftat, desto eindeutiger liegen bei den Tätern genetisch-organisch-psychische Störungen vor." Der Folgerung, die er im nächsten Satz anschließt ,Damit erscheint ein reines Präventivstrafrecht alternativlos ...", ist allerdings nicht beizupflichten. Vielmehr liegt die m.E. überzeugendere Alternative in der Ausrichtung des strafrechtlichen Unwerturteils auf das Tatunrecht und in einer Abschaffung des $\S 21 \mathrm{StGB}$. 
wenn nur noch gefragt wird, $o b$ ein Täter normativ vollkommen inkompetent war (dann entfällt mangels Zugehörigkeit zur Kommunikationsgemeinschaft die strafrechtliche Kommunikation), im Übrigen aber darauf verzichtet würde, den Grad der individuellen normativen Ansprechbarkeit zu ermitteln. Dass außerdem das Wegfallen der schwierigen Abgrenzungsfragen, die $\S 21$ StGB auferlegt, eine Erleichterung für die Rechtsprechungspraxis bedeuten würde, liegt auf der Hand. Das wäre zwar für sich genommen kein maßgebliches Argument, wohl aber in Ergänzung des hier zugrunde gelegten Blicks auf die Aufgabe strafrechtlicher Urteile. Diese Aufgabe liegt darin, Unrecht festzustellen und deshalb grundsätzlich normativ ansprechbaren Tätern einen Vorwurf zu machen, nicht aber darin, zu versuchen, die Persönlichkeit des Täters nach diffizilen Feinabstufungen ihrer normativen Kompetenz auszuleuchten. 


\section{Schlusswort}

Karl Schumann hat mit dem leicht spöttischen Blick des Soziologen prognostiziert, dass ,die Strafrechtswissenschaft auch die gegenwärtig boomende Neurokriminologie domestizieren“" werde. ${ }^{191}$ Diese Prognose teile ich - aber nicht als distanzierte Bemerkung zur konservativen Haltung von Juristen, sondern aus der Überzeugung, dass ein vergangenheitsorientiertes Unwerturteil, das dem Täter das begangene Unrecht vorwirft, auch ohne zusätzlichen Schuldvorwurf zu legitimieren ist. Es besteht kein Anlass für pessimistische Annahmen des Inhalts, dass die Rezeption von Erkenntnissen der Neurowissenschaften das Strafrecht in eine tiefe Krise führen müsse oder sogar unserer moralischen Praxis und dem Rechtssystem insgesamt die Grundlagen entziehen würde. Im Bereich des Strafrechts sind für ein konsequentes Umstellen auf Unrechtsstatt Schuldvorwürfe allerdings Modifikationen in der Verbrechenslehre und im Gesetz erforderlich. Voraussetzung für einen solchen Schritt ist es, sich von einer für viele Zeitgenossen immer noch dominanten „kulturell habitualisierten Erwartung " 192 zu befreien, nämlich der Vorstellung, dass Werturteile über Handlungen sich auf das Innere des Handelnden beziehen müssten. Einer solchen „Privilegierung reflexiver Innerlichkeit " 193 ist entgegenzusetzen, dass es Aufgabe des Strafrechts ist, unter Berücksichtigung der 2. Person-Perspektive darüber zu befinden, dass und in welchem Ausmaß gegenüber anderen bestehende Verhaltensanforderungen missachtet und Unrecht begangen wurde.

191 Schumann, Fünf Thesen zum Thema „Konsequenzen: Lebenswissenschaften und Kriminalpolitik“, in: Böllinger u.a. (Hrsg.), Gefährliche Menschenbilder, 2010, S. 433, $434 \mathrm{f}$.

192 Krüger, in: ders. (Hrsg.), Hirn als Subjekt?, 2007, S. 61.

193 Krüger (Fn. 192), S. 61. 


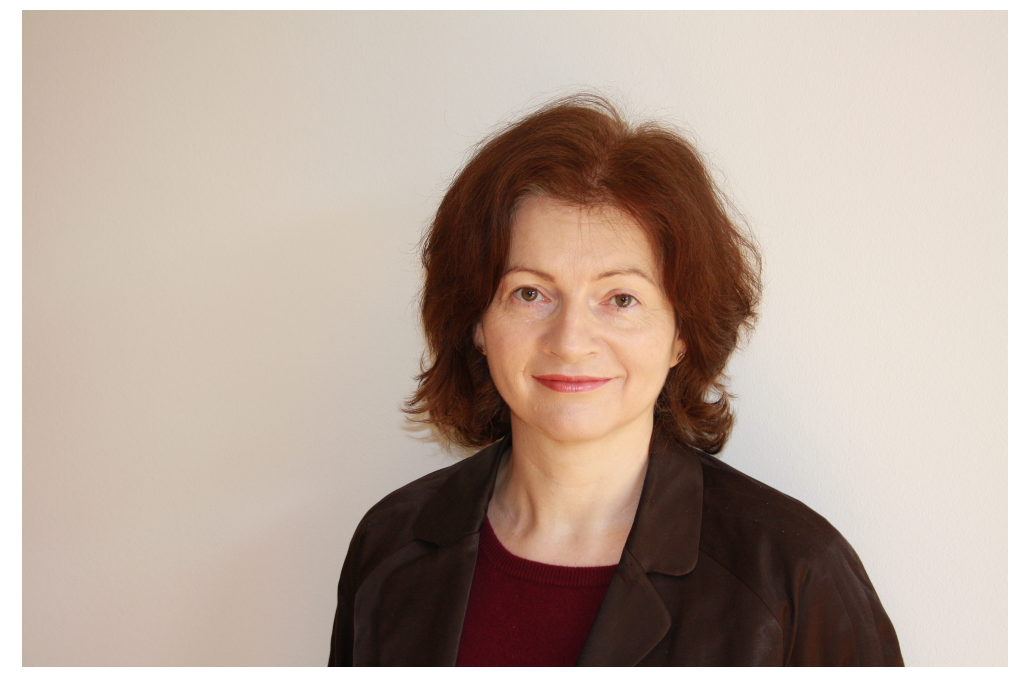

Prof. Dr. jur. Tatjana Hörnle, M. A.

(Rutgers State University of New Jersey)

Humboldt-Universität zu Berlin,

Juristische Fakultät, Lehrstuhl für Strafrecht, Strafprozessrecht, Rechtsphilosophie und Rechtsvergleichung

Unter den Linden 6, 10099 Berlin

Telefon +49 (0)30/2093-3376/3448, Telefax: +49 (0)30/2093-3513

E-Mail: Tatjana.Hoernle@rewi.hu-berlin.de 
$1982-1988$

$1988-1991$

$1991-1993$

$1993-1999$

1998

$2000-2003$

2002

23. Januar 2003

Februar, März 2003

April - August 2003
Studium der Rechtswissenschaften an der Eberhard-KarlsUniversität Tübingen

Ableistung des juristischen Vorbereitungsdienstes in Berlin

Studium als DAAD-Stipendiatin an der School of Criminal Justice, Rutgers State University of New Jersey, Erwerb des Masters of Arts in Criminal Justice

Wissenschaftliche Assistentin am Institut für Rechtsphilosophie und Rechtsinformatik der LMU, Lehrstuhl Prof. Dr. Schünemann

Promotion an der Juristischen Fakultät, ,summa cum laude“ Habilitationsstipendium der Deutschen Forschungsgemeinschaft

Visiting Fellow am Institute of Criminology, University of Cambridge, England, und am Wolfson College, Cambridge

Habilitation mit der venia legendi „Strafrecht, Strafprozessrecht, Rechtsphilosophie, Rechtsvergleichung“

Stipendium im Rahmen des Hochschul- und Wissenschaftsprogramms (Exzellenz-Pool)

Befristete Beschäftigung als Professorin für Strafrecht an der Universität Regensburg

Oktober 2003 - März 2004 Vertretung an der Ruhr-Universität Bochum

April 2004 - Juni 2009

Professorin an der Ruhr-Universität Bochum, Lehrstuhl für Strafrecht, Strafprozessrecht und Rechtsphilosophie

seit 1. Juli 2009

Professorin an der Humboldt-Universität zu Berlin, Lehrstuhl für Strafrecht, Strafprozessrecht, Rechtsphilosophie und Rechtsvergleichung

August 2011 - April 2012 Adjunct Professor, Faculty of Law, University of Toronto

April 2012

Ruf an die Albert-Ludwigs-Universität Freiburg (Nachfolge Prof. Dr. Frisch), abgelehnt

Dezember 2012 folge Prof. Dr. Dr. h.c. mult. B. Schünemann) 


\section{Ausgewählte Veröffentlichungen}

Tatproportionale Strafzumessung, Berlin 1999.

Das antiquierte Schuldverständnis der traditionellen Strafzumessungsrechtsprechung und -lehre, JZ 1999, S. 1080 - 1089.

Menschenwürde und Lebensschutz, ARSP 89 (2003), S. 318 - 338.

Grob anstößiges Verhalten. Strafrechtlicher Schutz von Moral, Gefühlen und Tabus, Frankfurt/M. 2005.

Unterschiede zwischen Strafverfahrensordnungen und ihre kulturellen Hintergründe, ZStW 117 (2005), S. $801-838$.

Die Rolle des Opfers in der Straftheorie und im materiellen Strafrecht, JZ 2006, S. $950-958$.

Töten, um viele Leben zu retten. Schwierige Notstandsfälle aus moralphilosophischer und strafrechtlicher Sicht, in: Festschrift für Rolf Dietrich Herzberg, Tübingen 2008, S. $555-574$.

Strafrechtliche Verbotsnormen zum Schutz von kulturellen Identitäten, in: Dreier/Hilgendorf (Hrsg.), Kulturelle Identität als Grund und Grenze des Rechts. Akten der IVRTagung vom 28. - 30. September 2006 in Würzburg (=ARSP Beiheft Nr. 113), Stuttgart 2008 , S. $315-337$.

Die verfassungsrechtliche Begründung des Schuldprinzips, in: Festschrift für Klaus Tiedemann, Köln 2008, S. 325 - 345.

Shooting Down a Hijacked Airplane - The German Discussion and Beyond, Criminal Law and Philosophy 3 (2009), S. $111-131$.

Paternalismus in der Medizin - am Beispiel der Eizellenspende in der Reproduktionsmedizin, in: von Hirsch/Neumann/Seelmann (Hrsg.), Paternalismus im Strafrecht, BadenBaden 2010, S. $111-128$.

Strafrecht und Rechtsphilosophie: Traditionen und Perspektiven, in: Festschrift zum zweihundertjährigen Bestehen der Juristischen Fakultät der HU Berlin, Berlin 2010, $1265-1281$.

Straftheorien, Tübingen 2011

Zur Konkretisierung des Begriffs „Menschenwürde“, in: Joerden/Hilgendorf/Petrillo/ Thiele (Hrsg.), Menschenwürde und moderne Medizintechnik, Baden-Baden 2011, S. $57-76$.

Wie weit reicht das Erziehungsrecht der Eltern? - Am Beispiel der Beschneidung von Jungen (zusammen mit Stefan Huster), JZ 2013, S. 328 - 339. 


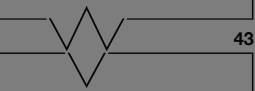

Jan Schröder

Theorie der

Gesetzesinterpretation

im frühen

20. Jahrhundert

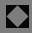

Nomos Verlag

\section{aat seine Bürger}

Iten am 9.11.2011

Jwe Volkmann

, 52 S., brosch., 16,-€

329-7387-2

shop.de/14571

Zeit verstärkt sich der Einuch der liberale Staat seine ner bestimmten Form des hinführen will; jedenfalls Regelungen, die als bevorternalistisch oder moralisieden werden Aus verschie.

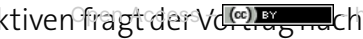
eit und den Grenzen einer

\section{Theorie der Gesetzesi} tation im frühen 20. J Vortrag gehalten am 19. M Von Prof. Dr. Dr. h.c. Jan Scr 2011, Band 43, 40 S., brosch. ISBN 978-3-8329-6857-1 www.nomos-shop.de/1397c

Die moderne Lehre von auslegung beruht im Wes der Interpretationstheorie Jahrhunderts. Deren Gruı neuer, positivistisch-volu Rechtsbegriff. Mit ihm hän wichtigsten Eigentümlich terpretationsliteratur nach men, nämlich die Uneinig 


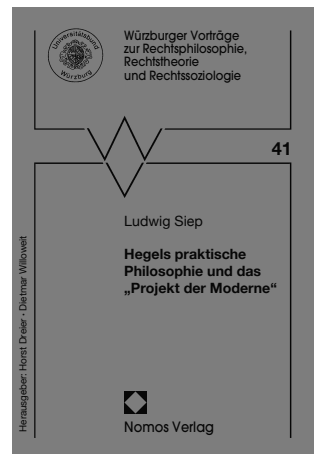

\section{zwischen Reinheit}

it

nen und die philo-

rundlagen der Rechts-

Iten am 30. Juni 2010

Agostino Carrino

55 S., brosch., 22,-€

29-6848-9

shop.de/13954

th der Frage nach der philoGrundlegung der „Reinen nach. Es untersucht dazu vor akantianismus, wobeider

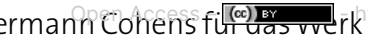
besondere Aufmerksamkeit

\section{Hegels praktische Phi und das „Projekt der I}

Vortrag gehalten am 24. November 2010

Von Prof. Dr. Ludwig Siep 2011, Band 41, 44 S., brosch., ISBN 978-3-8329-6765-9 www.nomos-shop.de/1383

Viele moderne Strömung schen Philosophie berufen - von der Frankfurter Schi amerikanischen Neopragm Verständnis von Moderne, rigkeit zu wichtigen mode lungen (Gruidrechte,libera ordnung, säkularer Staat) 